UCRL-ID-121791

\title{
Thermal-Hydrological Analysis of Large-Scale Thermal Tests in the Exploratory Studies Facility at Yucca Mountain
}

Thomas A. Buscheck

John J. Nitao

February 20, 1996

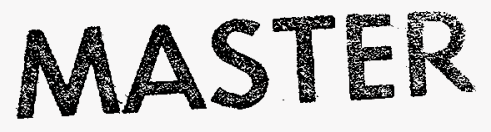





\section{DISCLAIMER}

This report was prepared as an account of work sponsored by an agency of the United States Government. Neither the United States Government nor any agency thereof, nor any of their employees, makes any warranty, express or implied, or assumes any legal liability or responsibility for the accuracy, completeness, or usefulness of any information, apparatus, product, or process disclosed, or represents that its use would not infringe privately owned rights. Reference herein to any specific commercial product, process, or service by trade name, trademark, manufacturer, or otherwise does not necessarily constitute or imply its endorsement, recommendation, or favoring by the United States Government or any agency thereof. The views and opinions of authors expressed herein do not necessarily state or reflect those of the United States Government or any agency thereof. 



\section{DISCLAIMER}

Portions of this document may be illegible in electronic image products. Images are produced from the best available original document. 



\section{Contents}

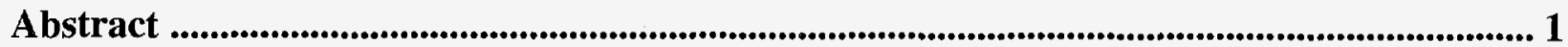

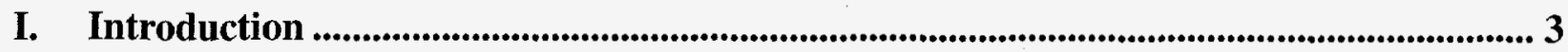

I.A Organization of This Report .................................................................................................... 4

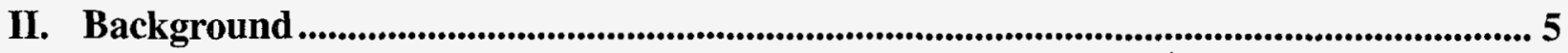

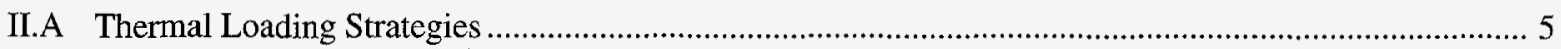

II.B Importance of Thermal-Hydrology on Radionuclide Containment in Waste Packages ........................... 6

II.C Importance of Thermal-Hydrology for Radionuclide Release and Transport ....................................... 9

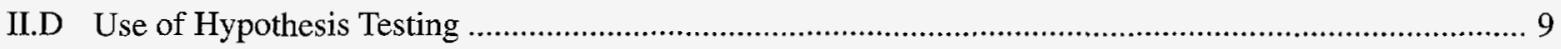

II.E Purpose of Thermal Testing .................................................................................................. 11

II.F Factors Affecting Thermal Test Size and Duration ......................................................................... 11

II.G Physical Criteria Affecting Thermal Test Size and Duration ........................................................ 12

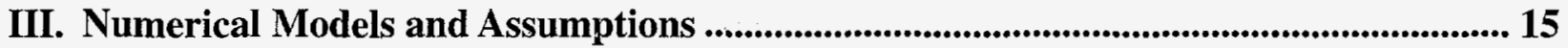

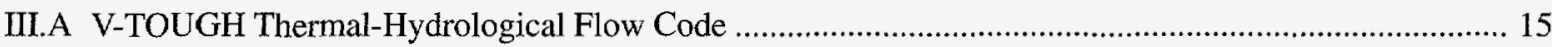

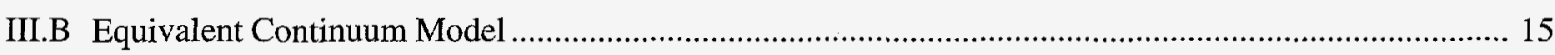

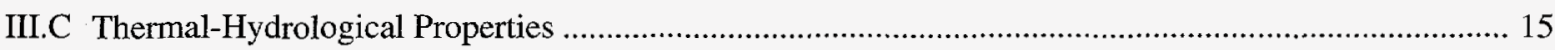

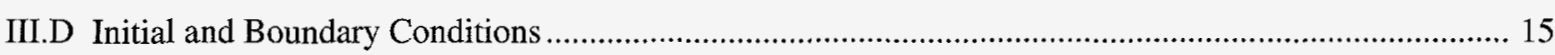

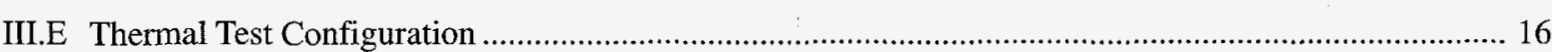

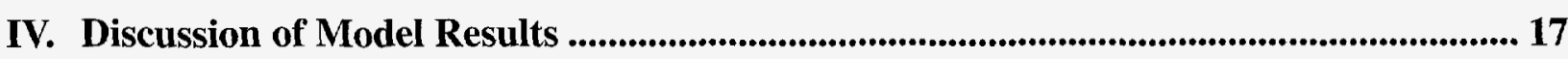

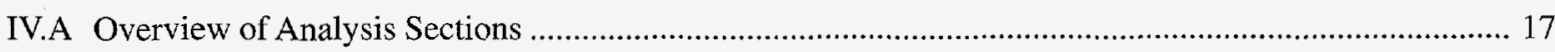

IV.B Major Thermal-Hydrological Flow Regimes .................................................................................. 17

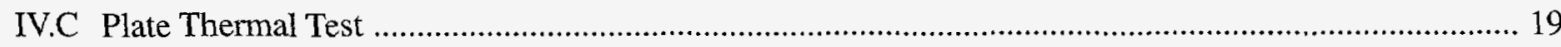

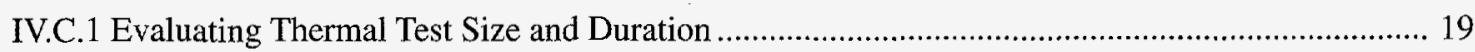

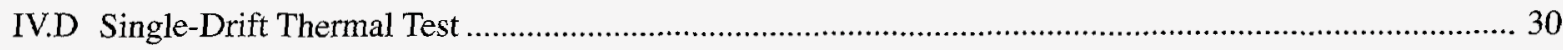

IV.D.1 Minimizing the Effect of Lateral Heat Loss .................................................................... 34

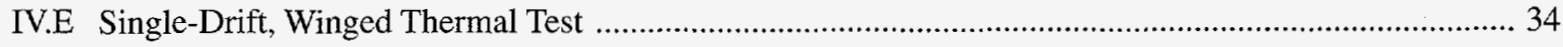

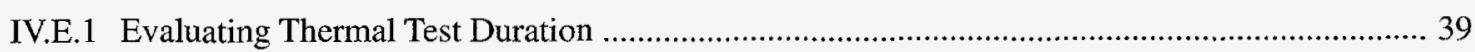

IV.E.2 Evaluating the Effects of Heterogeneity ......................................................................... 44

IV.E.3 Evaluating Accelerated Heating Rates .......................................................................... 47

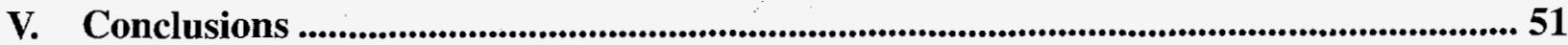

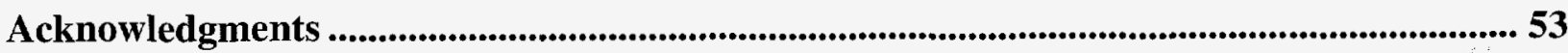

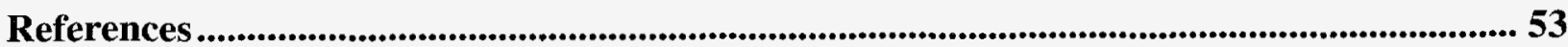


Ad 


\title{
Thermal-Hydrological Analysis of Large-Scale Thermal Tests in the Exploratory Studies Facility at Yucca Mountain
}

\begin{abstract}
In situ thermal tests, which are to be conducted in the Exploratory Studies Facility (ESF) at Yucca Mountain, will provide a major portion of the experimental basis supporting the validation of coupled thermal-hydrological-geomechanical-geochemical (T-H-M-C) process models required to assess the total system performance at the site. With respect to advective rock dryout, we have identified three major T-H flow regimes: (1) throttled, nonbuoyant, advective rock dryout; (2) unthrottled, nonbuoyant, advective rock dryout; and (3) unthrottled, buoyant, advective rock dryout. How these major T-H regimes influence the flow of heat, vapor, and condensate depends in part on whether vapor diffusion is substantially enhanced. With the V-TOUGH code, we modeled and evaluated a range of heater test sizes, heating rates, and heating durations under a range of plausible hydrological conditions to help optimize an in situ thermal test design that provides sufficient (and timely) information for determining (a) the dominant mode( $s$ ) of heat flow, (b) the major T-H regime(s) and processes (such as vapor diffusion) that govern the magnitude and direction of vapor and condensate flow, and (c) the influence of heterogeneous properties and conditions on the flow of heat, vapor, and condensate.

For the plate thermal test, which uniformly heats a disk-shaped area, we evaluated a wide range of test areas, ranging from 50 to $5077 \mathrm{~m}^{2}$. We evaluated the single-drift thermal test, which consists of a row of large-waste-package-sized heaters sitting on the floor of the heater drift, and then developed an optimized thermal test configuration, called the single-drift, winged thermal test, in which the heater drift is flanked by wing heater arrays. For this configuration, we considered three heating schedules (with 1-, 2-, and 4-yr full-power heating periods) and three heating rates $\left(122,177\right.$, and $\left.236 \mathrm{~W} / \mathrm{m}^{2}\right)$. On the basis of these evaluations, we recommend a minimum thermal test area of 1000 to $1500 \mathrm{~m}^{2}$, a minimum full-power heating period of $2 \mathrm{yr}$, and an areal power density of between 122 and $177 \mathrm{~W} / \mathrm{m}^{2}$ averaged over the heated area.

For determining the dominant T-H regime(s) and dominant heat-flow mode(s), the most important diagnostic measurements are vertical temperature and gas-phase pressure profiles and gas-phase pressure and relative humidity $R H$ histories in the drift. For determining the degree of vapor diffusion enhancement, the most diagnostic measurement is the $R H$ history in the drift during cooldown. For determining the influence of heterogeneity on the flow of heat, vapor, and condensate, the most important diagnostic measurements are the horizontal distributions of temperature and liquid saturation (or $R H$ ) and the $R H$ history in the drift during heatup. A full-power heating period of at least $6 \mathrm{yr}$ could be required to determine whether heat conduction can overwhelm the effects of heterogeneity on temperature and liquid saturation distributions near the heater drift.
\end{abstract}




\section{Introduction}

This report describes the modeling and scoping analysis that will be used to help design and plan the large-scale in situ heater tests to be conducted in the Exploratory Studies Facility (ESF), which will be located in the unsaturated zone (UZ) at Yucca Mountain. This report will focus on the first ESF thermal test, which will be installed and conducted as soon as tunnel access to the repository host rock (TSw2) is available. The current planning for this test calls for a drift-scale test that represents the emplacement of large waste packages (WPs), containing either 21 pressurized water reactor (PWR) spent nuclear fuel (SNF) assemblies or 40 boiling water reactor (BWR) SNF assemblies in an emplacement drift. The heater drift will contain a row of large-WP-sized heaters, and will be flanked, on either side, by arrays of borehole-emplaced "wing" heaters, placed close enough together to create a planar heat source on either side of the heater drift. Section IV.D explains why the single-drift, winged thermal test is the recommended configuration for the first ESF thermal test.

The first ESF thermal test will be followed by a longer-duration, larger-scale, multiple-drift ESF thermal test. In preparation for the year-2001 license application (LA) for the repository construction authorization, we must establish sufficient confidence in our ability to predict long-term thermal-hydrological (T-H) behavior in the engineered barrier system (EBS) and natural barriers. It is therefore anticipated that the first ESF thermal test will need to be conducted under an accelerated heating and cooldown schedule. The multiple-drift ESF thermal test will be conducted under a less-accelerated heating and cooldown schedule that will provide data for the year-2008 LA update (LU) for emplacement of waste in 2010.

A major objective of this study is to model and analyze a range of heater test sizes, heating rates, and heating durations for a range of plausible hydrological conditions to help optimize an in situ thermal test design that provides sufficient information to determine the following:

1. The dominant mode(s) of heat flow.

2. The major T-H regime(s) and thermal-hydrologicalgeomechanical-geochemical (T-H-M-C) processes that govern the magnitude and direction of vapor and condensate flow.

3. The major T-H regime(s), coupled T-H-M-C processes, and site conditions (such as ambient liquid flux) that govern dryout and rewetting of the dryout zone.
4. The influence of heterogeneous properties and conditions on the flow of heat, vapor, and condensate, with particular emphasis on rock dryout and rewetting.

Historically, heater tests in the ESF have been considered primarily to pertain to T-H-M-C behavior in the near-field (or WP) environment. The Site Characterization Plan (SCP) [DOE, 1988] refers to the ESF thermal tests as the Engineered Barrier System Field Test (EBSFT), indicating what was then regarded as the focus of those tests on providing information relevant to EBS and WP performance. With respect to WP performance, a primary goal of the ESF heater tests is understanding water contact modes (on WPs), including liquid-phase flow and condensation of water vapor, and the related temperature and chemistry. Another important goal is understanding how coupled T-H-M-C processes influence radionuclide mobilization (from the waste form), release (from the WP), and transport (in the EBS and near field). The influence of introduced (man-made) materials, such as backfill, on coupled T-H-M-C processes is an important consideration. Since the SCP was written, numerous studies [Buscheck and Nitao, 1992; Buscheck and Nitao, 1993a; Buscheck and Nitao, 1993b] have shown that significant decay-heatdriven T-H effects (and possibly, significant T-H-M-C effects) extend upwards all the way to the ground surface and downwards to deep into the saturated zone (SZ) below the water table. The ESF heater tests must therefore provide critically important information about decay-heat-driven T-H behavior and related coupled T-H-M-C processes that occur in a zone (called the altered zone) that is likely to extend vertically through much of the UZ and into the SZ. Another important goal for the ESF thermal tests is to help understand how coupled T-H-M-C processes influence radionuclide transport in the altered zone.

For this report, we apply the hydrological and thermal properties and hydrostratigraphy used in previous modeling studies of decay-heat-driven thermal-hydrological flow [Buscheck et al., 1993a; Buscheck et al., 1993b]. We examine the trade-offs between (1) meeting the 2001 LA schedule, (2) perturbing thermal-hydrological conditions in a large enough volume of rock relative to the spatial variability of fracture and matrix properties, and (3) generating conditions that are applicable to repository performance during the entire thermal loading cycle, including heatup and cooldown. 


\section{I.A Organization of This Report}

Because this report includes a fairly extensive discussion of background issues that are of importance to thermal testing, it may be helpful to summarize its organization briefly. Much of this background material is not covered (in its current form) in previous publications and, because of its relevance to thermal testing, is included in this report. Section II starts with a brief overview of the UZ at Yucca Mountain and of the major ambient and decay-heat-driven issues influencing WP performance and radionuclide transport. Section II.A discusses the principal thermal loading strategies and approaches, and includes a discussion of localized dryout (LD), an important, but as yet unpublished, approach to repository thermal management. Section II.B discusses the importance of thermal hydrology on radionuclide containment in WPs, with particular attention to the two major mechanisms of reducing relative humidity $R H$ on the WP. Of these two mechanisms, the so-called "local- $\triangle R H$ effect" has only recently been recognized and analyzed. The other mechanism, $R H$ reduction resulting from rock dryout, has been analyzed extensively [Buscheck and Nitao, 1994b]. Section II.C discusses the importance of thermal hydrology on radionuclide release from WPs and on radionuclide transport through the engineered and natural barriers. Section II.D discusses the use of hypothesis testing in building confidence in our models of thermal hydrological flow, including a more expanded discussion of subsidiary hypotheses than was provided in previous publications.

Sections II.E, II.F, II.G, III, IV, and V directly cover the subject of thermal test analysis. Section II.E discusses the major purpose of thermal testing and describes how thermal testing supports virtually all of the major waste isolation hypotheses that are being developed by the Civilian Radioactive Waste Management System (CRWMS). Section II.F discusses regulatory factors affecting thermal test size and duration. Section II.G discusses physical criteria that must be considered in optimizing a thermal test design to address both model validation needs and the 2001 LA schedule. Section III describes the models and assumptions used in the thermal test analysis. Section IV.B describes the major $\mathrm{T}-\mathrm{H}$ regimes that may be relevant to actual repositoryheat-driven T-H behavior. Sections IV.C through IV.E (covering model results and analysis) evaluate how effectively alternative thermal test configurations (including test size, heating rate, and heating duration) allow (1) determination of the T-H regime(s) that will dominate repository-heat-driven $\mathrm{T}-\mathrm{H}$ behavior and (2) observations of potentially critically important $\mathrm{T}-\mathrm{H}-\mathrm{M}-\mathrm{C}$ effects in the near field and the altered zone. Section V summarizes the conclusions of the thermal test analyses and makes recommendations for the design of the first ESF thermal test. 


\section{Background}

The U.S. Department of Energy (DOE) is investigating the suitability of the UZ at Yucca Mountain, Nevada, as a potential site for a high-level nuclear waste repository. The site [Montazer and Wilson, 1984] consists of a series of fractured, nonwelded to densely welded tuff units and is located about $120 \mathrm{~km}$ northwest of Las Vegas, Nevada, in an area of uninhabited desert. The potential repository location is in Topopah Spring moderately to densely welded tuff, approximately $350 \mathrm{~m}$ below the ground surface and $225 \mathrm{~m}$ above the water table [Klavetter and Peters, 1986]. Favorable aspects of Yucca Mountain relate primarily to its arid nature, which results in unsaturated conditions at the potential repository horizon.

To safely and permanently store nuclear waste, the potential repository system must limit gas- or liquid-phase transport of radionuclides to the accessible environment. In the failure scenario of greatest concern, liquid water would contact a waste package (WP), accelerate its failure rate, and eventually transport radionuclides to the water table. The degradational mechanisms of greatest concern for WP integrity, such as stress and pitting corrosion or microbial attack, require the presence of liquid water. The rates for many of these degradational mechanisms are increased under warm, humid conditions. For a repository located in the unsaturated zone, the primary concern is whether liquid water may contact the WP. This contact can arise from two effects. First, mobile liquid water, particularly water flowing in fractures, may contact the WP. Second, if $R H$ is high enough, a liquid film can exist on the surface of the WP even if mobile liquid water is absent.

Fluid flow in the UZ at Yucca Mountain involves liquid- and gas-phase flow through the fractures and through the rock matrix. Modeling and analytical studies of high-level radioactive waste isolation have demonstrated the potential importance of nonequilibrium flow processes between the fractures and the matrix [Buscheck et al., 1991; Nitao et al., 1993]. Except for regions with a perched water table or during transient recharge episodes, capillary forces cause most fractures to be drained of liquid water. Matrix permeability is extremely low, so matrix flow is of less concern than fracture flow for water contact by advective liquid flow and for radionuclide transport. This water may arise from three origins:

1. Natural infiltration of rainfall and snowmelt.

2. Condensate generated under boiling conditions.

3. Condensate generated under sub-boiling conditions.
The first source arises from the ambient system; the second and third are generated by radioactive decay heat, primarily from SNF. Repository-heat-driven, buoyant vapor flow and the binary diffusion of water vapor and air (called vapor diffusion) may play important roles in condensate generation [Buscheck and Nitao, 1994a]. A heterogeneous distribution of bulk permeability $k_{\mathrm{b}}$ can influence vapor and condensate flow under both boiling and sub-boiling conditions. Of particular concern are $k_{\mathrm{b}}$ distributions that promote the focusing of condensate flow, which could cause water to drip onto WPs even if average behavior would indicate otherwise [Buscheck and Nitao, 1994a].

Repository heat can result in regions of dryout and condensate buildup in the UZ. Modeling studies [Buscheck and Nitao, 1993a; Buscheck and Nitao, 1993b; Buscheck and Nitao, 1994a; Buscheck et al., 1994] have indicated that decay-heat-driven changes in the saturation distribution can persist for more than $100,000 \mathrm{yr}$, even for low areal mass loadings [AMLs, expressed in metric tons of uranium (MTU) per acre] that never drive temperatures close to the boiling point. These effects, along with temperature changes, can alter the hydrological, geochemical, and geomechanical properties that influence fluid flow and radionuclide transport.

\section{II.A Thermal Loading Strategies}

Nuclear waste isolation at Yucca Mountain is affected by three key factors: (1) ambient conditions at the proposed repository horizon are very humid (relative humidity $R H \approx 98-99 \%$ ) and are therefore very corrosive for most candidate WP materials; (2) ambient fracture flow is highly variable in time and space; and (3) radioactive decay heat significantly affects fluid flow for any practical AML. With respect to the thermal-hydrological (T-H) effects of decay heat, we have identified two thermal loading strategies:

Minimally heated (MH) repository: Select an AML and a thermal load distribution that limit (1) heat-driven vapor and condensate flow and (2) far-field temperature rise. The $\mathrm{MH}$ strategy relies on performance attributes other than decay heat (such as high-performance WP materials and capillary/diffusion barriers in the engineered and natural systems) to counter the effects of high $R H$ and fast fracture flow.

Constructively heated $(\mathrm{CH})$ repository: Select an AML and a thermal load distribution that use decay 
heat constructively - that is, to substantially reduce $R H$ and fracture flow near WPs. The $\mathrm{CH}$ strategy relies on demonstrating that heat, vapor, and liquid flow (including heterogeneous fracture flow) near WPs are dominated by heat conduction (and possibly vapor diffusion) and are therefore very predictable.

Various modeling studies [Buscheck and Nitao, 1994a; Buscheck and Nitao, 1994b; Buscheck et al., 1995] have identified two fundamental CH approaches:

Extended dryout (ED) approach: Use a high AML (>60 MTU/acre) to drive a large fraction of the initial pore water (in the rock) from the repository as a whole. The high areal power density associated with such an AML creates a thick superheated dryout zone (coalesced between emplacement drifts) and maintains above-boiling temperatures and low $R H$ in the repository rock (and on WPs) for thousands of years.

\section{Localized dryout (LD) approach: Maintain a} temperature difference between the WP and the drift wall that is large enough to reduce $R H$ on the WP. This is done with close axial WP spacing (generating a high line-heat load) and/or the use of low-thermal-conductivity backfill in the drift. Wide drift spacings and low to intermediate AMLs ( $<50-60 \mathrm{MTU} / \mathrm{acre}$ ) are used to (1) prevent the boiling zones from coalescing between drifts (and thereby limiting condensate buildup above the drifts) and (2) limit far-field temperature rise (as in the $\mathrm{MH}$ strategy).

There are two major T-H issues for the ED (highAML) approach. The first issue must be addressed for all AMLs; the second is unique to the ED approach. These two major T-H issues are as follows:

Coupled T-H-M-C effects: These effects must be addressed in both the near and far field, regardless of AML; however, their impact may depend on AML. The T-H-M-C effects of particular concern are (1) alteration of the vitric nonwelded Paintbrush tuff (PTn) unit that may affect its ability to attenuate (in time and space) net infiltration to the repository and (2) alteration of the basal vitrophyre (TSw3) that may influence whether water perches in (or immediately above) that unit and may reduce the mechanical stability of the repository.

Condensate buildup above the boiling zone: This effect may result from condensate and infiltration flux that is held up by the thick (coalesced) superheated zone created by a high-AML repository. These two issues will affect the containment, mobilization, and migration of radionuclides.

The LD approach (like the MH strategy) tends to limit far-field T-H-M-C effects and allows condensate to drain through the repository; neither of these results is as readily achieved with the ED approach. The LD approach can be implemented by a wide range of thermal design options [Buscheck et al., 1995], ranging from those that never cause above-boiling rock temperatures to those in which the boiling zones coalesce between the drifts (as in the ED approach).

\section{II.B Importance of Thermal Hydrology on Radionuclide Containment in Waste Packages}

To safely and permanently store waste, the repository system must limit gas- or liquid-phase transport of radionuclides to the accessible environment. A major concern is how water contacts a WP, thereby potentially affecting its integrity and (if containment is breached) affecting radionuclide dissolution (and release) and eventual transport to the water table. The degradational mechanisms of greatest concern for WP integrity, such as stress and pitting corrosion or microbial attack, require the presence of liquid water. The rates for many of these mechanisms are increased under warm, humid conditions.

The two primary modes of water contact on the WP are (1) advective liquid-phase flow and (2) condensation of water vapor that forms a liquid film on the WP. The critical factors for the second mode are the relative humidity $R H$ and temperature $T$ on the WP. Relative humidity is given by

$$
R H=\frac{P_{\mathrm{v}}}{P_{\text {sat }}(T)},
$$

where $P_{\mathrm{v}}$ is the local vapor pressure and $P_{\text {sat }}$ is the local saturated vapor pressure. If $100 \%$ of the gas phase is water vapor, as is the case for boiling conditions, then $P_{\mathrm{v}}=P_{\mathrm{g}}$, where $P_{\mathrm{g}}$ is the total gas-phase pressure. For example, if $P_{\mathrm{v}}=P_{\mathrm{g}}=1 \mathrm{~atm}$ and $T=T_{\mathrm{wp}}=225^{\circ} \mathrm{C}$, then $P_{\text {sat }}=25.48 \mathrm{~atm}$ (from steam tables) and $R H_{\mathrm{wp}}=3.9 \%$. The assumption that $P_{\mathrm{V}}=1 \mathrm{~atm}$ is reasonable if there is enough fracture connectivity and conductivity so that $k_{\mathrm{b}}>1$ millidarcy. If there were no fractures in the repository rock, then we would have $k_{\mathrm{b}}$ « 1 millidarcy and $P_{\mathrm{v}}$ would be much higher than $1 \mathrm{~atm}$; this would increase $R H$ by a corresponding factor. A critically important question is whether fracture connectivity and conductivity at Yucca Mountain are sufficient to prevent substantial pressurization of the gas phase near WPs. This question can be resolved during the LargeBlock Test (LBT) and ESF in situ thermal tests.

Regardless of whether mobile liquid water is present, ambient $R H$ at the repository horizon is humid 
( $98-99 \%)$. If the ambient $R H$ could be reduced enough, WP corrosion rates would be minimal [Stahl et al., 1994]. Moreover, even for breached WPs, wasteform dissolution (and radionuclide release) would be minimal if no mobile liquid water were present. There are two ways to reduce $R H$ on the WP:

1. Drive a large fraction of the ambient pore water (in the rock) away from the drifts. (This reduces $R H$ in the rock; $R H$ on the WP can be no greater than $R H$ in the rock.) This is most readily accomplished using the ED approach.

2. Maintain a large temperature difference between the (hotter) WP and the (cooler) drift wall. (This makes $R H$ on the WP lower than $R H$ in the rock at the drift wall.) This can be accomplished in either the ED or LD approaches.

The primary means of driving pore water from the vicinity of WPs are ventilation and decay-heat-driven drying. To reduce $R H$ to $70 \%$, the liquid saturation $S_{\mathrm{L}}$ (the fraction of the pore space filled with liquid water) must be reduced to less than 20\% (based on measurements made on TSw2). An AML that does not drive repository temperatures well above the boiling point will reduce average $R H$ conditions in the rock only slightly.

Even if repository heat does not substantially reduce average $R H$ conditions in the repository rock, it is still possible to substantially reduce $R H$ on the WP itself for a considerable time. A reduction in $R H$ between the drift wall and the WP arises from the temperature difference $\Delta T_{\text {drift }}$ between these locations. This effect (the "drift- $\Delta R H$ effect") occurs in addition to any reduction in $R H$ resulting from rock dryout $\left(\Delta R H_{\text {rock }}\right)$. Assuming uniform absolute humidity (i.e., $\left.P_{\mathrm{v}}\right)$ in the drift, the $R H$ on the WP, $R H_{\mathrm{wp}}$, is given by

$$
R H_{\mathrm{wp}}=R H_{\mathrm{dw}} \frac{P_{\mathrm{sat}}\left(T_{\mathrm{dw}}\right)}{P_{\mathrm{sat}}\left(T_{\mathrm{wp}}\right)},
$$

where $R H_{\mathrm{dw}}$ is $R H$ in the rock at the drift wall, $P_{\mathrm{sat}}$ is the local saturated vapor pressure, and $T_{\mathrm{dw}}$ and $T_{\mathrm{wp}}$ are the drift wall and WP temperatures. For example, if $T_{\mathrm{dw}}=80^{\circ} \mathrm{C}$ and $T_{\mathrm{wp}}=100^{\circ} \mathrm{C}$ and the drift wall is at ambient $R H(98.4 \%)$, then we have $R H_{\mathrm{wp}}=46 \%$.

A persistent $\Delta T_{\text {drift }}$ arises because the rows of WPs act like line-heat loads that impose a temperature increase on top of the temperature rise $\Delta T_{\text {rock }}$ in the repository rock; $\Delta T_{\text {rock }}$ depends primarily on $A M L$ and the thermal conductivity $K_{\text {th }}$ of the mountain [Buscheck and Nitao, 1993b; Buscheck and Nitao, 1994a; Buscheck and Nitao, 1994b]. Because $\Delta T_{\text {drift }}$ depends only on lineal mass loading (LML, expressed in
MTU/m of drift) and the thermal properties of the drift, $\Delta T_{\text {drift }}$ is increased by high LML and/or the use of low- $K_{\text {th }}$ granular backfill in the drift [Buscheck and Nitao, 1995]. This can be accomplished in either the LD or ED approaches. Thermal-hydrological model calculations show that with suitable backfill, $\Delta T_{\text {drift }}$ can keep $R H$ on the WP below $70 \%$ for $10,000 \mathrm{yr}$, even for AMLs that result in negligible rock dryout [Buscheck et al., 1995]. Proving that heat flow in the backfill is dominated by conduction establishes that $\Delta T_{\text {drift }}$ is very predictable. Note that Eq. (2) is applicable when $P_{\mathrm{V}}$ on the WP is in equilibrium with $P_{\mathrm{y}}$ in the rock at the drift wall. Nonuniform (or episodic) rewetting of the drift (particularly that caused by nonequilibrium fracture flow) may locally (or temporarily) cause $R H$ to be higher than predicted by Eq. (2).

During the repository heatup period, the rock surrounding the drift will become desaturated if $k_{\mathrm{b}}$ and the local AML are high enough, resulting in a reduced $R H$ in the rock (and on the WP itself). This reduction in $R H$ will persist at least as long as rock temperatures remain high, and it may persist long after the WP temperature has dropped below the boiling point. The reduction in RH will decrease both the likelihood and magnitude of WP corrosion, and the reduction in liquid-phase saturation will decrease the rate of liquid-phase diffusion of radionuclides in the backfill and host rock. For high AMLs, this desirable scenario may last for tens of thousands of years. For low to intermediate AMLs, the duration of the reduced- $R H$ period (resulting from rock dryout) may be substantially less, at least for average $R H$ conditions in the repository rock.

Higher AMLs will increase the volume of rock in which $S_{\mathrm{L}}$ and $R H$ are reduced. Because the boiling front is driven farther from the emplacement drifts, the probability that refluxing condensate will reach the drifts will be reduced. Because of the larger volume that must be rewetted, rewetting the repository to ambient (humid) conditions will take longer for a high-AML repository than for a low-AML repository. A large enough increase in the duration of reduced- $R H$ conditions reduces the temperatures associated with a given value of $R H$ because the repository rock cools down faster than it rewets. Consequently, once humid $R H$ conditions are eventually restored, WP temperatures will have decreased considerably, which is more favorable for reducing WP corrosion rates. Ideally, WPs would remain relatively dry until they are relatively cool.

Besides $R H$ and $T$, the potential for advective liquid-phase flow reaching the WP is of concern. An important issue for WP integrity involves the scenario of liquid water reaching and evaporating on a WP, 
thereby leaving an evaporative buildup of salt on the WP surface. The condensation of an aqueous surface film on the WP will depend on $R H$ and on the quantity and composition of any hygroscopic salts on the WP surface. The critical relative humidity $R H_{\text {crit }}$ for significant atmospheric corrosion is extremely sensitive to this effect [Jones, 1992]. Keeping liquid-phase flux away from the WP surface would prevent salts from precipitating on the WP and would thereby help keep $R H_{\text {crit }}$ very high. On the basis of the corrosion data reported by Jones (1992), the absence of salts on the WP could result in $R H_{\text {crit }}>90 \%$ and thereby greatly extend WP lifetimes and the period of radionuclide containment. The use of a suitable backfill might significantly reduce the likelihood that evaporating water would leave salts on the WP surface.

Microbially induced corrosion is also of concern and is strongly dependent on temperature and $R H$. High temperature and low $R H$ are generally detrimental to microbial growth, whereas intermediate temperatures and high $R H$ may favor microbial growth.

Condensate flow, whether driven by heat from an above-boiling or a sub-boiling repository, is one source of advective liquid-phase flow that may reach a WP. On average, the matrix will imbibe condensate fluxes until it becomes saturated. However, heterogeneities in the natural system can cause variations about the average flow field that could focus condensate onto WPs. Counteracting this variability in return condensate flux is the heat flux from the WPs, which will continue to boil condensate. In some cases, a higher AML may result in higher condensate fluxes and more variability, but the correspondingly higher heat flux will mitigate the problem of focused condensate drainage [Buscheck and Nitao, 1993a; Nitao et al., 1995]. The system is nonlinear, so it is difficult to determine optimum thermal loading without (1) extensive sensitivity analyses of alternative thermal designs, (2) experimental information obtained from in situ thermal tests, and (3) better information and understanding concerning how repository heat affects the overall UZ moisture balance. Repository heat might drive enough water vapor out of the top of the mountain to significantly reduce the UZ moisture content for tens of thousands of years. Conversely, mountain-scale, buoyant gas-phase convection might drive enough water vapor up from the $\mathrm{SZ}$ (into the UZ) to increase the UZ moisture content for tens of thousands of years [Buscheck and Nitao, 1994a; Buscheck et al., 1994]. Figure 1 shows the various decay-heat-driven processes and ambient site conditions that may significantly affect the moisture balance in the UZ. The moisture balance in the UZ

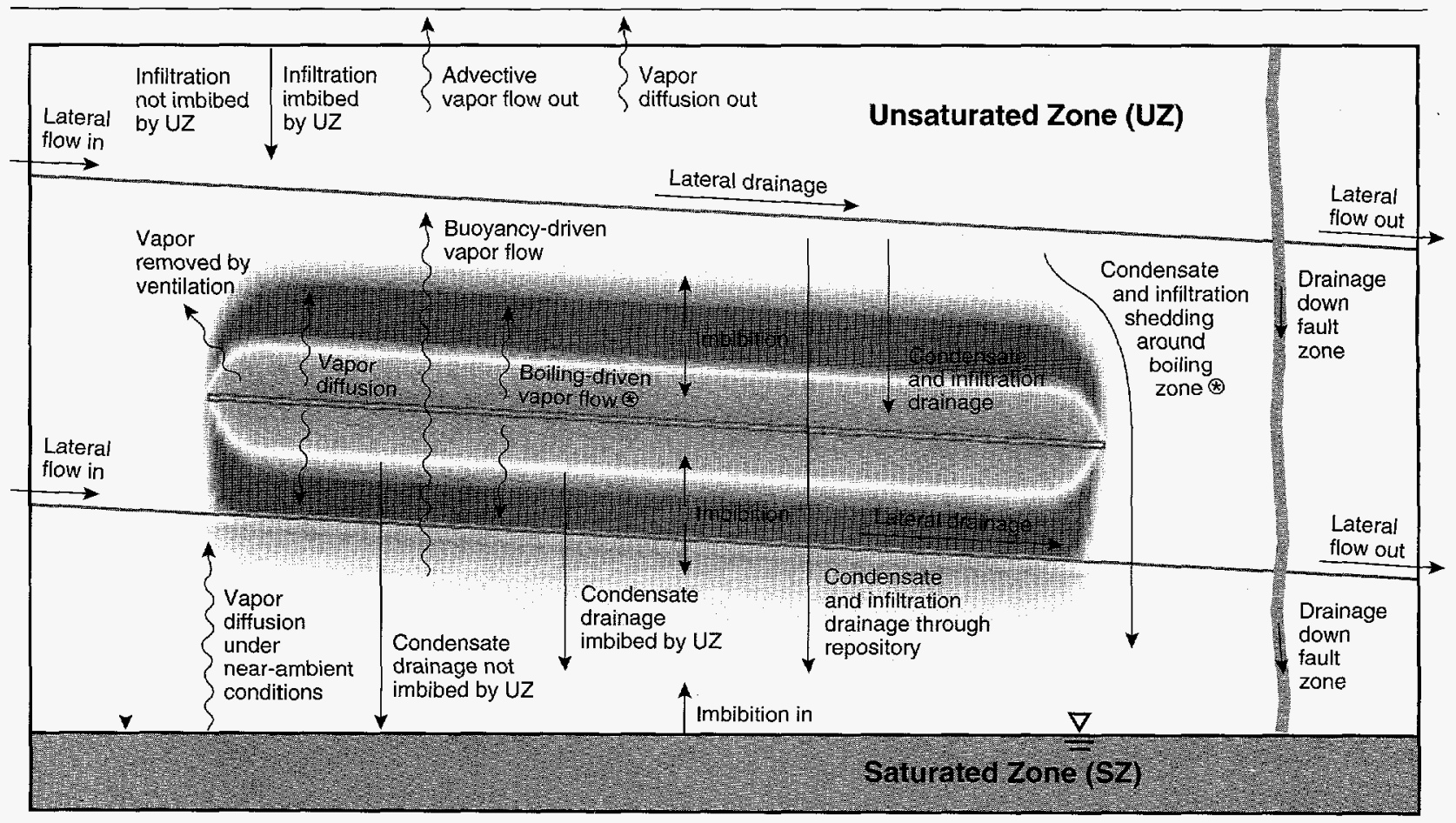

Figure 1. Moisture balance in the unsaturated zone (and above the repository itself) is affected by both ambient and decay-heat-driven processes. The two processes labeled with an asterisk $(*)$ are applicable only to above-boiling conditions; all other processes shown can occur under both sub-boiling and above-boiling conditions. 
(and, in particular, in the region above the repository) may play a very important role in the performance of the EBS, the natural barriers, and the total system.

\section{II.C Importance of Thermal Hydrology for Radionuclide Release and Transport}

Release of aqueous radionuclides to the natural environment would require that the WP was breached and that there was enough liquid water to dissolve radionuclides and transport them by advection or diffusion from the waste form to the surrounding rock. Both waste-form dissolution and advective radionuclide transport are minimized if no mobile liquid water is present. Diffusive radionuclide transport in the EBS is minimized if the liquid-phase saturation is low enough, particularly if a granular backfill and/or invert is used and if $R H$ in the drift remains low. The likelihood of this scenario depends strongly on T-H processes. The chemistry and temperature, and the advective velocity of the aqueous phase, will all affect waste-form degradation and radionuclide dissolution. Possible sources of advective liquid-phase flow are episodic surface infiltration and condensate drainage.

If the flux of water leaving the EBS (and carrying dissolved radionuclides) is high enough, some of the water will flow down fractures, where it will eventually be imbibed into the matrix or continue to the water table. Radionuclides imbibed in the matrix will be immobilized until the next pulse of fracture flow, whereupon some of the radionuclides will diffuse into the incoming stream if it is at a lower concentration. The remaining radionuclides will continue to imbibe and diffuse deeper into the matrix block. The likelihood of this advective transport scenario may be significantly reduced with the use of a suitable backfill or invert. The spatial and temporal extent of decay-heat-driven rock dryout will also play a very important role in the dynamics of fracture-matrix liquid-phase flow interaction and, consequently, in aqueous transport of radionuclides in the engineered and natural barrier systems. Because decay-heat-driven $\mathrm{T}-\mathrm{H}$ processes can dominate advective gas movement, they will also have a strong effect on the release and transport of gaseous radionuclides.

\section{II.D Use of Hypothesis Testing}

The subject of hydrological model validation has generated considerable debate. Konikow and Bredehoeft [1992] believe that the terms model validation and verification are misleading and that their use in groundwater science should be abandoned in favor of more meaningful model-assessment descriptors. This view echoes that of Popper [1959], who states:

"We cannot validate, we can only invalidate." Konikow and Bredehoeft believe that this "obligates us as scientists to perform a critical set of experiments in an attempt to test, or invalidate, our model (or hypothesis)." For many published "model validation" studies, the modelers history-matched their models, and in the process, used their models to estimate parameter distributions, stresses on the system, and boundary and initial conditions. The modelers imply that the resulting good fit constitutes model validation.

Konikow and Bredehoeft [1992] ask, rhetorically, "If the models cannot be validated, why are they useful?" They answer their question by stating: "Models provide a tool for critical analysis. They are a means to organize our thinking, test ideas for their reasonableness, and indicate which are the sensitive parameters. They point the way for further investigation. They help formulate critical experiments with which to test hypotheses." In our modeling studies of decay-heat-driven T-H flow, we have utilized idealizations of (1) the repository thermal load, (2) the distribution of hydrological and thermal properties, and (3) boundary and initial conditions. No individual model of the repository-UZ-SZ system is itself a "valid" representation; however, the combined use of our suites of model calculations provides a means to identify critical dependences, evaluate worst-case scenarios, and develop fundamental hypotheses, which can be addressed by subsequent analysis and testing.

A primary motivation for the minimally heated $(\mathrm{MH})$ repository strategy is to avoid or limit the significance of heat-mobilized fluid flow in the UZ. The underlying assumption is that by eliminating or limiting the spatial and temporal extent of boiling, one minimizes the major significant mechanism for mobilizing heat-driven fluid flow. However, there are mechanisms that occur under sub-boiling conditions that must be addressed in order to justify this assumption.

Testing the following hypotheses will determine whether a low-AML repository system based on the MH strategy avoids (or limits) significant heat-mobilized fluid flow near WPs:

MH-1: Mountain- and drift-scale buoyant gas-phase convection does not significantly mobilize moisture in the unsaturated zone (UZ).

MH-2: Vapor diffusion does not significantly mobilize moisture in the UZ.

MH-3: Heterogeneity in the heat load distribution and/or in gas- and liquid-phase pathways does not focus enough condensate drainage to drip onto WPs or to significantly increase liquid-phase flow in the UZ. 
For repository systems with thermal loads that significantly mobilize fluid flow, as is certainly the case with a high-AML repository, these same hypotheses address how that mobilization occurs.

Field tests, including the Large-Block Test (LBT), to be performed at Fran Ridge [Lin et al., 1994], and in situ thermal tests in the ESF will provide the most conclusive means of evaluating issues associated with thermal loading, including resolution of the major hypotheses. Portions of these tests should be conducted under sub-boiling conditions to support the resolution of hypotheses $\mathrm{MH}-1, \mathrm{MH}-2$, and $\mathrm{MH}-3$. Portions of the tests will be conducted under above-boiling conditions to address the effect of boiling for either a low- or high-AML repository system, and to provide information critical to establishing the maximum design thermal load of the repository.

Hypothesis testing can also help determine the extent to which a low- or high-AML repository system based on the $\mathrm{CH}$ strategy can generate conditions that enhance WP integrity and that reduce the potential for radionuclide dissolution and transport. The primary $\mathrm{CH}$ hypotheses are as follows:

CH-1: Heat, vapor, and liquid flow (including heterogeneous fracture flow) near WPs are dominated by heat conduction (and possibly vapor diffusion) and are therefore predictable.

CH-2: WP temperatures above the boiling point, and/or a $\Delta T$ between the WP and drift wall, result in a significant reduction in $R H$ and the absence of mobile liquid water on WPs.

CH-3: Ambient (humid) WP conditions are restored after WP temperatures have substantially cooled (i.e., well after the end of the boiling period).

The above-boiling heating stages of the LBT and of ESF thermal tests are needed to support the resolution of hypotheses $\mathrm{CH}-1, \mathrm{CH}-2$, and $\mathrm{CH}-3$ and to further support the resolution of hypotheses $\mathrm{MH}-1, \mathrm{MH}-2$, and MH-3. It is easier to evaluate the significance of buoyant gas-phase convection when thermal testing is conducted under above-boiling conditions [Buscheck et al., 1993b]. As discussed in Sec. IV.E.1, the cooldown rewetting stage of an above-boiling thermal test can provide significant diagnostic information about the degree of vapor diffusion enhancement.

Resolution of hypothesis $\mathrm{CH}-1$ would be facilitated by testing the following subsidiary hypotheses:

CH-1a: Mountain-scale, buoyant gas-phase convection does not dominate heat flow in the UZ.

CH-1b: The net infiltration flux above the repository (and below the PTn unit) is not high enough to substantially decrease the vertical thickness of the superheated zone (the zone of above-boiling temperatures) above the repository.

CH-1c: The integrity of the superheated zone is not substantially compromised by variability in the heat load distribution (including edge-cooling effects) or by heterogeneity in the distribution of infiltration flux and condensate drainage. In other words, focused advective liquid-phase flow does not overwhelm the decay-heatdriven heat flux enough to permanently collapse (down to WP locations) local regions of the superheated zone.

If it is substantially enhanced, vapor diffusion increases the heat loss from the repository (and from WPs) in a predictable manner (which is very similar to that resulting from heat conduction). The net infiltration flux (in particular, that below the PTn unit) may be reduced if the decay-heat-steepened, near-ground-surface temperature gradient increases the evapo-transpirative loss of moisture to the atmosphere.

Resolution of hypothesis $\mathrm{CH}-2$ would be facilitated by testing the following subsidiary hypotheses:

CH-2a: Variability in the heat load distribution and/or heterogeneity in gas- and liquid-phase (fracture) pathways does not focus enough infiltration flux and condensate drainage to drip onto WPs.

CH-2b: Vaporization and vapor flow are not throttled by low $k_{\mathrm{b}}$ to cause a large enough increase in $P_{\mathrm{g}}$ that suppresses $R H$ reduction.

In addition to heterogeneity, subsidiary hypothesis $\mathrm{CH}-2 \mathrm{a}$ also depends on whether the net infiltration flux is high enough (at least locally) to collapse regions of the superheated zone. If it is substantially enhanced, vapor diffusion tends to mitigate the effects of nonequilibrium liquid-phase fracture flow and thereby helps to maintain drier WP conditions.

Resolution of hypothesis $\mathrm{CH}-3$ would be facilitated by testing the following subsidiary hypothesis:

CH-3a: The net infiltration flux above the repository (and below the PTn unit) is not high enough to allow the rewetting front in the rock matrix to closely follow the retreat of the nominal boiling front.

A highly spatially heterogeneous and episodic distribution of infiltration flux could focus liquid-phase flux onto no more than a few WPs, while reducing the overall rate of rewetting of the dryout zone. The latter effect would occur if episodic nonequilibrium liquid-phase fracture flow drained quickly through the dryout zone before being completely imbibed by the rock matrix. Whether the liquid-phase flux reaching WPs occurs primarily as episodic pulses or as steady "seeps and weeps" will significantly affect waste-form 
degradation and radionuclide dissolution and release from WPs. If it is substantially enhanced, vapor diffusion tends to suppress fast liquid-phase rewetting of the rock matrix and nonequilibrium liquid-phase fracture flow.

\section{II.E Purpose of Thermal Testing}

In situ thermal tests (also called heater tests) have been included in the SCP [DOE, 1988] in response to regulatory requirements for site characterization and to test the coupled thermal-hydrological-geomechanicalgeochemical (T-H-M-C) process models required to assess the total system performance at the site. In situ heater tests conducted under thermal loading conditions that are reasonably representative of repository conditions are required to provide an understanding of coupled processes, including the following:

1. T-H behavior, with emphasis on identifying the dominant mode(s) of heat flow and the dominant T-H regime(s) (Sec. IV.B); the degree of vapor diffusion enhancement; modes of water contact on WPs; and heat-driven alteration of flow and transport properties in the engineered and natural barriers.

2. Geochemical behavior, with emphasis on coupling with $\mathrm{T}-\mathrm{H}$ behavior; alteration of flow and transport properties; and the resulting chemistry of water that returns to the EBS (possibly including backfill) and WP locations.

3. Geomechanical behavior, with emphasis on heat-driven opening and closing of fractures and the initiation of new fractures and on the influence of those effects on flow and transport properties, on $\mathrm{T}-\mathrm{H}$ behavior, and on the geomechanical stability of the emplacement drifts.

4. The influence of introduced (man-made) materials, such as backfill, on coupled T-H-M-C processes, with emphasis on water contact modes and the related chemistry.

Several tests, whose objective is to understand these processes, are described in the SCP [DOE, 1988]. To understand the many coupled processes that are likely to occur in the host rock, and to adequately sample the variety of rock types required for repository performance assessment, scientists may need more than one type and location of test. The sufficiency of any test (with respect to scope, size, and duration) for making findings on the compliance of the site with the performance objectives will depend on adequate representation of the heterogeneity of the rock being tested and on the waste isolation strategy that is adopted by the
Civilian Radioactive Waste Management System (CRWMS). A waste isolation strategy is currently being developed by CRWMS, but has not yet been formally adopted. A waste isolation strategy that is based on taking advantage of waste emplacement in the $\mathrm{UZ}$ and on the constructive use of decay heat could include the following five elements:

- Favorable environment for WPs provided by (a) the unsaturated host rock, (b) the low liquid-phase flux near WPs, and (c) an extended period of low relative humidity $R H$ on WPs (low $R H$ until WPs are relatively cool).

- Long-term radionuclide containment provided by robust WPs in conjunction with a favorable WP environment.

- Limited mobilization of radionuclides within the WPs provided by minimal moisture contact by liquid-phase flux and condensation of water vapor.

- Slow release and transport of radionuclides through the EBS provided by limited liquid-phase flux and low moisture content in the EBS.

- Slow migration and significant dilution of radionuclides in the geosphere.

Slow rewetting of the dryout zone (addressed by hypothesis $\mathrm{CH}-3$ ) may be a major factor contributing to slow radionuclide migration in the $\mathrm{UZ}$. Decay-heatdriven, buoyant liquid-phase convection in the $S Z$ may be the major mechanism driving radionuclide dilution in the geosphere for tens of thousands of years [Buscheck and Nitao, 1993b; Buscheck and Nitao, 1994a]. Heater testing in the ESF and the LBT [Lin et al., 1994] and related analyses will provide key essential technical input for virtually all of the waste isolation elements.

\section{II.F Factors Affecting Thermal Test Size and Duration}

The required size and duration of in situ thermal tests are influenced by regulatory requirements, model testing needs, and the need for scientific credibility. The requirements of the Nuclear Regulatory Commission (NRC) relevant to in situ testing are found in $10 \mathrm{CFR}$ 60 [NRC, 1990]. Site characterization must include in situ exploration and testing at the depths at which WPs would be emplaced unless the Commission determines that this is not necessary for a specific site [NRC, 1990]. The results of in situ testing will be used to develop the information contained in the safety analysis report (SAR) that will be part of the LA. The SAR must include a description of the hydrological, geochemical, and geomechanical properties and 
conditions of the site and the anticipated response of these systems to the maximum design thermal load of the repository [NRC, 1990].

The assessment of the site presented in the SAR must include an evaluation of repository performance and a description of the measures used to test the adequacy of the process models that provide the basis for performance assessment. The analyses must be supported by an appropriate combination of in situ tests, laboratory tests representative of field conditions, monitoring data, and natural analog studies [NRC, 1990]. The NRC issued its "Generic Technical Position on In Situ Testing During Site Characterization for High-Level Nuclear Waste Repositories" (GTP) to provide guidance to the DOE on in situ testing [NRC, 1985]. The introductory sections of the GTP state that in situ tests should represent a realistic repository environment as closely as possible. However, it was recognized that the time available for these tests is far shorter than the period of post-closure performance. The NRC staff [NRC, 1985] specifically noted that there is a "deficient understanding of the effects of heat on rock and mineral behavior as well as the induced hydrological and geochemical changes." The results of in situ tests can be used to test the process models and to reduce the uncertainties in the prediction process.

\section{II.G Physical Criteria Affecting Thermal Test Size and Duration}

Because of limited time before the license application (LA) in 2001, some of the in situ ESF thermal tests will have to be accelerated relative to actual thermal loading conditions. A major objective of in situ thermal test analysis [Buscheck et al., 1993a; Buscheck et al., 1993b] is to examine the trade-offs between test duration (and heating rate) and the generation of T-H conditions applicable to repository performance during the entire thermal loading cycle, including heatup and cooldown. During both heatup and cooldown, the thermal test will accelerate changes in time and space, including the following:

1. The transition from sub-boiling to boiling conditions.

2. The transition from boiling to above-boiling conditions.

3. The transition from above-boiling to sub-boiling conditions.

It is important that the accelerated thermal cycle not preclude the occurrence of coupled T-H-M-C phenomena that may be important to boiling, dryout, and rewetting under actual repository conditions. It is equally important that the accelerated thermal cycle not introduce complex phenomena that are not relevant to actual repository conditions.

An important part of this study is to conduct T-H scoping calculations of the ESF thermal tests in order to design tests that provide useful and timely information needed for resolution of the major hypotheses and to observe potentially critical intercoupling between thermal-hydrological processes and geomechanical and geochemical processes. The heat load must be applied to the rock during the tests in a way that is relevant to repository conditions, and the experimental design must allow substantial resolution of the major $\mathrm{MH}$ and $\mathrm{CH}$ hypotheses described in Sec. II.D.

A primary concern is that the area of heated rock be large enough to accomplish the following:

- Incorporate a network of fractures that is sufficiently connected to allow examination of important decayheat-driven processes such as boiling, vapor diffusion, buoyant gas-phase convection, and nonequilibrium, liquid-phase fracture flow.

- Permit the possible development of condensate perching above the boiling zone.

- Examine whether heterogeneity in the gas- and liquid-phase pathways focuses enough condensate drainage to cause water to drip onto WPs.

- Prevent edge-cooling effects from dominating $\mathrm{T}-\mathrm{H}$ behavior.

- Diagnose the significance of buoyant gas-phase convection on moisture movement and heat flow.

Model calculations have already been conducted [Buscheck et al., 1993a; Buscheck et al., 1993b] that address the question of in situ thermal test size. Those calculations show that a heated area of $1475 \mathrm{~m}^{2}$ would be adequate to prevent edge-cooling effects from dominating $\mathrm{T}-\mathrm{H}$ behavior at the center of the test. Section IV.C of this report addresses the question of thermal test size.

To determine the size and duration of the in situ thermal tests, the following criteria should also be considered:

1. Volume of the dryout zone.

2. Rate of change of temperature.

3. Maximum rock temperatures.

4. Spatial temperature gradients.

5. Extent and duration of condensate perching.

6. Velocity of the dryout front.

The first criterion relates to the scale of the dryout zone relative to the scale of the heterogeneity of the fracture properties, particularly fracture spacing and 
connectivity. Because boiling-driven dryout and buoyant gas-phase convection are very dependent on the fracture system, it is necessary to dry out a sufficient volume of rock to include an interconnected fracture system. Past estimates of this volume were based on the assumption of at least one fracture per foot horizontally and many fewer fractures per foot vertically. We estimated that a rock mass of about $20 \mathrm{~m}$ diameter would be large enough to have interconnected fracture clusters [Buscheck et al., 1993b]. If the dryout zone is small relative to the scale of heterogeneity or connectivity, it may be that boiling-driven dryout, buoyant gas-phase convection, and condensate drainage are completely dominated by the local heterogeneity. Moreover, models that incorporate bulk averages of matrix and fracture properties require tests in which bulk averages are statistically meaningful.

The second, third, and fourth criteria relate to the potential for geomechanical and geochemical effects to significantly alter the $\mathrm{T}-\mathrm{H}$ properties in a way that is not representative of repository thermal loading conditions. The fifth and sixth criteria relate primarily to thermal-hydrological-geochemical coupling at the refluxing front, which may result in geochemical alteration of fracture and matrix properties. If the dryout front is driven too quickly, there will be inadequate time for geochemical effects to occur. Note that an increase in boiling (and dryout rate) will be accompanied by an increased condensate flux in the refluxing zone. One might therefore expect that the increased condensate flux would compensate for the reduced overall time during which a given region of fractured rock is exposed to refluxing conditions. If condensate sheds off the sides of the boiling zone, there will be a net loss of fluid from the refluxing system, increasing the overall rate of dryout. If condensate shedding is particularly effective, substantial overdriving of the dryout rate (relative to applicable repository conditions) will have the effect of reducing the potential for reflux-driven redistribution of minerals in fractures. 


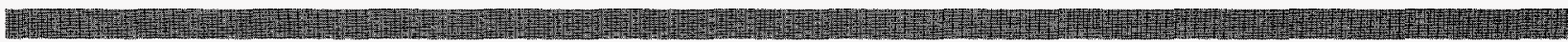




\section{Numerical Models and Assumptions}

\section{III.A V-TOUGH Thermal-Hydrological Flow Code}

All thermal-hydrological calculations were carried out using the V-TOUGH (vectorized transport of unsaturated groundwater and heat) code [Nitao, 1989].

V-TOUGH is Lawrence Livermore National Laboratory's enhanced version of the TOUGH code, which is a member of the Mulkom family of multiphase, multicomponent codes developed at Lawrence Berkeley National Laboratory [Pruess, 1987]. V-TOUGH is a multidimensional numerical simulator capable of modeling the coupled transport of water, vapor, air, and heat in fractured porous media.

\section{III.B Equivalent Continuum Model}

Because of the impracticality of discretely accounting for all of the fractures at Yucca Mountain, it was necessary to account for fractures using the equivalent continuum model (ECM). The assumption of capillary-pressure and thermal equilibrium between fractures and matrix allows the fracture and matrix properties to be pore-volume-averaged into an equivalent medium. The bulk porosity $\phi_{\mathrm{b}}$, bulk saturation $S_{\mathrm{b}}$, and bulk hydraulic conductivity $K_{\mathrm{b}}$ of the equivalent medium are given by the relations

$$
\begin{aligned}
\phi_{\mathrm{b}} & =\phi_{\mathrm{f}}+\left(1-\phi_{\mathrm{f}}\right) \phi_{\mathrm{m}}, \\
S_{\mathrm{b}} & =\frac{S_{\mathrm{f}} \phi_{\mathrm{f}}+S_{\mathrm{m}}\left(1-\phi_{\mathrm{f}}\right) \phi_{\mathrm{m}}}{\phi_{\mathrm{f}}+\left(1-\phi_{\mathrm{f}}\right) \phi_{\mathrm{m}}}, \\
K_{\mathrm{b}} & =K_{\mathrm{m}}\left(1-\phi_{\mathrm{f}}\right)+K_{\mathrm{f}} \phi_{\mathrm{f}},
\end{aligned}
$$

where the subscripts $m$ and $f$ refer to the matrix and fractures, respectively. Because of the low $K_{\mathrm{m}}$ in the $\mathrm{UZ}$, the value of $K_{\mathrm{b}}$ is almost completely determined by $K_{\mathrm{f}}$ and $\phi_{\mathrm{f}}$ for most fracture spacings and permeabilities.

\section{III.C Thermal-Hydrological Properties}

All major hydrostratigraphic units in the $\mathrm{UZ}$ at Yucca Mountain are included in the models [Klavetter and Peters, 1986; Peters et al., 1984]. This hydrostratigraphic profile has been used in previous modeling studies of nonequilibrium liquid-phase fracture flow [Buscheck et al., 1991], studies of T-H behavior at the drift and repository scale [Buscheck and Nitao, 1992; Buscheck and Nitao, 1993a; Buscheck and Nitao, 1993b; Buscheck et al., 1994;
Buscheck and Nitao, 1994a; and Buscheck and Nitao, 1994b], and scoping studies of large-scale in situ thermal tests [Buscheck et al., 1993a; and Buscheck et al., 1993b]. The data for wet and dry thermal conductivity $K_{\text {th }}$ were obtained from the Reference Information Base (RIB) [DOE, 1990]. We applied the RIB version $3 K_{\text {th }}$ values, as we did in previous T-H calculations [Buscheck and Nitao, 1992; Buscheck et al., 1993a; and Buscheck et al., 1993b]. As in those previous studies, we assumed initial saturation conditions corresponding to the steady-state saturation profile obtained by Buscheck et al. [1991] for a net infiltration flux of $0 \mathrm{~mm} / \mathrm{yr}$, yielding a saturation of $68 \%$ at the thermal test horizon.

The reference- $k_{\mathrm{b}}$ case assumed $k_{\mathrm{b}}=280$ millidarcy (equivalent to three 100-mm fractures per meter). To investigate the sensitivity of T-H behavior to $k_{\mathrm{b}}$, we considered $k_{\mathrm{b}}=1,10$, and 280 millidarcy, and 84 darcy. Most of the calculations assumed "nominal" vapor diffusion (vapor diffusion tortuosity factor $\tau_{\text {eff }}=0.2$ ). For $k_{\mathrm{b}}=280$ millidarcy, we also considered the case of "enhanced" vapor diffusion $\left(\tau_{\text {eff }}=20\right)$ in which the rate of vapor diffusion is 100 times greater than in the nominal case.

\section{III.D Initial and Boundary Conditions}

We assume the same initial vertical distribution of temperature $T$, liquid-phase saturation $S_{\mathrm{L}}$, and gas-phase pressure $P_{\mathrm{g}}$ as in previous calculations for a zero net infiltration flux [Buscheck et al., 1991; Buscheck and Nitao, 1992; Buscheck and Nitao, 1993a; Buscheck and Nitao, 1993b; Buscheck et al., 1993a; Buscheck et al., 1993b; Buscheck et al., 1994; Buscheck and Nitao, 1994a; Buscheck and Nitao, 1994b]. We assume that the in situ thermal tests are to be conducted at the repository horizon, which is assumed to be $343.1 \mathrm{~m}$ below the ground surface [Buscheck et al., 1993a; Buscheck et al., 1993b]. Because of the relatively short duration of the in situ thermal tests, there is not sufficient time for the heaters to interfere with the model boundaries. Therefore, the results of this study are insensitive to whether we treat the water table as a fixed-depth, constant-temperature boundary or explicitly represent T-H flow in the SZ. The results are also insensitive to the depth at which the ESF thermal test is conducted, as long as it is conducted primarily in the TSw2 unit (the repository host rock). Differences in $T, S_{\mathrm{L}}$, and $P_{\mathrm{g}}$ within the TSw1-TSw2 depth interval are negligible with respect to depth. 


\section{III.E Thermal Test Configuration}

This study analyzed three basic types of in situ thermal test design:

a. Plate thermal test: A uniformly heated disk-shaped area is approximated with the use of horizontalborehole-emplaced heaters in closely spaced, parallel, small-diameter boreholes. The model used to analyze this test configuration assumes a uniform, planar, diskshaped heat source with a vertical thickness of $1.5 \mathrm{~m}$.

b. Single-drift thermal test: This consists of a row of large-WP-sized heaters located on the center of the floor of a drift having dimensions similar to those of an actual WP emplacement drift. The model assumes that the heaters can be approximated by an infinitely long, line-heat load.

c. Single-drift, winged thermal test: This has the same geometry as the single-drift thermal test with the addition of two arrays of "wing" heaters, which are emplaced in closely spaced, small-diameter horizontal boreholes that effectively create a uniform planar heat load on either side of the heater drift. This heating configuration can effectively simulate accelerated coalescence of the boiling zones between neighboring WP emplacement drifts without resorting to excessively high temperatures near the heater drift.

The in situ heater tests are represented with two kinds of models [Buscheck et al., 1993a; Buscheck et al., 1993b]: (1) a two-dimensional, $X-Z$, verticalcross-sectional model that assumes the heated footprint of the test is infinitely long in the third dimension, and (2) a "quasi-three-dimensional" $R-Z$ model that assumes axisymmetry about the vertical axis through the center of the heater array. The $R-Z$ model is used to represent thermal test configuration a.

For thermal test configurations $b$ and $c$, the $X-Z$ model explicitly represents the details of the drift heaters, heater drifts, and wing heater arrays in the vertical plane transverse to the drift axis. The cross-sectional dimension of the heater is $1.5 \times 1.5 \mathrm{~m}$. The cross-sectional dimension of the heater drift is $4.4 \times 4.4 \mathrm{~m}$. For the reference single-drift, winged thermal test configuration, the wing heater array is assumed to generate a planar heat load over the interval $4<|x|<14 \mathrm{~m}$ from the drift centerline (on either side of the heater drift). For the reference heating-rate case, the lineal heat load generated by the drift heaters is
$0.8 \mathrm{~kW} / \mathrm{m}$ along the drift axis, corresponding to an areal power density (APD) of $100 \mathrm{~W} / \mathrm{m}^{2}$ averaged over the interval $(-4<|x|<4 \mathrm{~m})$ separating the two wing heater arrays. The inner half of the wing heater arrays $(4<|x|<9 \mathrm{~m})$ generates an APD of $105 \mathrm{~W} / \mathrm{m}^{2}$, while the outer half generates an APD of $157.5 \mathrm{~W} / \mathrm{m}^{2}$. The entire heater array (drift heaters plus wing heaters) generates an APD of $122 \mathrm{~W} / \mathrm{m}^{2}$ averaged over the $28-\mathrm{m}$-wide heated area. Because it is two-dimensional, this model assumes that the heater drifts are infinitely long, effectively neglecting heat loss due to heat flow parallel to the drift axes. Two accelerated singledrift, winged thermal tests were also analyzed with APDs of 177 and $236 \mathrm{~W} / \mathrm{m}^{2}$ averaged over the 28-m-wide heated area.

The $R-Z$ model represents a disk-shaped uniform heat source with a given radius and a vertical thickness of $1.5 \mathrm{~m}$. The $R-Z$ model can be also used to approximate the effects of a finite-length, single-drift, winged thermal test heating a square region covering the same area as the disk. Because the single-drift, winged heater test is designed to create a coalesced dryout region at very early time, it can be approximated by a smeared-heat-source model. The $R-Z$ model has the advantage of accurately accounting for the overall heat flow (including the heat flow in the axial direction of the single-drift, winged heater tests). In an earlier study of multi-drift heater tests [Buscheck et al., 1993a; Buscheck et al., 1993b], comparisons between the two-dimensional $X-Z$ model and the $R-Z$ model showed outstanding agreement in rock temperature at the center of the heater array for the first 4 yr of full-power heating. The dryout behavior predicted by the respective models also agreed reasonably well for $t>2 \mathrm{yr}$. For the current study, we used the $R-Z$ model to analyze heated areas of $50,270,490,1475$, and $5077 \mathrm{~m}^{2}$.

For the reference case $\left(\mathrm{APD}=122 \mathrm{~W} / \mathrm{m}^{2}\right)$, we considered three heating durations: 1-, 2-, and 4-yr full-power heating periods. The heater power is linearly ramped to zero in one year following the end of the full-power heating period. For the accelerated-rate cases $\left(\mathrm{APD}=177\right.$ and $236 \mathrm{~W} / \mathrm{m}^{2}$ ), we considered 1- and 2-yr full-power heating periods. 


\section{Discussion of Model Results}

\section{IV.A Overview of Analysis Sections}

When this modeling study began, five major thermal test configurations were under consideration:

1. Single-element thermal test.

2. Plate thermal test.

3. Single-drift thermal test.

4. Single-drift, winged thermal test.

5. Multi-drift thermal test.

Because of their respective merits, early plans were to run at least three of these configurations concurrently during the first set of ESF thermal tests. More recently, planning for the first set of ESF thermal tests has focused on configurations 1 and 4. Configuration 5 (multi-drift thermal test) will be used in the second set of ESF thermal tests, which will heat a larger area and will have longer heatup and cooldown periods. In the following sections, we analyze configurations 2,3 , and 4 . Analyses of configuration 5 have also been conducted [Buscheck et al., 1993a; Buscheck et al., 1993b]. Calculations of small-area plate thermal tests (e.g., the $50-\mathrm{m}^{2}$ test described in Sec. IV.C) can be applied to analyzing configuration 1 , whereas calculations of large-area plate thermal tests (e.g., the $5077-\mathrm{m}^{2}$ test described in Sec IV.C) can be applied to analyzing configuration 5 .

We begin with a discussion (Sec. IV.B) of the major decay-heat-driven thermal-hydrological (T-H) flow regime(s) that will govern the magnitude and direction of decay-heat-driven vapor flow in the UZ at Yucca Mountain. A major objective of this study is to determine a thermal test design (including test size, heating rate, and heating duration) that will facilitate the determination of the dominant $\mathrm{T}-\mathrm{H}$ regime(s) in a timely fashion.

In Sec. IV.C we use the $R$ - $Z$ model to evaluate plate thermal test size and duration. The $R-Z$ model, which is effectively a smeared-heat-source model, is directly applicable to the plate thermal test; however, it can also be used to approximate the heating from a square heater array having the same heated area as the disk-shaped heater array. This approximation yields a reasonably accurate representation of the temperature distribution for the multi-drift thermal test configuration [Buscheck et al., 1993a; Buscheck et al., 1993b]. After the dryout zones coalesce ( $t \geq 2 \mathrm{yr}$ ), the $R-Z$ model yields a good representation of dryout behavior in the multi-drift test. Because the single-drift, winged heater test is designed to create a coalesced dryout region at very early time, it can be accurately approximated with the smeared-heatsource $R-Z$ model. Therefore, the evaluation of plate thermal test size and duration in Sec. IV.C is also applicable to the single-drift, winged heater test.

In Secs. IV.D and IV.E we use the $X$ - $Z$ verticalcross-sectional model, which explicitly represents the details of the drift heaters, heater drifts, and wing heater arrays in the vertical plane transverse to the drift axes. In Sec. IV.D we analyze the single-drift heater test and compare it with the reference single-drift, winged heater test. In Secs. IV.E.1, IV.E.2, and IV.E.3 we analyze the single-drift, winged heater test, and we discuss how the thermal tests can be used to differentiate between the three major T-H regimes and to determine the degree to which vapor diffusion is enhanced. In Sec. IV.E.1 we evaluate heater test size and duration and the representativeness of T-H behavior in the single-drift, winged heater test as compared to the expected drift-scale T-H behavior in the actual repository. In Sec. IV.E. 2 we evaluate the effect of a heterogeneous distribution of bulk permeability $k_{\mathrm{b}}$ on dryout and rewetting behavior and on the temperature distribution, and we consider the implications these effects may have on a recommended thermal test duration. Finally, in Sec. IV.E. 3 we evaluate accelerated heating schedules.

\section{IV.B Major Thermal-Hydrological Flow Regimes}

Perhaps the single most important purpose of the ESF thermal tests is to determine the major decay-heatdriven T-H flow regime(s) that will govern the magnitude and direction of vapor flow (and the resulting condensate flow) in the UZ at Yucca Mountain. We list below the three major T-H flow regimes with respect to advective rock dryout. Note that the numbered points (describing various attributes of the regimes) are listed in parallel: the first point addresses the dominant mode of heat flow, the second point addresses $R H$ reduction, points 3 and 4 address the relative contribution of vapor diffusion to rock dryout, and point 5 addresses the predominant direction of vapor flow. Points 6 through 8 pertain only to the unthrottled buoyant regime. The following discussion is summarized in Table 1.

Throttled, nonbuoyant advective rock dryout: the regime in which $k_{\mathrm{b}}$ is low enough ( $k_{\mathrm{b}}<1$ millidarcy) to significantly throttle the rate of boiling-driven advective rock dryout. The threshold $k_{\mathrm{b}}$ below which rock dryout is throttled decreases with increasing AML. 


\begin{tabular}{|c|c|c|c|}
\hline $\begin{array}{l}\text { Thermal } \\
\text { processes }\end{array}$ & $\begin{array}{l}\text { Throttled nonbuoyant } \\
\text { regime }\end{array}$ & $\begin{array}{l}\text { Unthrottled nonbuoyant } \\
\text { regime }\end{array}$ & $\begin{array}{l}\text { Unthrottled buoyant } \\
\text { regime }\end{array}$ \\
\hline $\begin{array}{l}\text { Boiling-driven } \\
\text { rock dryout }\end{array}$ & $\begin{array}{l}\text { For high AMLs, is a } \\
\text { major contributor to } \\
\text { rock dryout } \\
\text { - For low AMLs, is only } \\
\text { locally significant* }\end{array}$ & $\begin{array}{l}\text { For high AMLs, is the } \\
\text { major contributor to } \\
\text { rock dryout } \\
\text { For low AMLs, is only } \\
\text { locally significant* }\end{array}$ & $\begin{array}{l}\text { For high AMLs, is the major } \\
\text { contributor to rock dryout } \\
\text { For low AMLs, is only locally } \\
\text { significant* }\end{array}$ \\
\hline $\begin{array}{l}\text { Buoyant } \\
\text { gas-phase } \\
\text { convection- } \\
\text { driven } \\
\text { rock dryout }\end{array}$ & $\begin{array}{l}\text { Insignificant } \\
\text { contribution to rock } \\
\text { dryout }\end{array}$ & $\begin{array}{l}\text { Insignificant } \\
\text { contribution to rock } \\
\text { dryout }\end{array}$ & $\begin{array}{l}\text { For high AMLs ( } k_{b}>40 \text { darcy), } \\
\text { contributes to rock dryout } \\
\text { For low AMLs, is a major } \\
\text { contributor to rock dryout } \\
\text { - Enhanced vapor diffusion can } \\
\text { significantly reduce buoyant } \\
\text { gas-phase convection }\end{array}$ \\
\hline $\begin{array}{l}\text { Vapor } \\
\text { diffusion-driven } \\
\text { rock dryout }\end{array}$ & $\begin{array}{l}\text { For high AMLs, may } \\
\text { be a significant } \\
\text { contributor to rock } \\
\text { dryout (if enhanced) } \\
\text { - For low AMLs, is the } \\
\text { major contributor to } \\
\text { rock dryout (if } \\
\text { enhanced) }\end{array}$ & $\begin{array}{l}\text { For high AMLs, is a } \\
\text { minor contributor to } \\
\text { rock dryout } \\
\text { - For low AMLs, is a } \\
\text { major contributor to } \\
\text { rock dryout (if } \\
\text { enhanced) }\end{array}$ & $\begin{array}{l}\text { For high AMLs, is a minor } \\
\text { contributor to rock dryout } \\
\text { - For low AMLs, is a major } \\
\text { contributor to rock dryout (if } \\
\text { enhanced) }\end{array}$ \\
\hline $\begin{array}{l}\text { Total rock } \\
\text { dryout }\end{array}$ & $\begin{array}{l}\text { - Dominated by heat } \\
\text { conduction }\end{array}$ & $\begin{array}{l}\text { Dominated by heat } \\
\text { conduction, unless } \\
\text { focused liquid flow } \\
\text { strongly depresses the } \\
\text { upper boiling front }\end{array}$ & $\begin{array}{l}\text { For high AMLs, is dominated } \\
\text { by heat conduction, unless } \\
\text { focused liquid flow strongly } \\
\text { depresses the upper boiling } \\
\text { front }\end{array}$ \\
\hline Heat flow & $\begin{array}{l}\text { - Conduction-dominated } \\
\text { - Enhanced vapor } \\
\text { diffusion can increase } \\
\text { the repository cooling } \\
\text { rate }\end{array}$ & $\begin{array}{l}\text { Conduction-dominated, } \\
\text { unless focused liquid } \\
\text { flow strongly depresses } \\
\text { the upper boiling front } \\
\text { Enhanced vapor } \\
\text { diffusion can increase } \\
\text { the repository cooling } \\
\text { rate }\end{array}$ & $\begin{array}{l}\text { - Conduction-dominated, unless } \\
k_{\mathrm{b}}>40 \text { darcy and/or focused } \\
\text { liquid flow strongly depresses } \\
\text { the upper boiling front } \\
\text { For } k_{\mathrm{b}}>40 \text { darcy, buoyant } \\
\text { gas-phase convection becomes } \\
\text { dominant, particularly at the } \\
\text { edge of the repository }\end{array}$ \\
\hline $\begin{array}{l}\text { Heat-pipe } \\
\text { zones }\end{array}$ & - Will be limited & $\begin{array}{l}\text { - May be significant, } \\
\text { particularly where } \\
\text { focused liquid flow } \\
\text { occurs }\end{array}$ & $\begin{array}{l}\text { May be significant, } \\
\text { particularly where focused } \\
\text { liquid flow occurs }\end{array}$ \\
\hline$R H$ reduction & $\begin{array}{l}\text { - May be small, because } \\
P_{\mathrm{g}} \text { rise is large }\end{array}$ & $\begin{array}{l}\text { May be large, because } \\
P_{\mathrm{g}} \text { rise is small }\end{array}$ & $\begin{array}{l}\text { - May be large, because } P_{\mathrm{g}} \text { rise } \\
\text { is small }\end{array}$ \\
\hline
\end{tabular}

*In the vicinity of the emplacement drifts. 
1. Heat flow is conduction-dominated, resulting in a vertically symmetrical temperature profile.

2. Because $P_{\mathrm{g}}$ could rise substantially above $1 \mathrm{~atm}$, $R H$ reduction may be substantially less than it would be under unthrottled conditions.

3. For high AMLs, vapor diffusion (if significantly enhanced) may significantly contribute to rock dryout and vapor transport.

4. For low AMLs, vapor diffusion (if significantly enhanced) is the major contributor to rock dryout and vapor transport.

5. Vapor transport and the development of the dryout zone are dominated by temperature gradients, and are therefore generally vertically symmetrical about the heated horizon.

Unthrottled, nonbuoyant advective rock dryout: the regime in which $k_{\mathrm{b}}$ is high enough $\left(k_{\mathrm{b}}>1\right.$ millidarcy) not to significantly throttle the rate of boiling-driven advective rock dryout, but not high enough $\left(k_{\mathrm{b}}<5\right.$ darcy) to allow buoyant gas-phase convection to dominate the direction of vapor flow.

1. Heat flow is conduction-dominated, resulting in a vertically symmetrical temperature profile, unless focused liquid flow depresses the upper boiling front.

2. Because $P_{\mathrm{g}}$ does not rise significantly above $1 \mathrm{~atm}$ (particularly for $k_{\mathrm{b}}>10$ millidarcy), $R H$ reduction can be large.

3. For high AMLs, the relative contribution of vapor diffusion (even if enhanced) to rock dryout and vapor transport is small.

4. For low AMLs, the relative contribution of enhanced vapor diffusion to rock dryout and vapor transport can be large.

5. Vapor transport and the development of the dryout zone are dominated by temperature gradients and are therefore generally vertically symmetrical about the heated horizon unless focused liquid flow strongly depresses the upper boiling front.

Unthrottled, buoyant advective rock dryout: the regime in which $k_{\mathrm{b}}$ is high enough not to throttle the rate of boiling-driven advective rock dryout and is also high enough ( $k_{\mathrm{b}}>5$ darcy) to allow buoyant gas-phase convection to dominate the direction of vapor flow.

1. Heat flow is primarily conduction-dominated (although the temperature profile is vertically asymmetrical) unless focused liquid flow depresses the upper boiling front. For $k_{b}>40$ darcy, buoyant gas-phase convection dominates heat flow, significantly reducing the duration of boiling conditions at the repository horizon.
2. Because $P_{\mathrm{g}}$ does not rise significantly above $1 \mathrm{~atm}$, $R H$ reduction can be large.

3. For high AMLs, the relative contribution of vapor diffusion (even if enhanced) to rock dryout and vapor transport is small.

4. For low AMLs, the relative contribution of enhanced vapor diffusion to rock dryout and vapor transport can be large.

5. Vapor transport and the development of the dryout zone are dominated by gas-phase density gradients that drive much of the vapor flow above the repository horizon, resulting in vertically asymmetrical temperature and $S_{\mathrm{L}}$ profiles.

6. For high AMLs, buoyant gas-phase convection does not contribute significantly to rock dryout unless $k_{\mathrm{b}}>40$ darcy.

7. For low AMLs, buoyant gas-phase convection may be the major contributor to rock dryout (even contributing to $R H$ reduction).

8. For all AMLs, enhanced vapor diffusion can significantly reduce the magnitude of buoyant gas-phase convection.

\section{IV.C Plate Thermal Test}

In the plate thermal test, a disk-shaped area is uniformly heated. The plate heating configuration could be achieved with horizontal-borehole-emplaced heaters in closely spaced, parallel, small-diameter boreholes. This heating geometry was considered because it offers the advantage of being accurately represented by an $R-Z$ axisymmetric model. The $R-Z$ model is computationally much more economical than a corresponding three-dimensional model, and that economy makes it amenable to parameter sensitivity analyses. The $R-Z$ model also has the advantage (over two-dimensional vertical-cross-sectional models) of being able to represent three-dimensional heat flow, so it is better able to represent the heat balance during the thermal test (particularly at late time). The finite areal extent of the heater array can be explicitly accounted for with this model. The $R-Z$ model assumes a uniform planar disk-shaped "smeared" heat source with a vertical thickness of $1.5 \mathrm{~m}$. The $R-Z$ model is also useful in analyzing the single-drift, winged thermal test.

\section{IV.C.1 Evaluating Thermal Test Size and Duration}

With the $R$ - $Z$ model, we analyzed heater array areas of $50,270,490,1475$, and $5077 \mathrm{~m}^{2}$, which (more than adequately) span the range of insufficiently sized to sufficiently sized thermal tests. In this section, we focus on the ability of the thermal tests to differentiate 
between two of the three major T-H regimes described in Sec. IV.B, namely unthrottled, nonbuoyant advective rock dryout and unthrottled, buoyant advective rock dryout. We therefore considered two values of bulk permeability, with $k_{\mathrm{b}}=280$ millidarcy resulting in $\mathrm{T}-\mathrm{H}$ behavior that is characteristic of the unthrottled nonbuoyant regime and $k_{\mathrm{b}}=84$ darcy resulting in $\mathrm{T}-\mathrm{H}$ behavior that is characteristic of the unthrottled buoyant regime. Our goal is to identify the thermal test size and duration that are sufficient to facilitate the determination of the dominant $\mathrm{T}-\mathrm{H}$ regimes(s) in a timely fashion. We assumed the value of $\tau_{\text {eff }}=0.2$ for the vapor diffusion tortuosity factor, which corresponds to the case in which vapor diffusion is not enhanced.

The ability to distinguish between the buoyant and the nonbuoyant unthrottled regimes has been covered in previous studies [Buscheck et al., 1993a; Buscheck et a1., 1993b]. Figure 2 shows the dimensionless liquid saturation distributions for a plate thermal test with a radius of $21.7 \mathrm{~m}$ and areal power density APD = $78 \mathrm{~W} / \mathrm{m}^{2}$ averaged over the $1475-\mathrm{m}^{2}$ heated area. As in past studies [Buscheck et al., 1993b], when analyzing dryout and re-wetting behavior we use the dimensionless liquid saturation $\bar{S}_{\mathrm{L}}$ given by

$$
\begin{aligned}
& \bar{S}_{\mathrm{L}}=\frac{S_{\mathrm{L}}-S_{\mathrm{L}, \text { init }}}{S_{\mathrm{L}, \text { init }}}, \text { if } S_{\mathrm{L}}<S_{\mathrm{L}, \text { init }}, \\
& \bar{S}_{\mathrm{L}}=\frac{S_{\mathrm{L}}-S_{\mathrm{L}, \text { init }}}{S_{\mathrm{L}, \max }-S_{\mathrm{L}, \text { init }}}, \text { if } S_{\mathrm{L}}>S_{\mathrm{L}, \text { init }},
\end{aligned}
$$

where $S_{\mathrm{L}}$ is the current liquid saturation, $S_{\mathrm{L} \text {,init }}$ is the initial (or ambient) liquid saturation, and $S_{\mathrm{L}, \max }$ is the maximum liquid saturation (usually taken to be unity). For the 280-millidarcy case (Fig. 2a,b), buoyant gas-phase convection does not significantly affect the direction of vapor flow, so vapor flow is vertically symmetrical about the heater horizon. The effect of the symmetrical vapor flow is partially offset by condensate shedding, which results in a greater condensate volume below the heater horizon (Fig. 3f). The equivalent continuum model (ECM) probably underrepresents how nonequilibrium fracture flow may result in significant condensate shedding during the thermal tests.

For the 84-darcy case (Fig. 2c,d), buoyant gas-phase convection dominates the direction of vapor flow, so that all of the vapor flow is driven upward to where it condenses above the dryout zone. The effect of the vertically asymmetrical vapor flow on the condensate distribution can also be seen in Fig. 3d-f. Condensate shedding resulting from nonequilibrium fracture flow may substantially offset (i.e., mask) the effects of buoyant gas-phase convection on the condensate distribution. Consequently, in situ measurements of changes in the liquid saturation distribution may be an inadequate indicator of the significance of gas-phase buoyancy. It is therefore desirable to have some other means of diagnosing the significance of gas-phase buoyancy. If the heated area is large enough (as is the case for $1475 \mathrm{~m}^{2}$ ), the temperature distribution is highly diagnostic of the importance of gas-phase buoyancy and is insensitive to whether substantial condensate shedding occurs.

The influence of vapor and condensate flow on the temperature profile is very apparent in the 280 -millidarcy and 84-darcy cases (Fig. $3 \mathrm{a}-\mathrm{c}$ ). The temperature profile is flattened at the nominal boiling point $\left(T_{\mathrm{b}} \approx 96^{\circ} \mathrm{C}\right)$. Vapor is driven (by higher $P_{\mathrm{V}}$ in the boiling zone) away from the heater horizon to where lower temperatures cause it to condense. Above the heater horizon, much of this condensate returns to the boiling zone, driven by three mechanisms: (1) capillary imbibition in the matrix, (2) capillary imbibition in small-aperture fractures, and (3) gravity drainage in fractures. Gravity drainage in the matrix is not significant in comparison with matrix imbibition, which is driven by very strong capillary pressure gradients that arise from liquid saturation gradients at the dryout front. Below the heater horizon, only the first two mechanisms, capillary imbibition in the matrix and fractures, contribute to condensate flow back toward the boiling zone; the third mechanism, gravity drainage in fractures, tends to drain condensate away from the boiling zone.

Above the heater horizon, the return flow of condensate toward the boiling zone establishes a heat transfer mechanism (driven by the convection of latent heat) called the gravity-driven heat-pipe effect [Nitao, 1988]. If this heat transfer mechanism occurs below the heater horizon, it is driven by the capillary-driven heatpipe effect. Pruess et al. (1984) were the first to model the capillary-driven heat-pipe effect in conjunction with $\mathrm{T}-\mathrm{H}$ behavior at Yucca Mountain. Given adequately high mass flux rates of the countercurrent flow of vapor and condensate, heat pipes can sustain a given heat flux with a much shallower temperature gradient than is associated with conduction. Consequently, heat pipes are associated with a flat temperature profile, with temperatures close to $96^{\circ} \mathrm{C}$, if $k_{\mathrm{b}}$ is large enough not to cause $P_{\mathrm{v}}$ to rise substantially above 1 atm. Mass fluxes associated with gravity-driven fracture flow are generally greater than those associated with capillary-driven flow in either the matrix or fractures. Above the heater horizon, condensate drainage in fractures is generally the dominant source of liquid flow back to the boiling 
zone. While the flattening of the temperature profile above the heater horizon results primarily from gravity-driven refluxing (the heat-pipe effect), the flattening of the temperature profile below the heater horizon in the 280 -millidarcy case results from the capillary-driven heat-pipe effect. Because all of the vapor flow is upward in the 84-darcy case, there is no heat-pipe zone below the heater horizon.

The vertical temperature profiles (Fig. $3 a-c$ ) are clearly diagnostic of buoyant versus nonbuoyant behavior. For the 280 -millidarcy case, the vertical temperature profile is vertically symmetrical about the

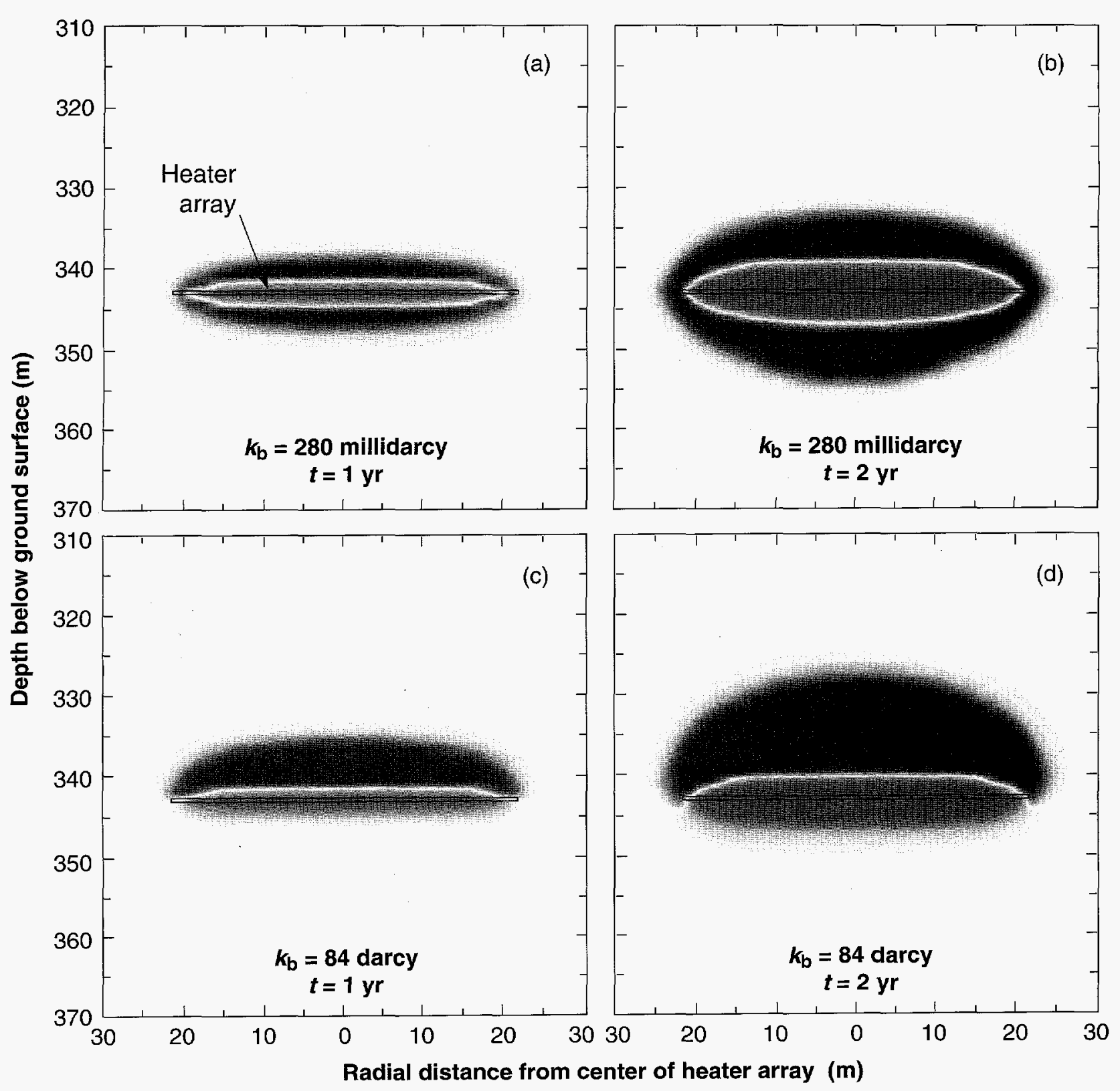

Figure 2. Dimensionless liquid saturation distribution for an array of horizontal-borehole-emplaced heaters heating a disk-shaped area with a radius of $21.7 \mathrm{~m}$ and $\mathrm{APD}=78 \mathrm{~W} / \mathrm{m}^{2}$ averaged over the $1475-\mathrm{m}^{2}$ heated area. Vapor diffusion tortuosity factor $\tau_{\text {eff }}=0.2$. The medium-shaded area surrounding the heater array corresponds to regions that are drier than ambient liquid saturation (dryout zone). The dark-shaded areas correspond to regions that are wetter than ambient liquid saturation (condensation zone). The light shading surrounding the dark-shaded area corresponds to a small rise in liquid saturation (outer edges of the condensation zone). No shading indicates no change in liquid saturation. 
heater horizon. The flattening of the temperature profile at $96^{\circ} \mathrm{C}$ occurs both above and below the heater horizon in the 280-millidarcy case, while for the 84-darcy case it occurs only above the heater horizon. The vertical extent of the upper flattened-temperature zone (i.e., the heat-pipe zone) in the buoyant (84-darcy) case is more than three times that in the nonbuoyant (280-millidarcy) case. The upper boiling front is also higher in the buoyant than in the nonbuoyant case. This difference in front heights amounts to $3 \mathrm{~m}$ at $t=1 \mathrm{yr}, 6 \mathrm{~m}$ at $t=2 \mathrm{yr}$, and $9 \mathrm{~m}$ at $t=4 \mathrm{yr}$ (Fig. 3a-c). For the 84-darcy case, the vertical asymmetry is quite evident at $t=2 \mathrm{yr}$; the upper boiling front is $12 \mathrm{~m}$ above the heater horizon, while the lower boiling front is only $3 \mathrm{~m}$ below the heater horizon. Therefore, within the first $2 \mathrm{yr}$ of fullpower heating, the $1475-\mathrm{m}^{2}$ test can clearly discriminate between the buoyant and nonbuoyant unthrottled regimes.

Figures 4 and 5 provide virtually the same picture as those in Figs. 2 and 3, but for a plate thermal test with a radius of $40.2 \mathrm{~m}$ and $\mathrm{APD}=78 \mathrm{~W} / \mathrm{m}^{2}$ averaged over the $5077-\mathrm{m}^{2}$ heated area. Figure $5 \mathrm{a}-\mathrm{c}$ indicates that differences in the upper boiling front heights is

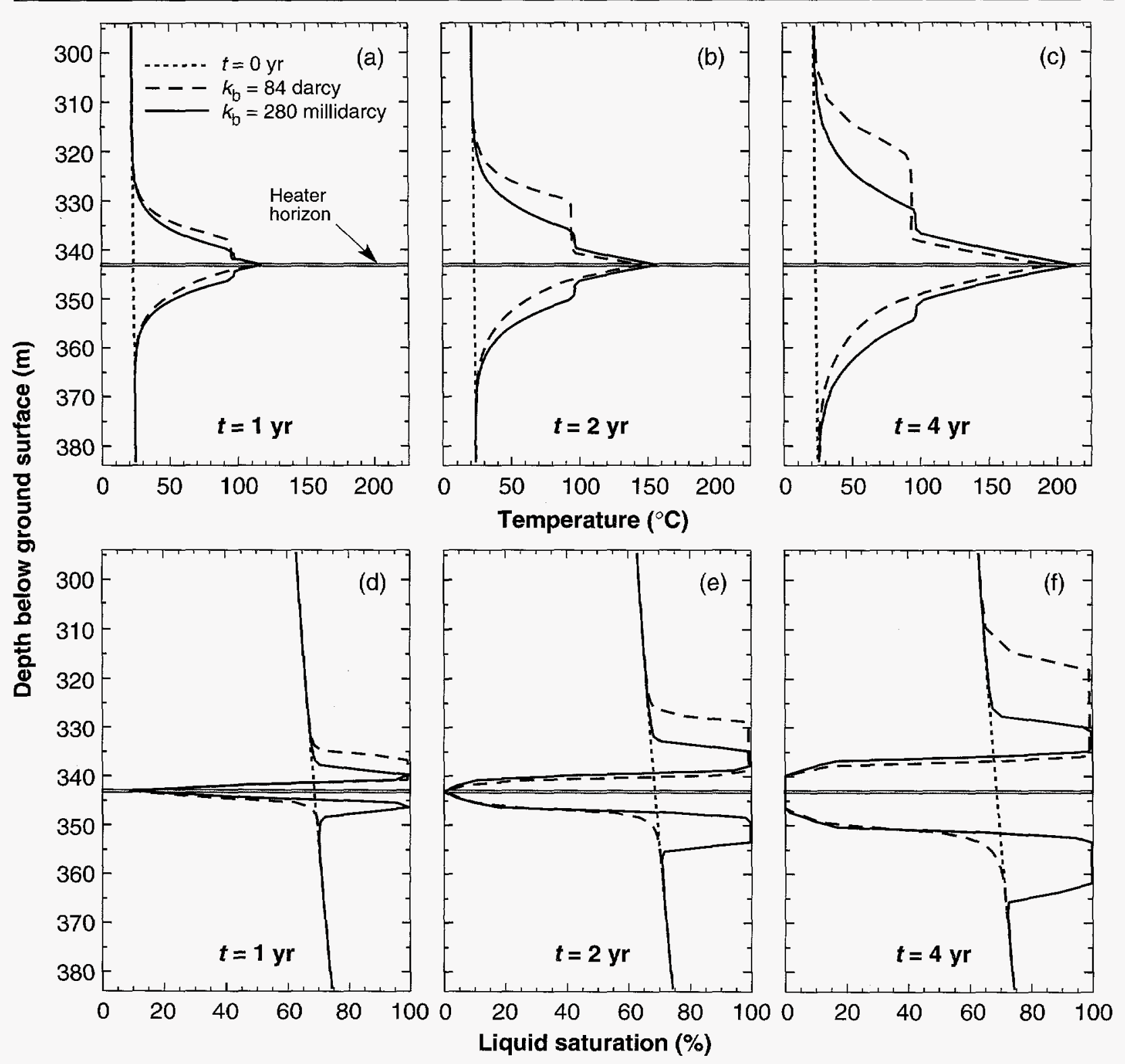

Figure 3. $(a, b, c)$ Vertical temperature profile and (d, e, f) liquid saturation profile along the centerline of an array of horizontal-borehole-emplaced heaters heating a disk-shaped area with a radius of $21.7 \mathrm{~m}$ and $\mathrm{APD}=78 \mathrm{~W} / \mathrm{m}^{2}$ averaged over the $1475-\mathrm{m}^{2}$ heated area. Vapor diffusion tortuosity factor $\tau_{\mathrm{eff}}=0.2$. 
virtually the same as that in the $1475-\mathrm{m}^{2}$ case.

Therefore, with respect to the ability of these respective thermal tests to discriminate between the buoyant and nonbuoyant unthrottled regimes, there is no apparent advantage to going to a larger test size than the $1475-\mathrm{m}^{2}$ case.
To investigate the minimum thermal test size that could be used to diagnose the significance of gas-phase buoyancy, we analyzed a plate thermal test with a radius of $4.0 \mathrm{~m}$ and $\mathrm{APD}=247 \mathrm{~W} / \mathrm{m}^{2}$ averaged over the $50-\mathrm{m}^{2}$ heated area (Figs. 6 and 7). As in the $1475-\mathrm{m}^{2}$ and $5077-\mathrm{m}^{2}$ tests, the 280 -millidarcy case results in

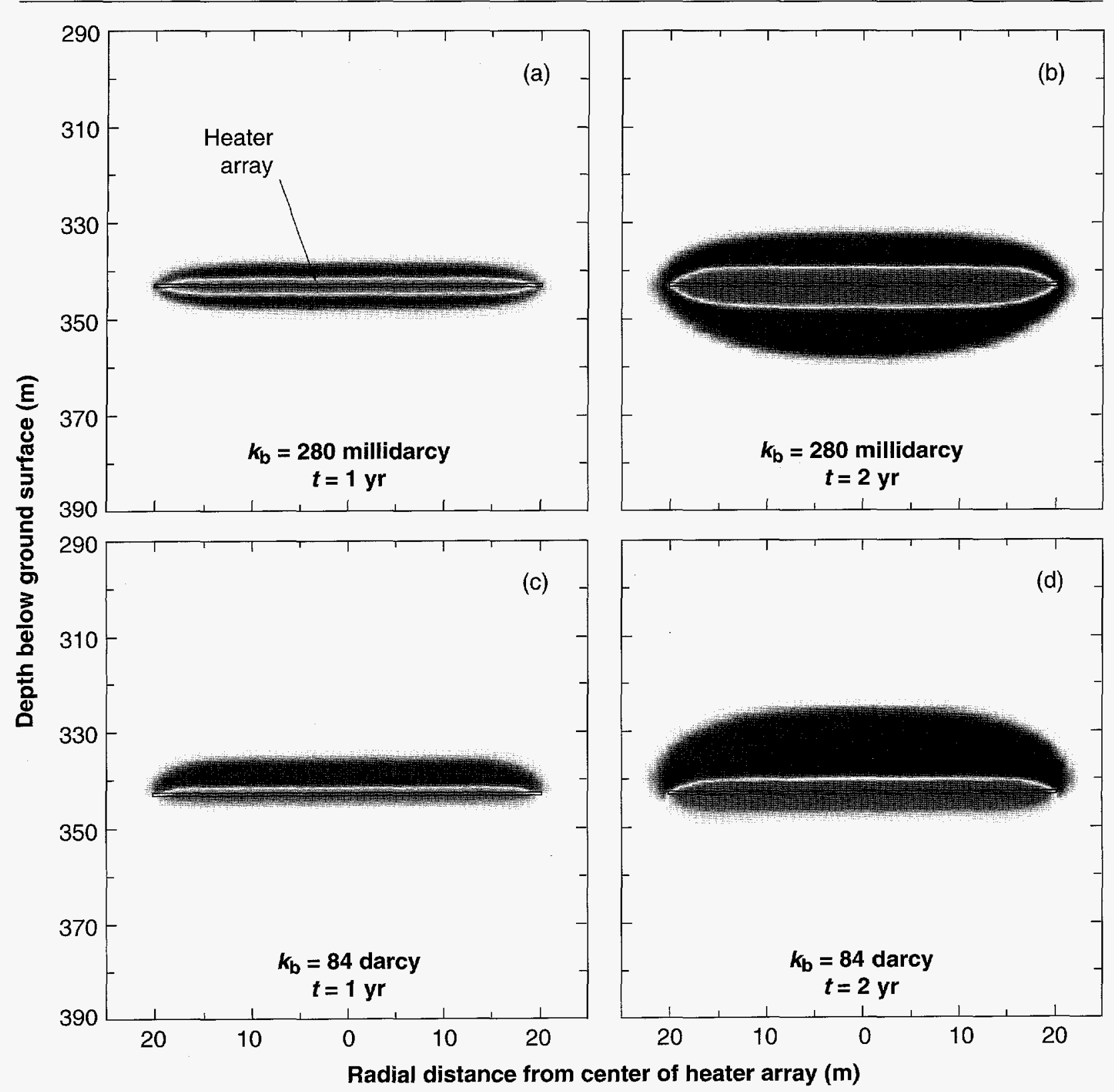

Figure 4. Dimensionless liquid saturation distribution for an array of horizontal-borehole-emplaced heaters heating a disk-shaped area with a radius of $40.2 \mathrm{~m}$ and APD $=78 \mathrm{~W} / \mathrm{m}^{2}$ averaged over the $5077-\mathrm{m}^{2}$ heated area. Vapor diffusion tortuosity factor $\tau_{\text {eff }}=0.2$. The medium-shaded area surrounding the heater array corresponds to regions that are drier than ambient liquid saturation (dryout zone). The dark-shaded areas correspond to regions that are wetter than ambient liquid saturation (condensation zone). The light shading surrounding the dark-shaded area corresponds to a small rise in liquid saturation (outer edges of the condensation zone). No shading indicates no change in liquid saturation. 
vertically symmetrical vapor flow (Fig. 6), while the 84-darcy case results in vertically asymmetrical vapor flow. Unlike the larger tests, the $50-\mathrm{m}^{2}$ test creates very little condensate buildup above the dryout zone for the 280-millidarcy case (Fig. 7e-f).

The $1475-\mathrm{m}^{2}$ and $5077-\mathrm{m}^{2}$ tests (Figs. $2 \mathrm{a}, \mathrm{b}$ and $4 a, b)$ result in very broad, tabular dryout zones and well-developed, tabular zones of condensate buildup, whereas the $50-\mathrm{m}^{2}$ test results in a spherical dryout zone, surrounded by a very diffuse, weakly developed zone of condensate buildup (Fig. 6a,b). Because of their size, the $1475-\mathrm{m}^{2}$ and $5077-\mathrm{m}^{2}$ tests have a broad region in which heat flow is effectively linear (upwards and downwards), while heat flow in the $50-\mathrm{m}^{2}$ test is essentially spherical. In the $1475-\mathrm{m}^{2}$ and $5077-\mathrm{m}^{2}$ tests, the temperature at the center of the heater array increases almost linearly with time (Fig. 8a). Accordingly, the vertical thickness of the dryout zone also grows linearly with time (Fig. 8b). Because of the spherical heat flow in the $50-\mathrm{m}^{2}$ test, the maximum temperature is nearly attained within the first year (Figs. $7 a-c$ and $8 a$ ). Accordingly, the maximum spatial extent of the dryout

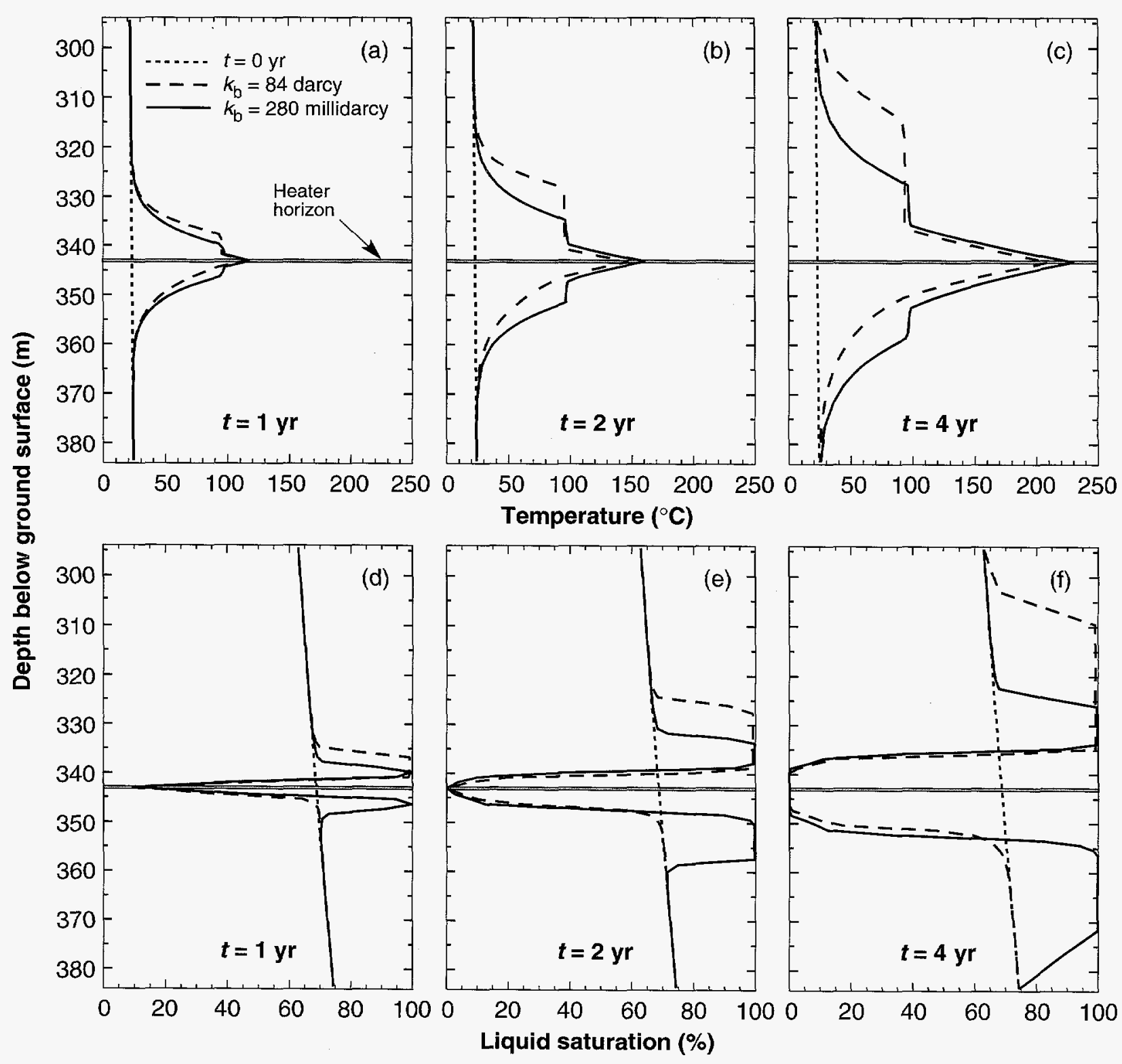

Figure 5. (a, b, c) Vertical temperature profile and $(\mathrm{d}, \mathrm{e}, \mathrm{f})$ liquid saturation profile along the centerline of an array of horizontal-borehole-emplaced heaters heating a disk-shaped area with a radius of $40.2 \mathrm{~m}$ and APD $=78 \mathrm{~W} / \mathrm{m}^{2}$ averaged over the $5077-\mathrm{m}^{2}$ heated area. Vapor diffusion tortuosity factor $\tau_{\mathrm{eff}}=0.2$. 
zone in the $50-\mathrm{m}^{2}$ test is effectively attained within the first year (Fig. 8b). Because the boiling front is not expanding after the first year, a diminishing mass flux of water vapor is being generated. Condensate buildup is consequently minimal because condensate can shed off the sides of the boiling zone and/or be imbibed by the surrounding rock matrix about as fast as it is generated. This behavior is consistent with observations made during the G-Tunnel single-element heater test [Ramirez et al., 1991], in which there was virtually no indication of any increase in liquid saturation in the condensation zone (or anywhere outside the dryout

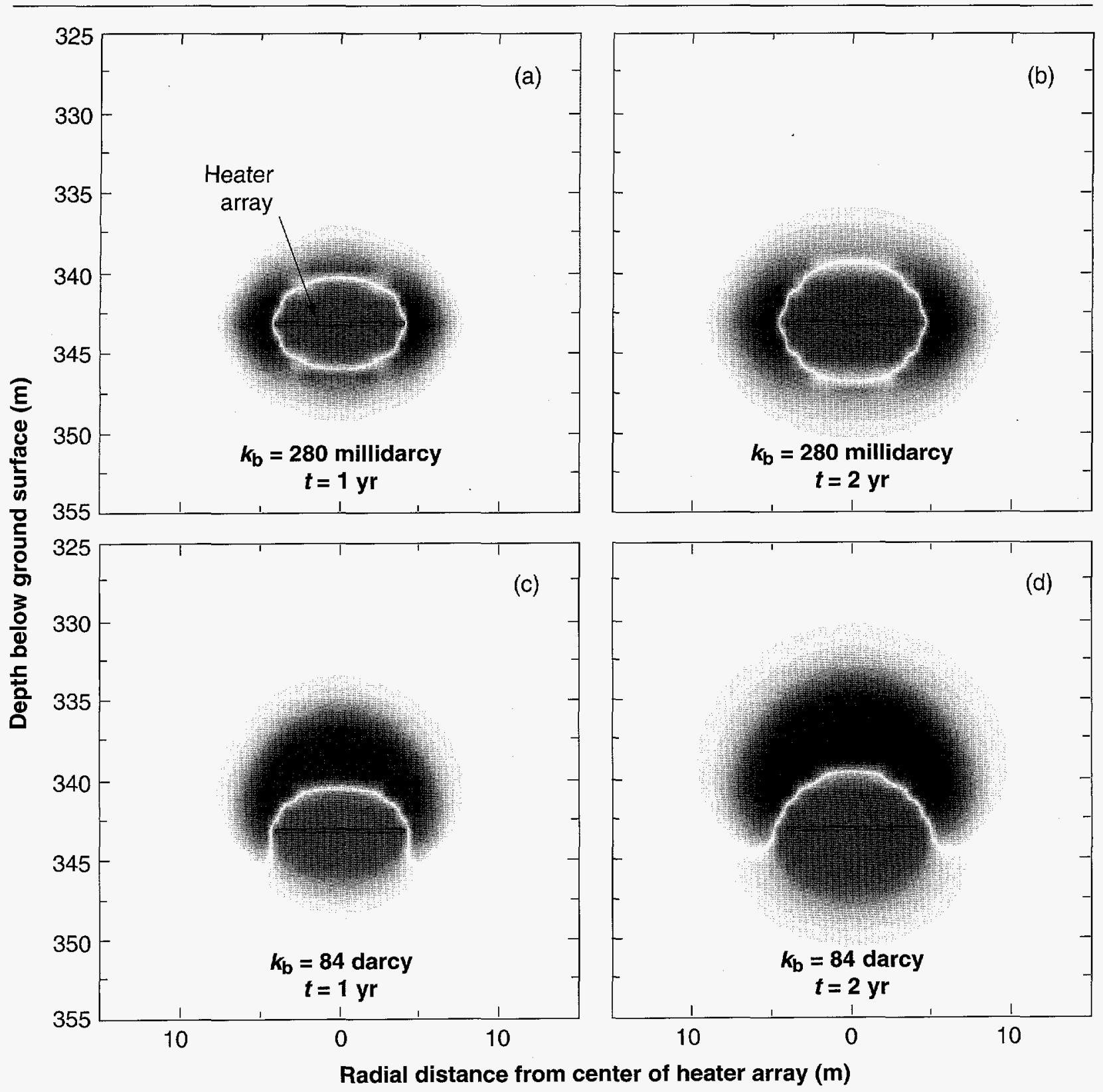

Figure 6. Dimensionless liquid saturation distribution for an array of horizontal-borehole-emplaced heaters heating a disk-shaped area with a radius of $4.0 \mathrm{~m}$ and $\mathrm{APD}=247 \mathrm{~W} / \mathrm{m}^{2}$ averaged over the $50-\mathrm{m}^{2}$ heated area. Vapor diffusion tortuosity factor $\tau_{\text {eff }}=0.2$. The medium-shaded area surrounding the heater array corresponds to regions that are drier than ambient liquid saturation (dryout zone). The dark-shaded areas correspond to regions that are wetter than ambient liquid saturation (condensation zone). The light shading surrounding the dark-shaded area corresponds to a small rise in liquid saturation (outer edges of the condensation zone). No shading indicates no change in liquid saturation. 
zone). It is important to note that any single-element heater test (regardless of its heated length) would result in minimal condensate buildup (and minimal refluxing) above the boiling zone. The absence of any refluxing zone would seriously degrade the ability of a thermal test to provide for observations of potentially critical intercoupling between T-H and geochemical processes.

For the 84-darcy case, the $50-\mathrm{m}^{2}$ thermal test does result in a narrow zone of condensate buildup above the boiling zone (Fig. 7d-f). However, the effect of buoyant convection-dominated vapor flow is not apparent in the vertical temperature profile (Fig. $7 \mathrm{a}-\mathrm{c}$ ). The corresponding vertical temperature profiles for the 280-millidarcy and 84-darcy cases are virtually indistinguishable from each other. A $50-\mathrm{m}^{2}$ thermal test is therefore not large enough to diagnose the significance of gas-phase buoyancy. It is important to note that any single-element heater test (regardless of its heated length) is unlikely to provide any useful information about the significance of gas-phase buoyancy.

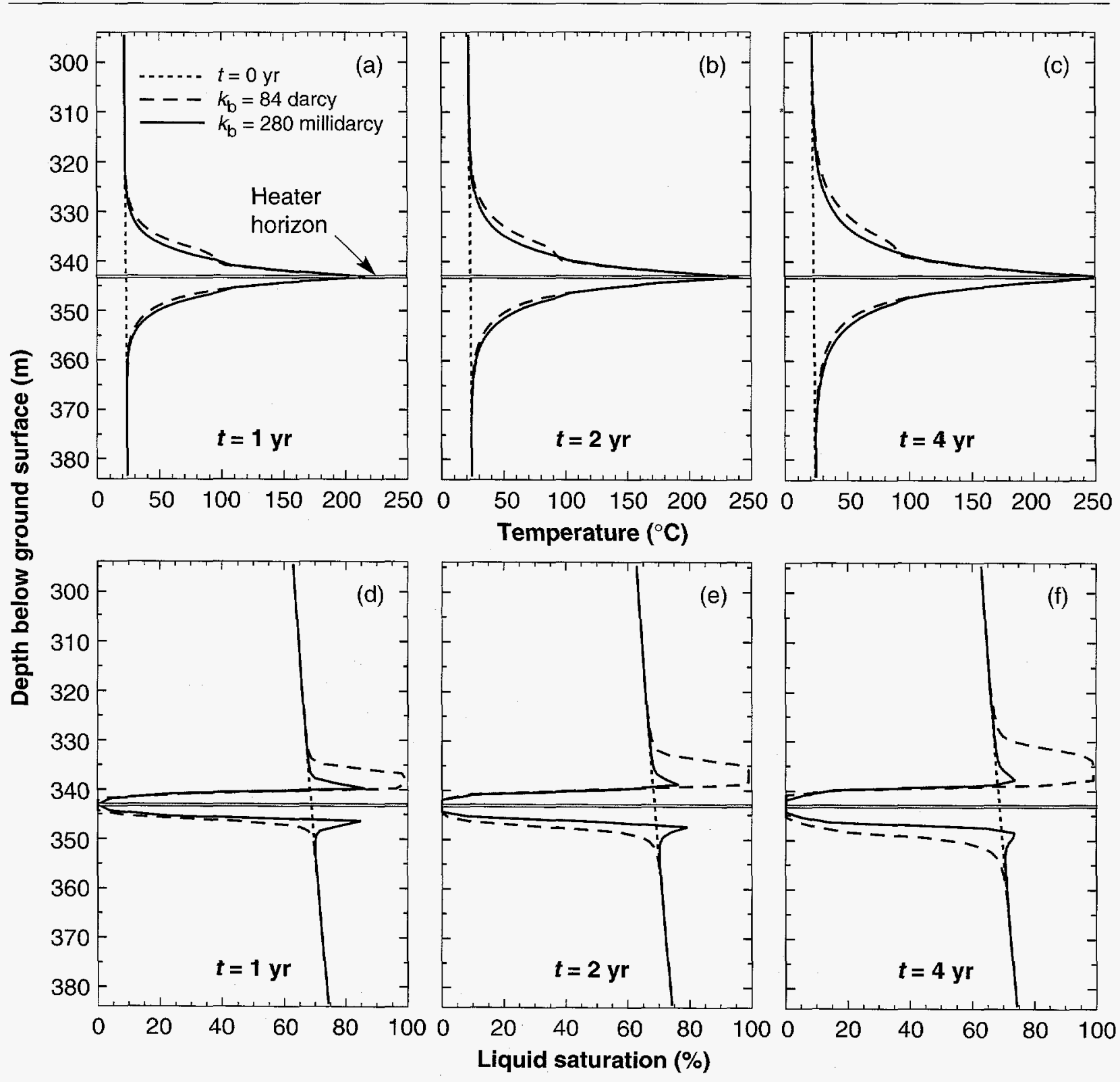

Figure 7. $(a, b, c)$ Vertical temperature profile and $(d, e, f)$ liquid saturation profile along the centerline of an array of horizontal-borehole-emplaced heaters heating a disk-shaped area with a radius of $4.0 \mathrm{~m}$ and APD $=247 \mathrm{~W} / \mathrm{m}^{2}$ averaged over the $50-\mathrm{m}^{2}$ heated area. Vapor diffusion tortuosity factor $\tau_{\mathrm{eff}}=0.2$. 

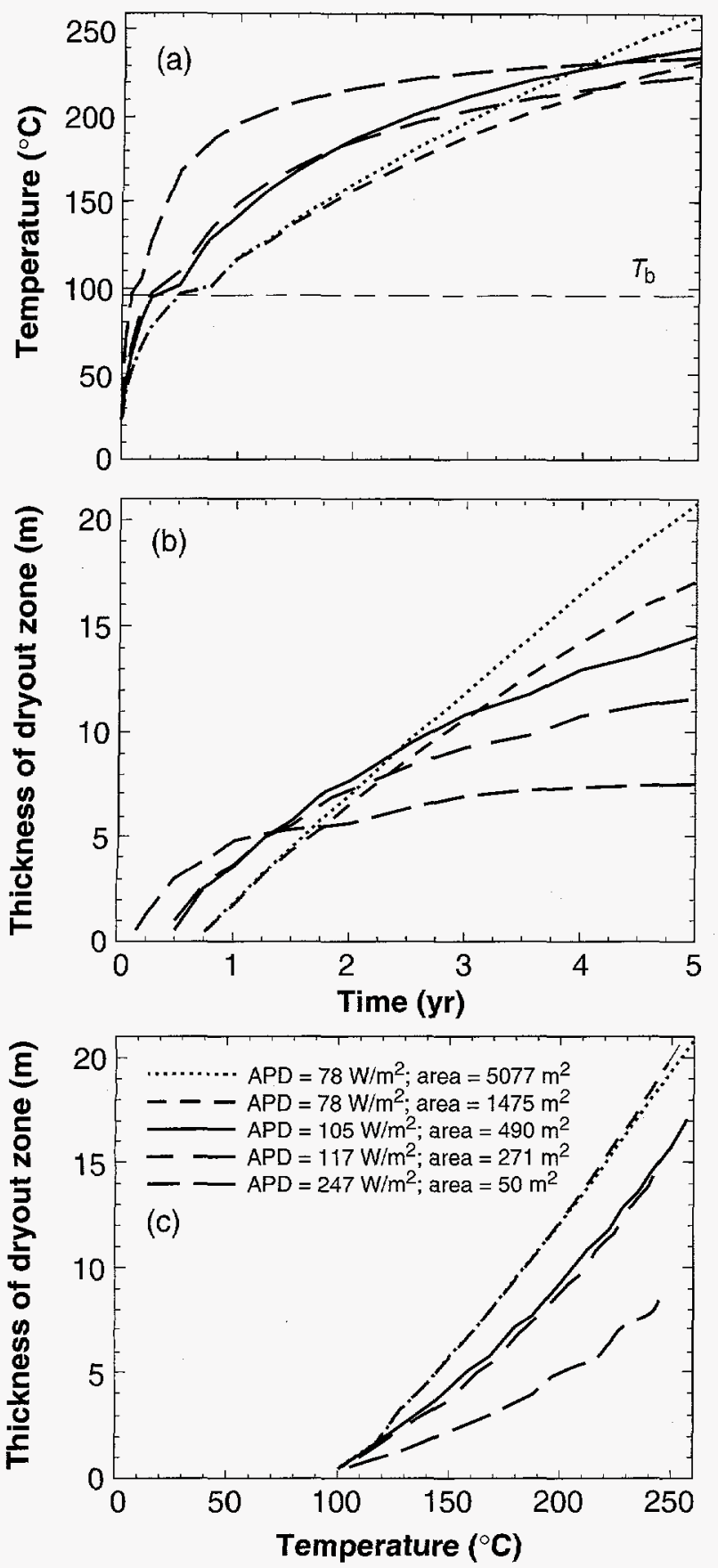

Figure 8. Results of heating at full power for $5 \mathrm{yr}$. (a) Temperature and (b) vertical dryout zone thickness at the center of an array of horizontal-borehole-emplaced heaters heating a disk-shaped area for various combinations of APD and heated area. The APD is averaged over the listed areas. (c) Vertical dryout zone thickness vs temperature at the center of the heater array. Bulk permeability $k_{\mathrm{b}}=280$ millidarcy and vapor diffusion tortuosity factor $\tau_{\text {eff }}=0.2$.
To continue the determination of the minimum thermal test size that could be used to diagnose the significance of gas-phase buoyancy, we analyzed a plate thermal test with a radius of $9.3 \mathrm{~m}$ and APD $=117 \mathrm{~W} / \mathrm{m}^{2}$ averaged over the $271-\mathrm{m}^{2}$ heated area. As in the three test sizes already analyzed, the 280-millidarcy case results in vertically symmetrical vapor flow (Fig. 9), while the 84-darcy case results in strong vertical asymmetry. Unlike the $50-\mathrm{m}^{2}$ test, the $271-\mathrm{m}^{2}$ test does result in a narrow zone of condensate buildup for the 280-millidarcy case (Fig. 10d-f), which effectively reaches its maximum extent within the first year. Because of its small size, the $271-\mathrm{m}^{2}$ test effectively results in spherical heat flow. The effect of gas-phase buoyant convection-dominated vapor flow can be seen in the vertical temperature profile (Fig. 10a-c); however, the resulting upward shift in the upper boiling front is only $2 \mathrm{~m}$ at $t=2 \mathrm{yr}$ (as against $6 \mathrm{~m}$ in the $1475-\mathrm{m}^{2}$ test) and does not continue to grow as in the $1475-\mathrm{m}^{2}$ and $5077-\mathrm{m}^{2}$ tests (Figs. $3 \mathrm{a}-\mathrm{c}$ and $5 \mathrm{a}-\mathrm{c}$ ). The $271-\mathrm{m}^{2}$ thermal test is therefore only marginally useful in diagnosing the significance of gas-phase buoyancy.

To better determine the minimum thermal test size that could be used to diagnose the significance of gas-phase buoyancy, we analyzed a plate thermal test with a radius of $12.5 \mathrm{~m}$ and $\mathrm{APD}=105 \mathrm{~W} / \mathrm{m}^{2}$ averaged over the $490-\mathrm{m}^{2}$ heated area. As in the four test sizes already described, the 280-millidarcy case results in vertically symmetrical vapor flow (Fig. 11), while the 84-darcy case results in strong vertical asymmetry. The difference in upper boiling front heights (in the buoyant versus nonbuoyant case) amounts to $3 \mathrm{~m}$ at $t=$ $1 \mathrm{yr}, 4 \mathrm{~m}$ at $t=2 \mathrm{yr}$, and $6 \mathrm{~m}$ at $t=4 \mathrm{yr}$ (Fig. 12a-c). For the 84-darcy case, the vertical asymmetry is already evident at $t=1 \mathrm{yr}$; the upper boiling front is $6.4 \mathrm{~m}$ above the heater horizon, while the lower boiling front is only $2 \mathrm{~m}$ below the heater horizon. At $t=2 \mathrm{yr}$, the upper boiling front is $10.4 \mathrm{~m}$ above the heater horizon, while the lower boiling front is only $3.7 \mathrm{~m}$ below the heater horizon. Within the first $2 \mathrm{yr}$ of full-power heating, the $490-\mathrm{m}^{2}$ heater test can therefore clearly discriminate between the buoyant and the nonbuoyant unthrottled regimes.

It is important to consider the relation between dryout zone thickness and temperature (Fig. 8c) in optimizing a thermal test design. Ideally, an adequately thick dryout zone could be created without resorting to temperatures that were too high to be representative of actual repository conditions. For a relatively shortduration, accelerated-rate thermal test, it is desirable to create an adequately thick dryout zone in about 1.5 to $4 \mathrm{yr}$. As is discussed in Sec. IV.E.3, achieving a given dryout zone thickness sooner (as is accomplished with 
an accelerated heating rate) will come at the price of higher temperatures. One can limit the temperature required to achieve a given dryout zone thickness within a given time if the heated area is large enough. The APDs of the five cases considered in this section (Fig. 8) were chosen so that the temperature $T_{\mathrm{c}}$ at the center of the heater array fell in the range $215<T_{\mathrm{c}}<230^{\circ} \mathrm{C}$ at $t=4 \mathrm{yr}$. Because the influence of the edge-cooling effect on $T_{\mathrm{c}}$ increases with decreasing test size, the smaller tests require a higher APD to achieve a given $T_{\mathrm{c}}$ at a given time. Figure $8 \mathrm{c}$ clearly shows that the $T_{\mathrm{c}}$ associated with a given dryout zone thickness increases

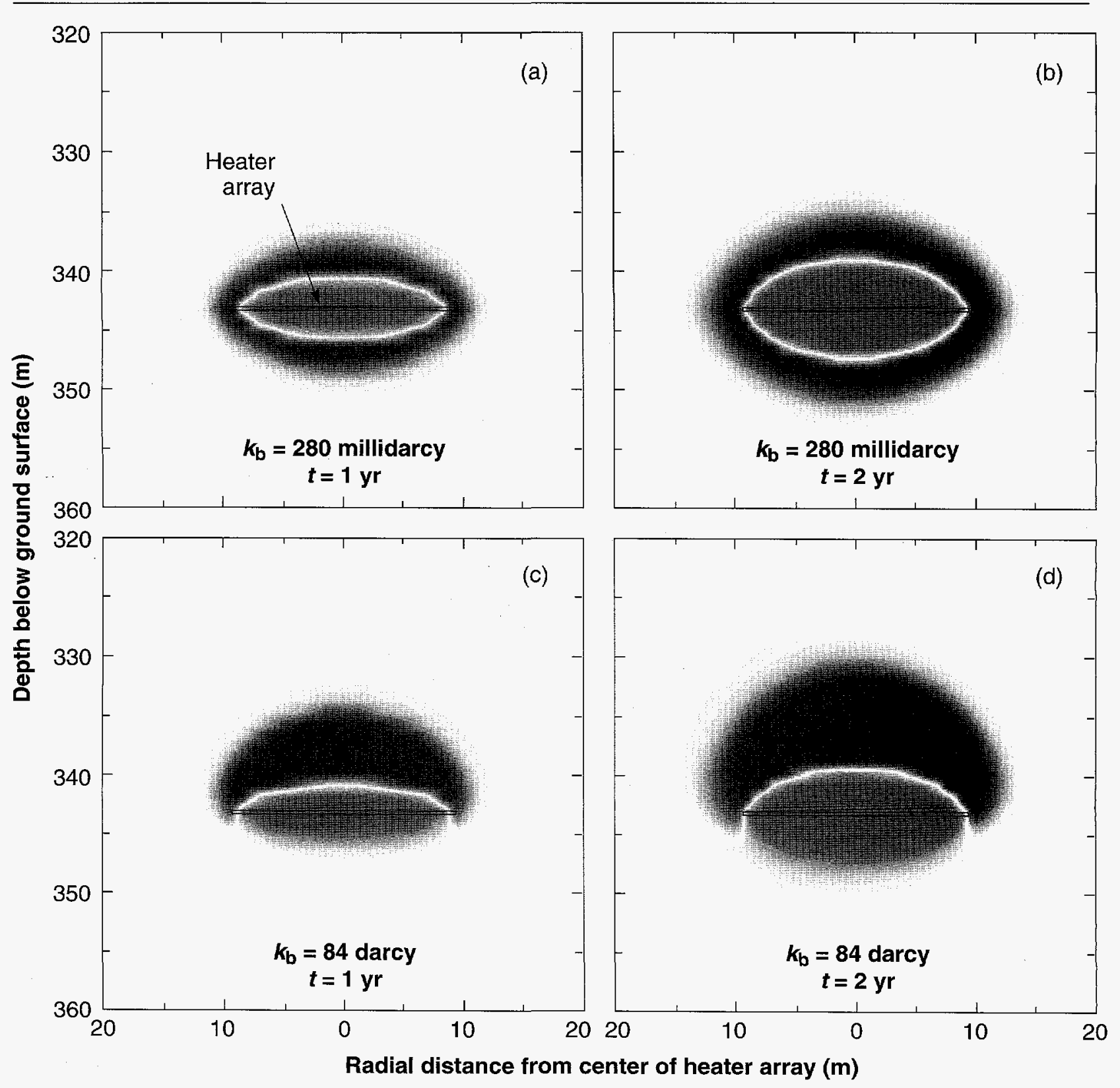

Figure 9. Dimensionless liquid saturation distribution for an array of horizontal-borehole-emplaced heaters heating a disk-shaped area with a radius of $9.3 \mathrm{~m}$ and $\mathrm{APD}=117 \mathrm{~W} / \mathrm{m}^{2}$ averaged over the $271-\mathrm{m}^{2}$ area. Vapor diffusion tortuosity factor $\tau_{\text {eff }}=0.2$. The medium-shaded area surrounding the heater array corresponds to regions that are drier than ambient liquid saturation (dryout zone). The dark-shaded areas correspond to regions that are wetter than ambient liquid saturation (condensation zone). The light shading surrounding the dark-shaded area corresponds to a small rise in liquid saturation (outer edges of the condensation zone). No shading indicates no change in liquid saturation. 
with decreasing thermal test size. Because the edge-cooling effect is greater for a smaller test size, it is necessary to drive $T_{\mathrm{c}}$ higher to compensate for the greater lateral heat loss and still dry out a given thickness within a given time. Note that the 1475 - and $5077-\mathrm{m}^{2}$ tests have virtually the same relationship between dryout zone thickness and temperature. Apparently, for (at least) the first five years, the temperature behavior at the center of the 1475- and $5077-\mathrm{m}^{2}$ tests is essentially that of an infinitely large heated area. The nearly linear temperature rise (Fig. 8a) and linear increase in dryout zone thickness (Fig. 8b) are also indicative of this fact.

A close inspection of the 490-, 1475-, and 5077- $\mathrm{m}^{2}$ tests (Fig. 8c) indicates that the minimum test area that limits the temperature rise associated with a given dryout zone thickness falls in the range 1000 to $1500 \mathrm{~m}^{2}$. (These areas correspond to disk radii of 17.8 and $21.8 \mathrm{~m}$, respectively.) This minimum area is applicable to a test having up to a 5-yr full-power heating period. The minimum test size would be larger for a longer-term thermal test.

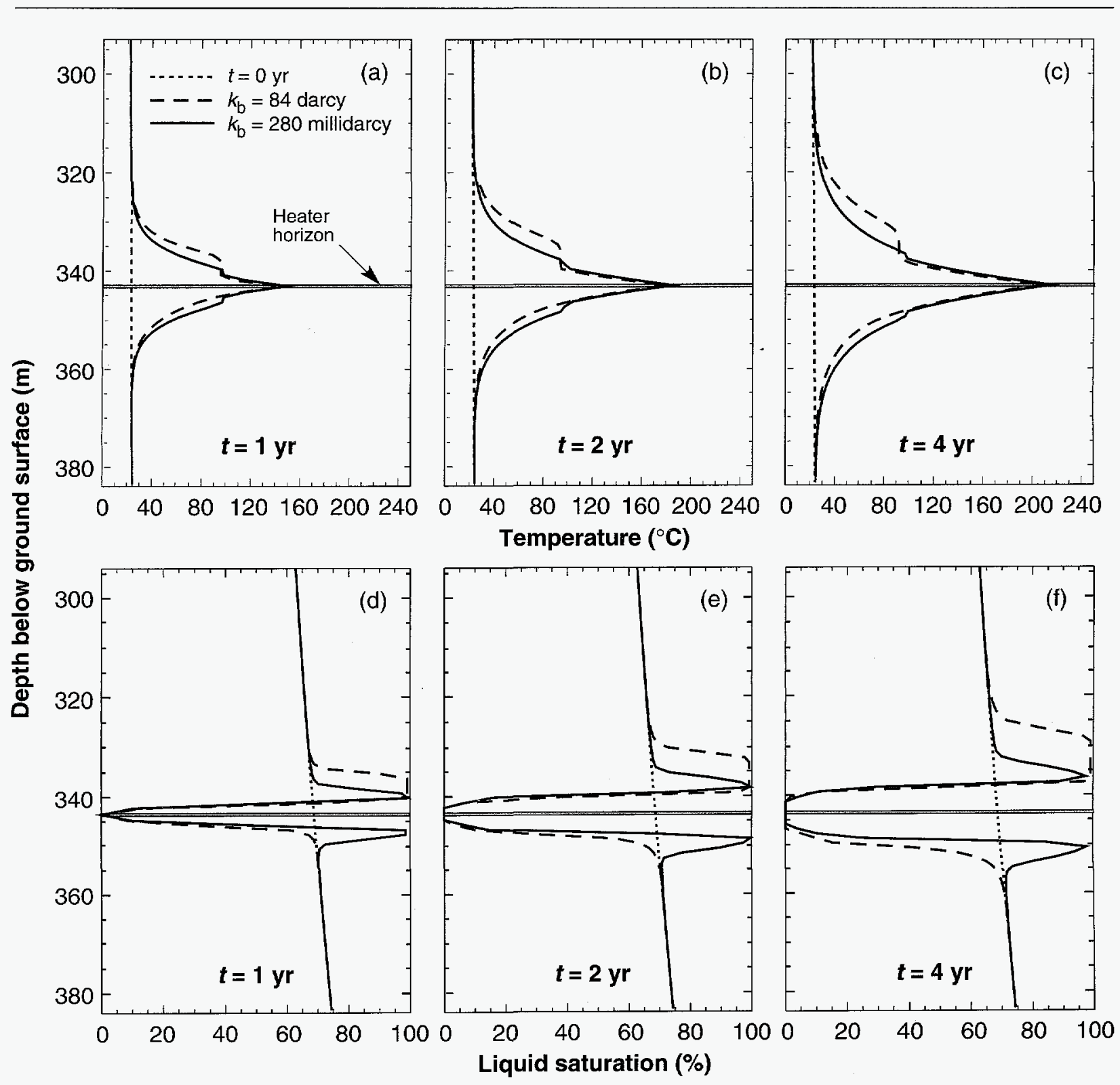

Figure 10. $(a, b, c)$ Vertical temperature profile and $(d, e, f)$ liquid saturation profile along the centerline of an array of horizontal-borehole-emplaced heaters heating a disk-shaped area with a radius of $9.3 \mathrm{~m}$ and APD $=247 \mathrm{~W} / \mathrm{m}^{2}$ averaged over the $271-\mathrm{m}^{2}$ heated area. Vapor diffusion tortuosity factor $\tau_{\mathrm{eff}}=0.2$. 


\section{IV.D Single-Drift Thermal Test}

In this section we continue to address the ability of thermal tests to differentiate between two of the three major T-H regimes described in Sec. IV.B, namely unthrottled, nonbuoyant advective rock dryout and unthrottled, buoyant advective rock dryout. For the single-drift test, we considered $k_{\mathrm{b}}=280$ millidarcy, which results in T-H behavior that is characteristic of the unthrottled nonbuoyant regime, and $k_{\mathrm{b}}=84$ darcy, which results in T-H behavior that is characteristic of the unthrottled buoyant regime. Our goal is to identify

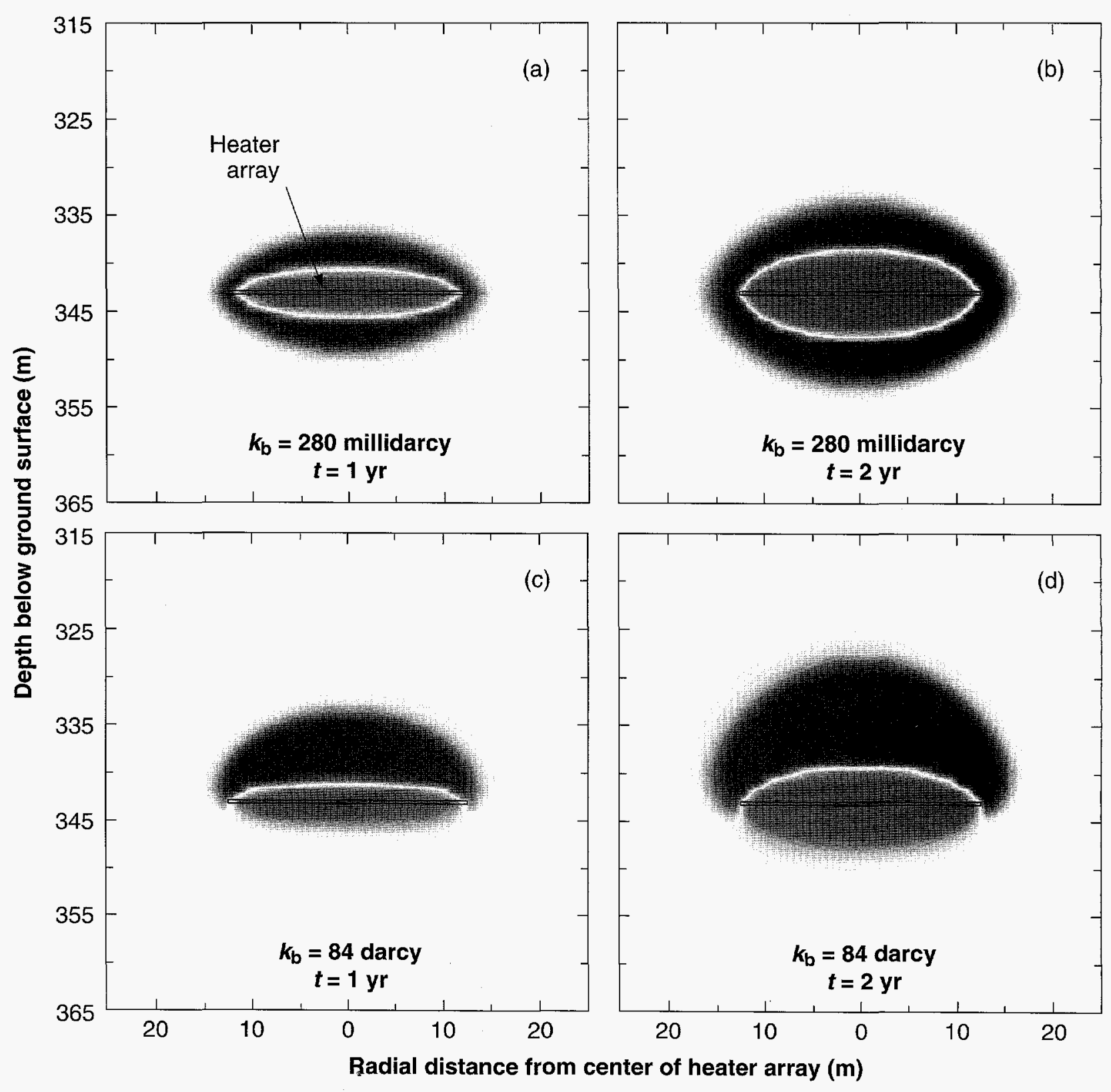

Figure 11. Dimensionless liquid saturation distribution for an array of horizontal-borehole-emplaced heaters heating a disk-shaped area with a radius of $12.5 \mathrm{~m}$ and $\mathrm{APD}=105 \mathrm{~W} / \mathrm{m}^{2}$ averaged over the $490-\mathrm{m}^{2}$ heated area. Vapor diffusion tortuosity factor $\tau_{\mathrm{eff}}=0.2$. The medium-shaded area surrounding the heater array corresponds to regions that are drier than ambient liquid saturation (dryout zone). The dark-shaded areas correspond to regions that are wetter than ambient liquid saturation (condensation zone). The light shading surrounding the dark-shaded area corresponds to a small rise in liquid saturation (outer edges of the condensation zone). No shading indicates no change in liquid saturation. 
the thermal test size and duration that is sufficient to facilitate the determination of the dominant $\mathrm{T}-\mathrm{H}$ regime(s) in a timely fashion.

The single-drift thermal test is analyzed using the $X-Z$ model, which explicitly represents the details of the drift heaters and heater drifts in the vertical plane transverse to the drift axes (Fig. 13). The $X-Z$ model assumes an infinitely long row of drift heaters. If the heated length is long enough, this assumption can be reasonable. In an earlier study of multi-drift heater tests [Buscheck et al., 1993a; Buscheck et al., 1993b], comparisons between the $X-Z$ and $R-Z$ models showed outstanding agreement in rock temperature at the center of the three-drift, $1475-\mathrm{m}^{2}$ thermal test for first $4 \mathrm{yr}$ of full-power heating. The dryout behaviors at the center of the test predicted by the two models also agreed reasonably well after the dryout zones coalesced $(t>2 \mathrm{yr})$. The heated length of the three-drift test was $38.4 \mathrm{~m}$. It is therefore reasonable to assume that if the single-drift thermal test has a heated length of about $40 \mathrm{~m}$, then T-H behavior at the center of the test should be that of an infinitely long heater test.

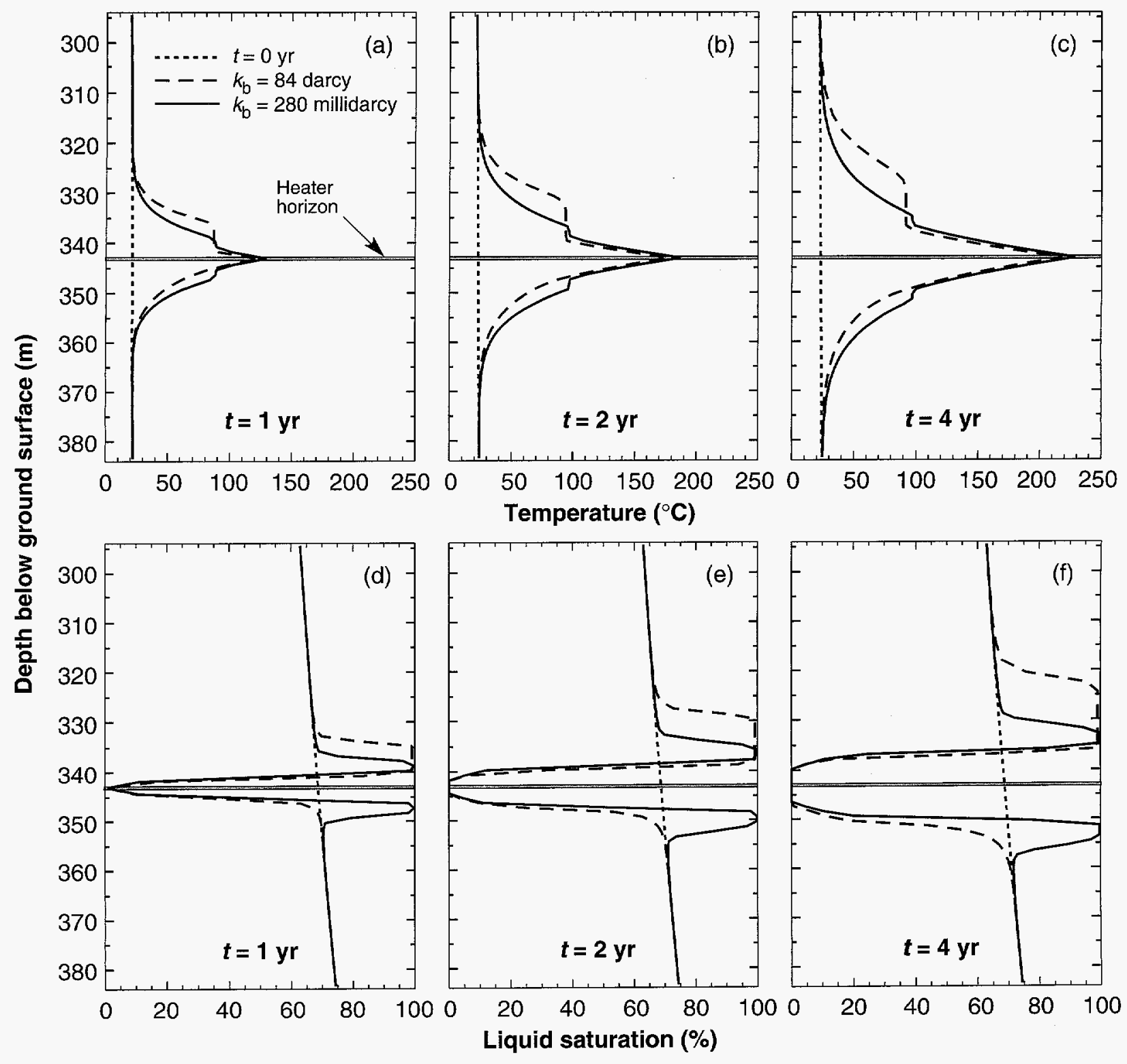

Figure 12. ( $a, b, c)$ Vertical temperature profile and $(d, e, f)$ liquid saturation profile along the centerline of an array of horizontal-borehole-emplaced heaters heating a disk-shaped area with a radius of $12.5 \mathrm{~m}$ and APD $=105 \mathrm{~W} / \mathrm{m}^{2}$ averaged over the $490-\mathrm{m}^{2}$ heated area. Vapor diffusion tortuosity factor $\tau_{\mathrm{eff}}=0.2$. 
We analyzed a range of lineal heat loads and found that a lineal heat load of at least $2.1 \mathrm{~kW} / \mathrm{m}$ was needed to create a vertical dryout zone thickness of $20 \mathrm{~m}$ within 4 yr (Figs. $14 \mathrm{f}$ and 15b). The substantial lateral heat loss in a single-drift test necessitates a very high centerline temperature $T_{\mathcal{c}}$ to achieve a significant vertical dryout zone thickness. As in the plate heater test, the 280-millidarcy case results in vertically symmetrical vapor flow, while the 84-darcy case results in strong vertical asymmetry (Fig. 13). The difference in upper boiling front heights (in the buoyant versus nonbuoyant case) amounts to $2 \mathrm{~m}$ at $t=1 \mathrm{yr}, 4 \mathrm{~m}$ at $t=2 \mathrm{yr}$, and $8 \mathrm{~m}$ at $t=4 \mathrm{yr}(\mathrm{Fig} .14 \mathrm{a}-\mathrm{c})$. For the 84-darcy case, the vertical asymmetry is already evident

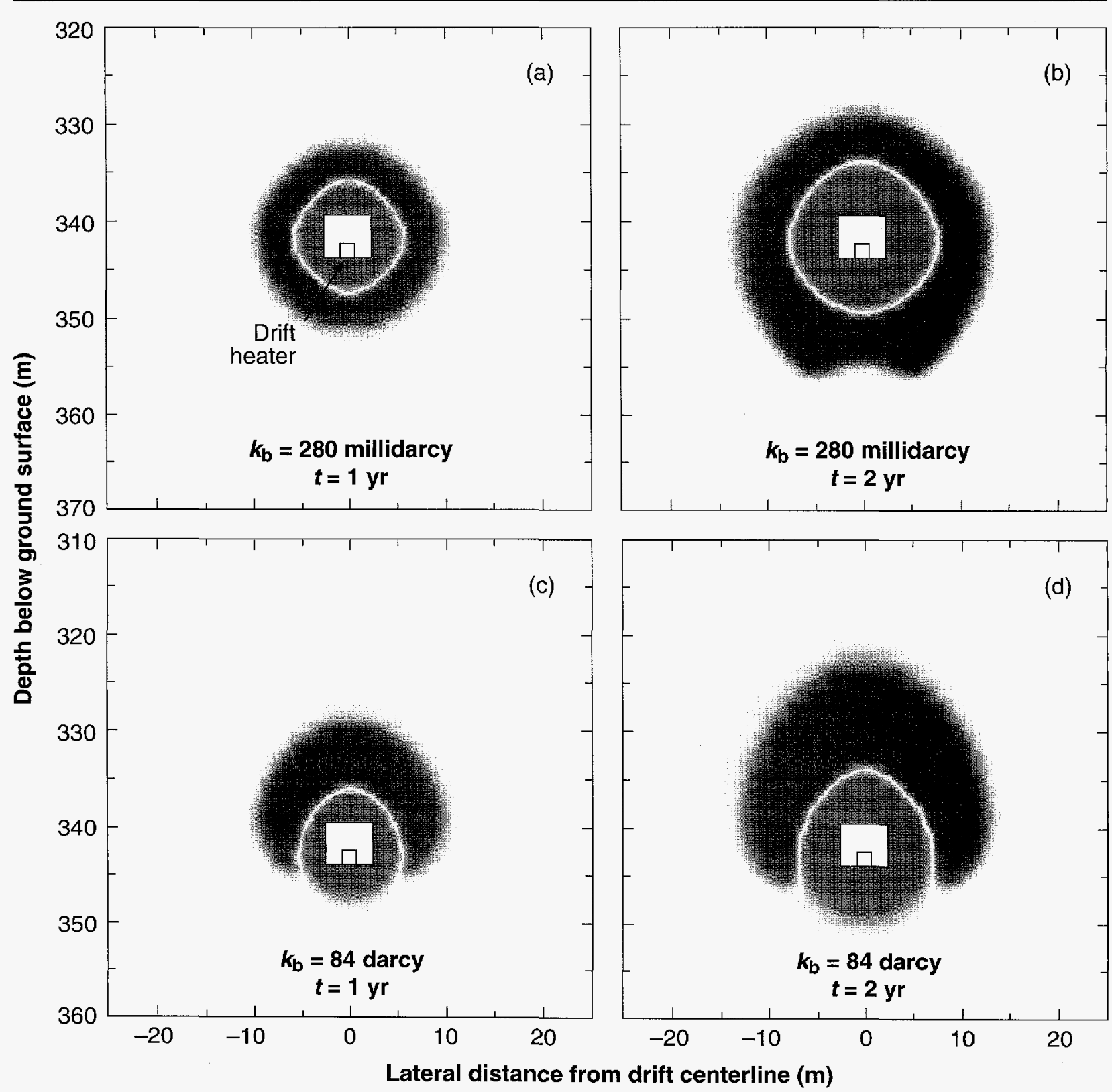

Figure 13. Dimensionless liquid saturation distribution orthogonal to a row of drift-emplaced, large-WP-sized heaters generating a lineal heat load of $2.1 \mathrm{~kW} / \mathrm{m}$. Vapor diffusion tortuosity factor $\tau_{\mathrm{eff}}=0.2$. The medium-shaded area surrounding the heater array corresponds to regions that are drier than ambient liquid saturation (dryout zone). The dark-shaded areas correspond to regions that are wetter than ambient liquid saturation (condensation zone). The light shading surrounding the dark-shaded area corresponds to a small rise in liquid saturation (outer edges of the condensation zone). No shading indicates no change in liquid saturation. 
at $t=2 \mathrm{yr}$; the leading edge of the upper boiling zone is $15 \mathrm{~m}$ above the heater horizon, while the leading edge of the lower boiling zone is only $5.5 \mathrm{~m}$ below the heater horizon. Within the first 2 yr of full-power heating, the $2.1-\mathrm{kW} / \mathrm{m}$, single-drift thermal test can therefore clearly discriminate between the buoyant and nonbuoyant unthrottled regimes.

For the 280-millidarcy case, the zone of condensate buildup is relatively narrow (Fig. 14d-f). The line-head load geometry results in radial heat flow and a cylindrical dryout zone that is surrounded by a well-developed zone of condensate buildup

(Fig. 13a-b). Because the ECM does not account for nonequilibrium fracture flow, it probably underrepresents condensate shedding around the dryout zone and overrepresents condensate buildup. Therefore, the single-drift thermal test may not be able to create a significant refluxing zone above the heaters. The absence of any refluxing zone would seriously degrade the ability of a thermal test to provide for observations of potentially critical intercoupling between T-H and geochemical processes.

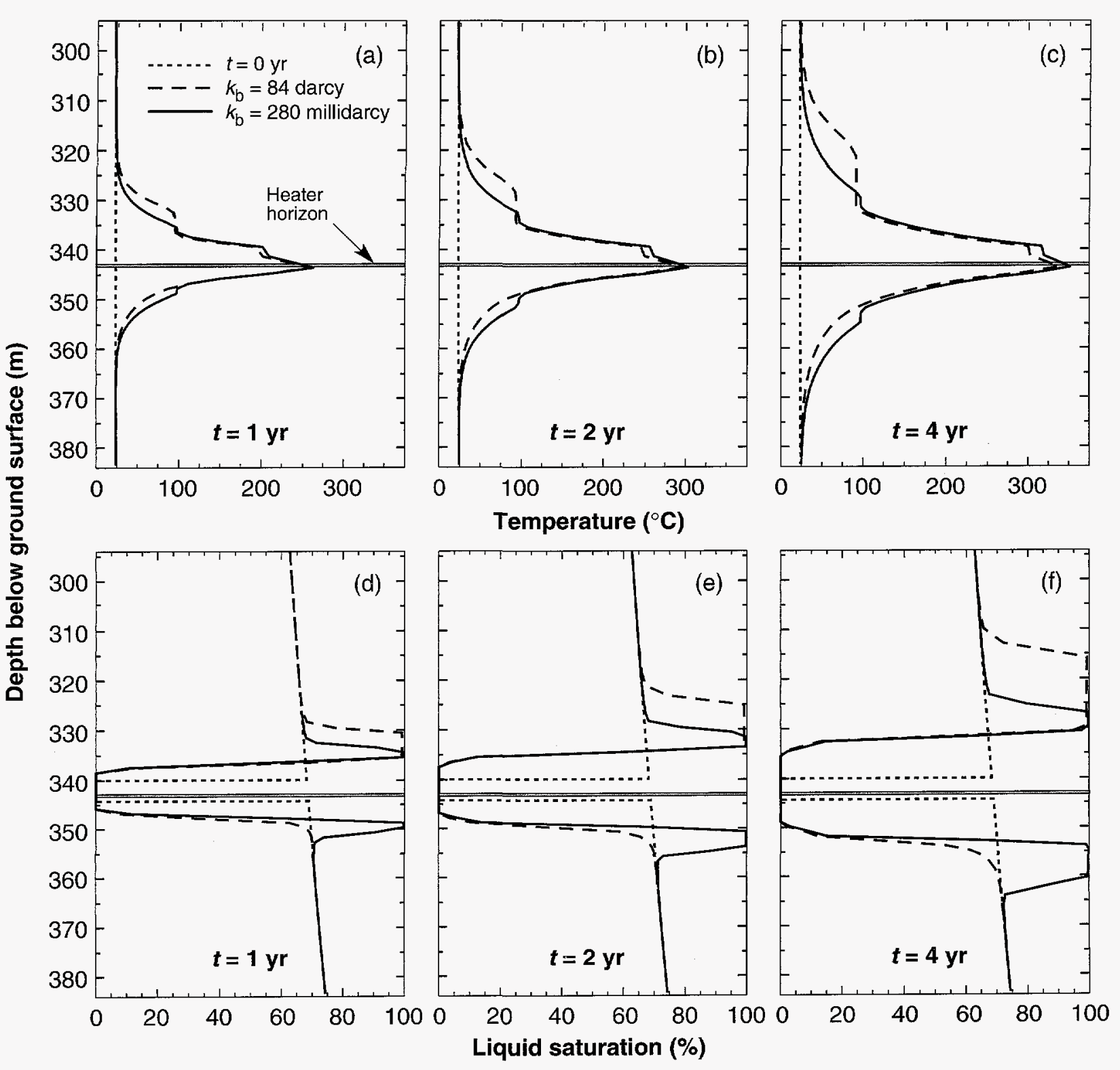

Figure 14. $(a, b, c)$ Vertical temperature profile and (d, e, f) liquid saturation profile along the centerline of a row of drift-emplaced, large-WP-sized heaters generating a lineal head load of $2.1 \mathrm{~kW} / \mathrm{m}$. Vapor diffusion tortuosity factor $\tau_{\text {eff }}=0.2$. 

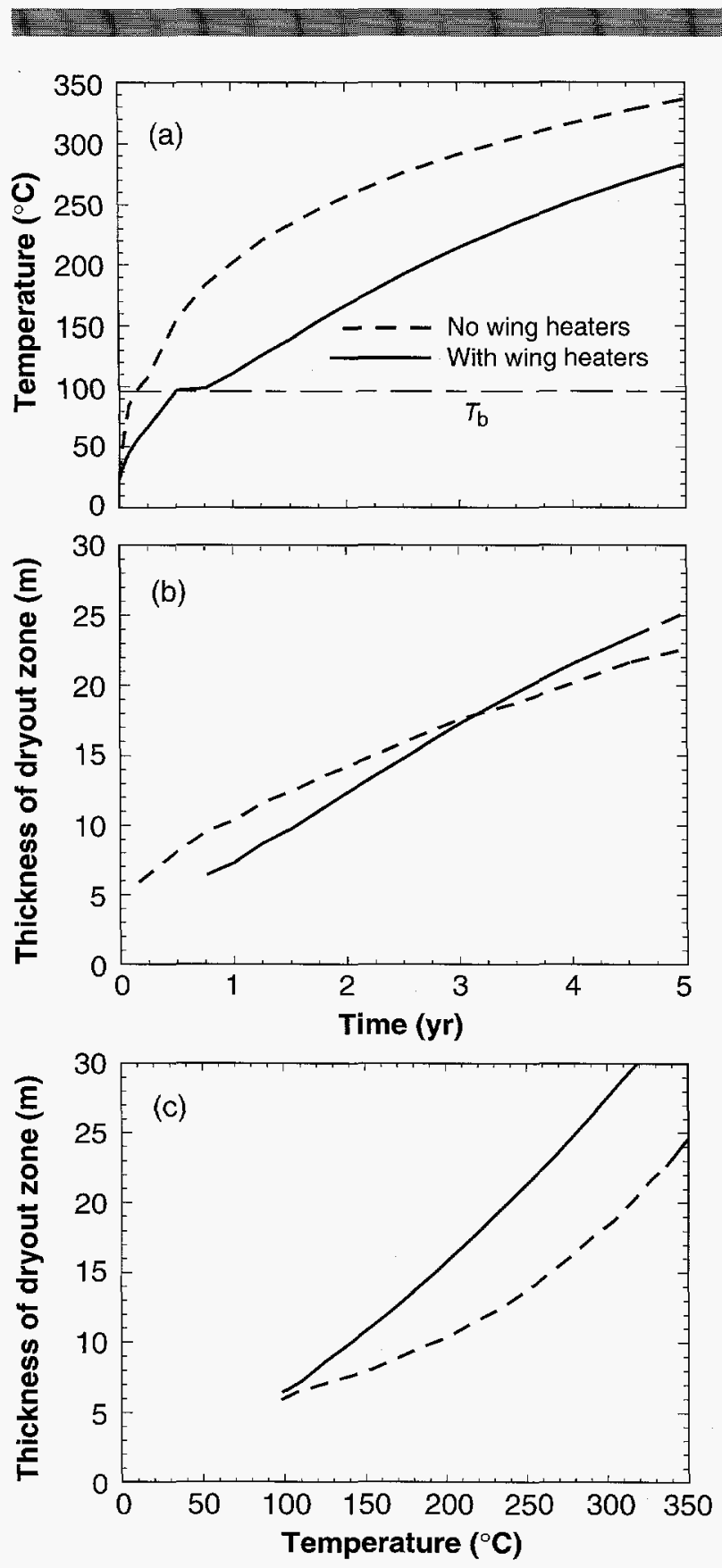

Figure 15. (a) Temperature at the upper drift wall and (b) vertical dryout zone thickness along the centerline of a row of drift-emplaced, large-WP-sized heaters generating a lineal heat load of $0.8 \mathrm{~kW} / \mathrm{m}$ (for the wing heater case) and flanked by two horizontal-boreholeemplaced wing heater arrays. The heater arrays are generating an APD of $105 \mathrm{~W} / \mathrm{m}^{2}$ over the interval $4<$ $|x|<9 \mathrm{~m}$ and $157.5 \mathrm{~W} / \mathrm{m}^{2}$ over the interval $9<|x|<14 \mathrm{~m}$ from the drift centerline. For the case with no wing heaters, the lineal heat load is $2.1 \mathrm{~kW} / \mathrm{m}$. (c) The vertical dryout zone thickness plotted as a function of temperature at the upper drift wall. Bulk permeability $k_{\mathrm{b}}=280$ millidarcy, and vapor diffusion tortuosity factor $\tau_{\text {eff }}=0.2$. 
ability of the thermal tests to differentiate between the three major T-H regimes described in Sec. IV.B. To address all three regimes, we considered $k_{\mathrm{b}}=1,10$, and 280 millidarcy, and 84 darcy. For most of the calculations we assumed the value $\tau_{\text {eff }}=0.2$ for tortuosity factor, which corresponds to the case of nominal vapor diffusion (in which vapor diffusion is not enhanced). For $k_{\mathrm{b}}=280$ millidarcy, we also considered the case of "enhanced" vapor diffusion $\left(\tau_{\text {eff }}=20\right)$ in which the rate of vapor diffusion is 100 times greater than in the nominal case.

Figure 16 shows the dimensionless liquid saturation distributions for the 280-millidarcy case during a 4-yr. full-power heating period. The dryout zones created by the drift heaters and wing heater arrays are just beginning to coalesce at $t=0.5 \mathrm{yr}$; at $t=1 \mathrm{yr}$, coalescence is fairly complete; and at $t=2 \mathrm{yr}$, a well-defined tabular dryout zone, surrounded by a tabular zone of condensate buildup, has developed. Because the 280 -millidarcy case pertains to the unthrottled nonbuoyant regime, vapor flow is vertically symmetrical about the heater horizon. The effect of the symmetrical vapor flow is partially offset by condensate shedding, which results in a larger condensate volume below the heater horizon (Fig. 16c,d). The ECM probably underrepresents how nonequilibrium fracture flow may result in significant condensate shedding during the thermal tests.

Figure 17 shows the vertical temperature profile along the centerline of the single-drift, winged thermal test at $t=2 \mathrm{yr}$. The vertical temperature profile is vertically symmetrical except inside the heater drift. This asymmetry results from the vertically asymmetrical heating geometry inside the drift: the heater sits directly on the floor of the drift, and the upper wall of the drift is $2.9 \mathrm{~m}$ above the top of the drift heaters. The temperature gradient above the heater arises from thermal radiation from the drift heaters to the drift wall surfaces, whereas the temperature gradient below the heater arises from heat conduction in the rock.

All of the calculations in this report were conducted with the RIB version 3 data for thermal conductivity $K_{\text {th }}$ [DOE, 1990]. Most of the recent calculations [Buscheck and Nitao, 1994a; Buscheck and Nitao, 1994b] of decay-heat-driven T-H behavior at Yucca Mountain use the RIB version $4 K_{\text {th }}$ data. We repeated the calculation of the single-drift, winged heater test with RIB version $4 K_{\text {th }}$ data and found very small differences in T-H behavior between these two cases. Because the dry value for $K_{\mathrm{th}}$ for the TSw2 is somewhat lower in RIB version $3\left(1.88 \mathrm{~W} / \mathrm{m}^{\circ} \mathrm{C}\right)$ than in RIB version $4\left(2.1 \mathrm{~W} / \mathrm{m}^{\circ} \mathrm{C}\right)$, temperatures on the drift heater and upper drift wall are about $10^{\circ} \mathrm{C}$ higher in the RIB version 3 case. Therefore, had we conducted the calculations in this report with the more recent RIB version $4 K_{\text {th }}$, it would have made little difference, except that slightly lower maximum temperatures (near the heaters) would have been predicted.

Figure 18 shows the horizontal temperature and liquid saturation profiles at the elevation of the upper drift wall ( $2.9 \mathrm{~m}$ above the top of the drift heaters) during a 4-yr full-power heating period. At $t=1 \mathrm{yr}$, the temperature along most of the heated horizon is at the nominal boiling point $\left(96^{\circ} \mathrm{C}\right)$; temperatures are above boiling only in the immediate vicinity of the heater drift. The near-boiling temperatures and liquid saturation buildup (Fig. 18b) at $t=1 \mathrm{yr}$ are indicative of refluxing conditions. Notice the two regions of pronounced condensate buildup (the outer edge of the heater drift and the outer edge of the wing heater array), which are indicative of regions of significant condensate flow. At $t=2 \mathrm{yr}$, the existence of a coalesced tabular dryout zone is evidenced by the above-boiling temperatures and the large reduction in liquid saturation along the entire heated horizon. The region of nearly saturated conditions at the outer edge of the wing heater array indicates a zone of substantial condensate shedding. A close inspection of the corresponding temperatures confirms this observation. During a 4-yr full-power heating period, the outer condensate shedding zone is gradually displaced laterally away from the heaters as it grows in width; the width of the shedding zone is about $4 \mathrm{~m}$ at $t=2 \mathrm{yr}$, and it grows to about $10 \mathrm{~m}$ at $t=4 \mathrm{yr}$. This gradual movement of the condensate shedding zone results in regions of rock being exposed to condensate shedding for considerable periods ( 2 to $3 \mathrm{yr}$ ) during the 4-yr full-power heating period. For a 2-yr full-power heating period, regions of rock would be exposed to condensate shedding for up to 1 yr. Prolonged periods of condensate shedding in fractures will provide an outstanding opportunity to observe potentially important intercoupling between $\mathrm{T}-\mathrm{H}$ and geochemical processes.

To address the ability of the single-drift, winged heater test to discriminate between the throttled and unthrottled nonbuoyant $\mathrm{T}-\mathrm{H}$ regimes, we considered $k_{\mathrm{b}}=1,10$, and 280 millidarcy. Figure 19 shows the vertical profiles of temperature $T$, liquid saturation $S_{\mathrm{L}}$, and gas-phase pressure $P_{\mathrm{g}}$ along the centerline of the reference single-drift, winged heater test at $t=2 \mathrm{yr}$ for these cases. The 280-millidarcy case (Fig. 19a) is associated with a distinet flattening of the temperature profile at $96^{\circ} \mathrm{C}$, both above and below the heater horizon. The flattened temperature zones correspond to the refluxing (i.e., heat pipe) zones. Such zones do not develop in the 1-millidarcy case; instead, temperatures increase sharply with decreasing distance to the heater horizon. In the 10-millidarcy case, the flattened temperature zones develop in a modified fashion, with temperatures increasing modestly with decreasing 
distance to the heater horizon. On the basis of this analysis, it appears that the single-drift, winged thermal test will allow observations that will help determine the significance of heat pipes within the first 1 to $2 \mathrm{yr}$ of full-power heating (item 1 in Table 2).
The differences in temperature profiles among these three cases are related to their different gas-pressure profiles (Fig. 19c); for the 280 -millidarcy case, $P_{\mathrm{g}}$ rises only $0.05 \mathrm{~atm}$ above ambient, whereas $P_{\mathrm{g}}$ rises $3.5 \mathrm{~atm}$ above ambient in the 1-millidarcy case. The

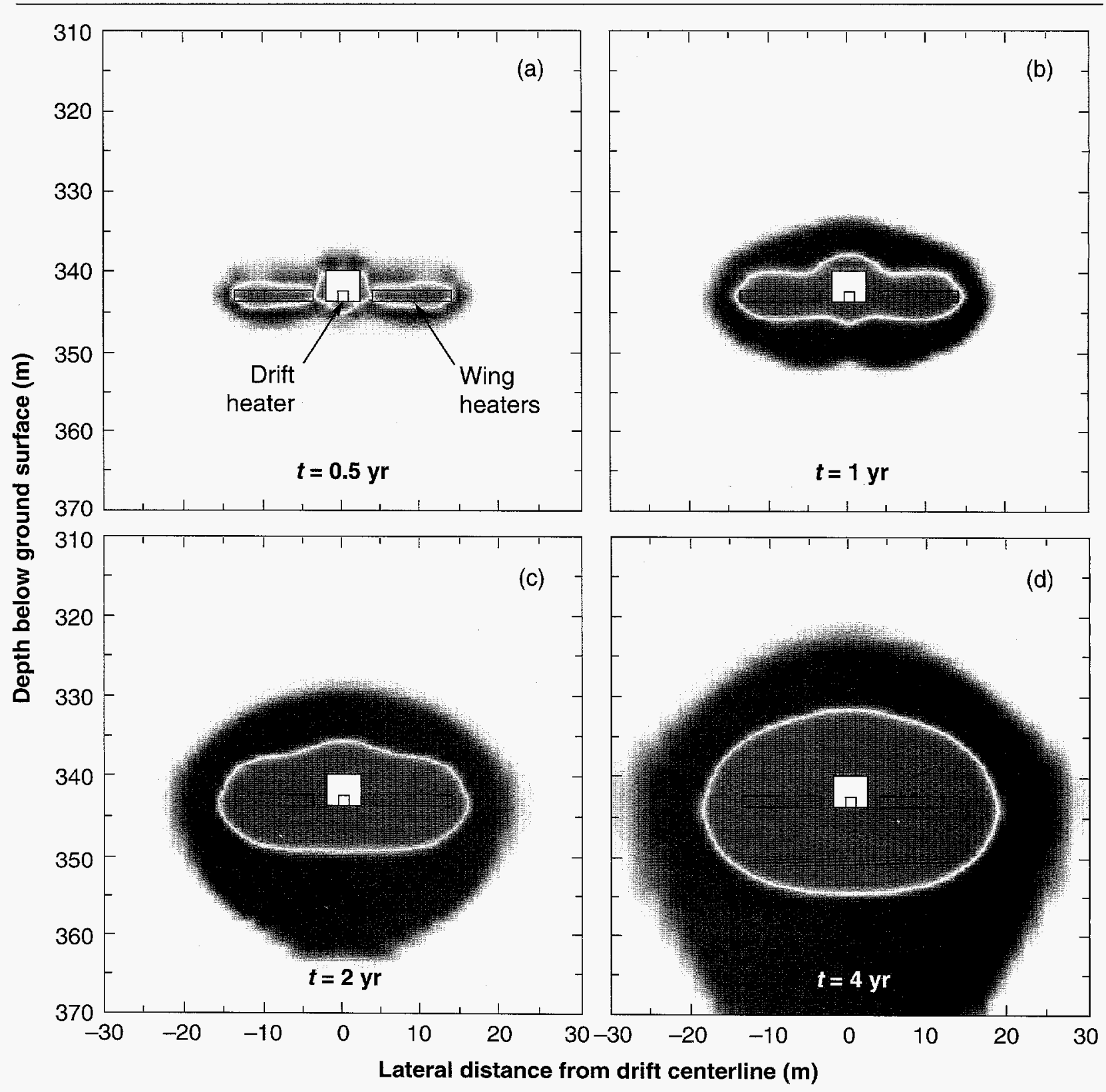

Figure 16. Dimensionless liquid saturation distribution orthogonal to a row of drift-emplaced, large-WP-sized heaters generating a lineal heat load of $0.8 \mathrm{~kW} / \mathrm{m}$ and flanked by two horizontal-borehole-emplaced wing heater arrays. The heater arrays are generating an APD of $105 \mathrm{~W} / \mathrm{m}^{2}$ over the interval $4<|x|<9 \mathrm{~m}$ and $157.5 \mathrm{~W} / \mathrm{m}^{2}$ over the interval $9<|x|<14 \mathrm{~m}$ from the drift centerline. Bulk permeability $k_{\mathrm{b}}=280$ millidarcy, and vapor diffusion tortuosity factor $\tau_{\text {eff }}=0.2$. The medium-shaded area surrounding the heater array corresponds to regions that are drier than ambient liquid saturation (dryout zone). The dark-shaded areas correspond to regions that are wetter than ambient liquid saturation (condensation zone). The light shading surrounding the dark-shaded area corresponds to a small rise in liquid saturation (outer edges of the condensation zone). No shading indicates no change in liquid saturation. 
much higher $P_{\mathrm{g}}$ substantially increases the saturation temperature $T_{\text {sat }}$ (i.e., the actual boiling temperature). This increase in $T_{\text {sat }}$ throttles the rate of rock dryout in the 1-millidarcy case, thereby decreasing the spatial extent of the dryout zone (Fig. 19b). Because the rates of vaporization and return condensate flow are substantially reduced, the large increase in $P_{\mathrm{g}}$ also shuts down (or at least reduces) the heat-pipe effect. In the 10-millidarcy case, $P_{\mathrm{g}}$ rises $0.8 \mathrm{~atm}$ above ambient, resulting in a modest increase in $T_{\text {sat }}$. Rock dryout in this case is therefore only slightly throttled, so that its liquid saturation profile differs only slightly from that of the 280-millidarcy case. Therefore, for $k_{\mathrm{b}}=10$ millidarcy, $\mathrm{T}-\mathrm{H}$ behavior during the thermal test is characteristic of the unthrottled nonbuoyant regime. In analyses of repository conditions [Buscheck and Nitao., 1993a; Buscheck and Nitao, 1993b], $k_{\mathrm{b}}=10$ millidarcy results in $\mathrm{T}-\mathrm{H}$ behavior that falls in the unthrottled nonbuoyant

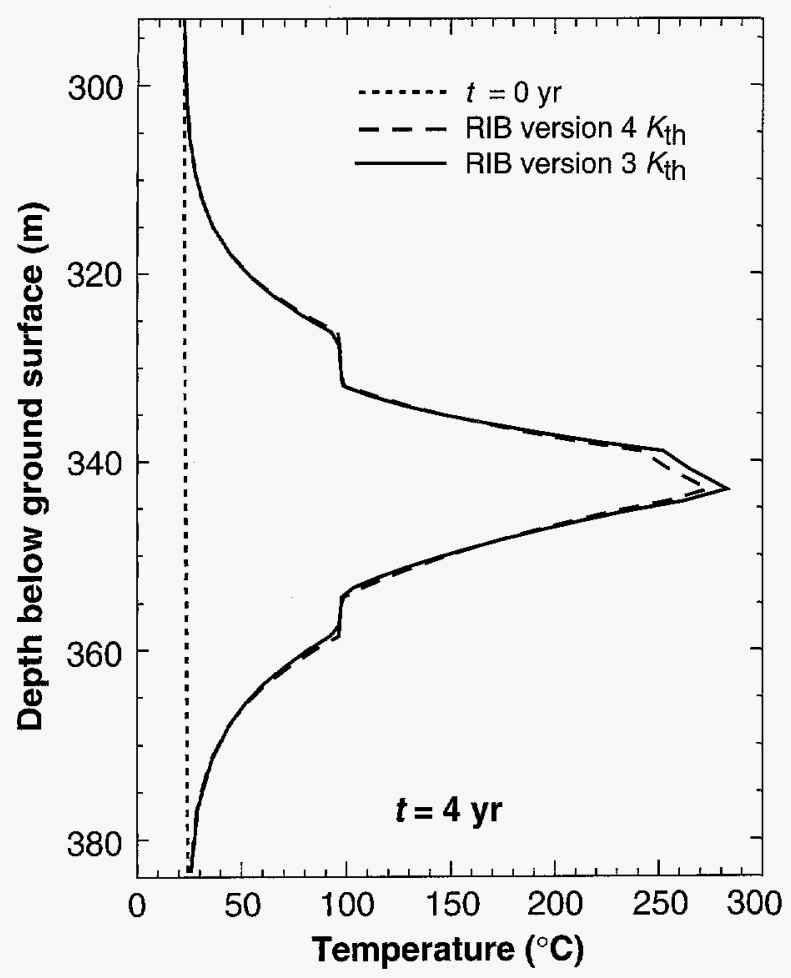

Figure 17. Vertical temperature profile along the centerline of a row of drift-emplaced, large-WP-sized heaters generating a lineal heat load of $0.8 \mathrm{~kW} / \mathrm{m}$ and flanked by two horizontal-borehole-emplaced wing heater arrays. The heater arrays are generating an APD of $105 \mathrm{~W} / \mathrm{m}^{2}$ over the interval $4<|x|<9 \mathrm{~m}$ and $157.5 \mathrm{~W} / \mathrm{m}^{2}$ over the interval $9<$ $|x|<14 \mathrm{~m}$ from the drift centerline at $t=4 \mathrm{yr}$. Bulk permeability $k_{\mathrm{b}}=280$ millidarcy, and vapor diffusion tortuosity factor $\tau_{\text {eff }}=0.2$. Curves are shown for two different thermal conductivity $K_{\text {th }}$ sets, including the RIB version $3 K_{\text {th }}$ values (reference case) and the RIB version $4 K_{\text {th }}$ values. regime for high AMLs, while for low AMLs, T-H behavior is marginally throttled.

On the basis of this analysis, it appears that the single-drift, winged thermal test can clearly discriminate between the throttled and unthrottled nonbuoyant T-H regimes within the first 1 to 2 yr of full-power heating (item 2 in Table 2). However, one must note the importance of isolating the heater drift from direct pneumatic interference with the rest of the tunnel system in the ESF. If the heater drift were not sufficiently isolated from the tunnel system, the buildup in gas-phase pressure in the heater drift (and the resultant throttled dryout behavior) might be compromised. It is therefore
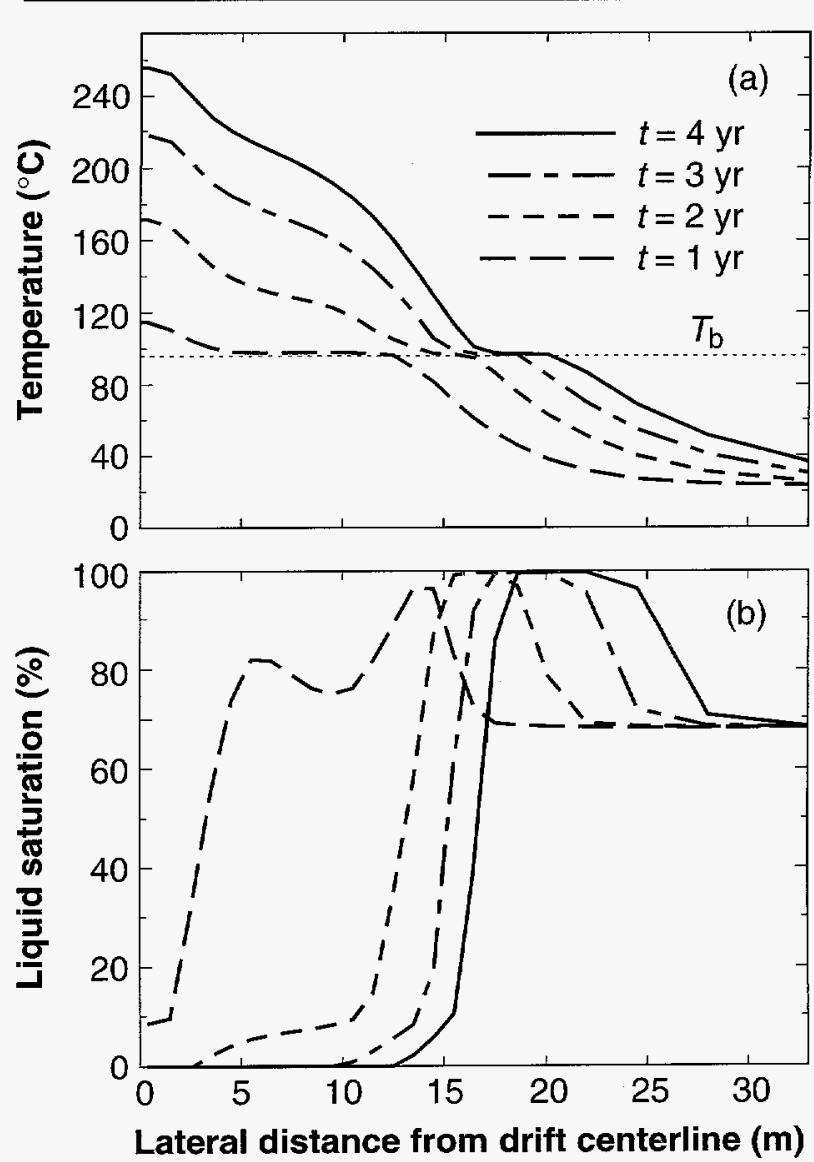

Figure 18. (a) Horizontal temperature profile and (b) liquid saturation profile at the elevation of the upper drift wall (2.9 $\mathrm{m}$ above the top of the drift heaters) for a row of drift-emplaced, large-WP-sized heaters generating a lineal heat load of $0.8 \mathrm{~kW} / \mathrm{m}$ and flanked by two horizontal-borehole-emplaced wing heater arrays. The heater arrays are generating an APD of $105 \mathrm{~W} / \mathrm{m}^{2}$ over the interval $4<|x|<9 \mathrm{~m}$ and $157.5 \mathrm{~W} / \mathrm{m}^{2}$ over the interval $9<|x|<14 \mathrm{~m}$ from the drift centerline. Bulk permeability $k_{\mathrm{b}}=280$ millidarcy, and vapor diffusion tortuosity factor $\tau_{\text {eff }}=0.2$. 
important that measures be taken to pneumatically isolate the heater drift from the rest of the ESF tunnel system. Because of safety concerns, it may not be possible to allow $P_{\mathrm{g}}$ to build up in the heater drift more than a few tenths of an atmosphere. It may therefore be necessary to bleed off some of the $P_{\mathrm{g}}$ buildup and monitor the flux of water vapor leaving the heater drift through such a pressure relief system. The vapor flux through this system would be indicative of the degree of throttling of advective dryout that would have occurred had the $P_{\mathrm{g}}$ buildup not been limited by bleeding off the excess steam.

To address the ability of the single-drift, winged heater test to discriminate between the buoyant and nonbuoyant unthrottled $\mathrm{T}-\mathrm{H}$ regimes, we considered $k_{\mathrm{b}}=280$ millidarcy and 84 darcy. Figure 20 gives the vertical profiles of temperature $T$, liquid saturation $S_{\mathrm{L}}$, and gas-phase pressure $P_{\mathrm{g}}$ along the centerline of the reference single-drift, winged heater test at $t=2 \mathrm{yr}$ for these cases. The 280 -millidarcy case results in vertically symmetrical vapor flow, while the 84-darcy case results in strong vertical asymmetry (Fig. 20b). At $t=2 \mathrm{yr}$, the upper boiling front in the buoyant case is $7 \mathrm{~m}$ higher than in the nonbuoyant case (Fig. 20a). The vertical asymmetry is quite evident in the 84-darcy case; the upper boiling front is $17 \mathrm{~m}$ above the heater horizon, whereas the lower boiling front is only $5.5 \mathrm{~m}$ below the heater horizon. Within the first 1 to 2 yr of full-power heating (items 3 and 4 in Table 2), the single-drift, winged thermal test can therefore clearly discriminate between the buoyant and nonbuoyant unthrottled regimes.

The degree of vertical asymmetry in the temperature profile will be a strong indication as to whether buoyant gas-phase convection dominates overall heat flow in the test region. Because the degree of vertical asymmetry will be evident within the first 1 to $2 \mathrm{yr}$, the single-drift, winged thermal test will be indicative of the relative importance of buoyant gas-phase heat convection (item 5 in Table 2). As is discussed in Sec. IV.E.1, the temperature history in the heater drift (Fig. 21), particularly during the cooldown period, will also be diagnostic of whether buoyant gas-phase convection dominates overall heat flow in the test region.

The cause of the nonbuoyant versus buoyant vapor flow is clearly evident in the $P_{\mathrm{g}}$ profiles (Fig. 20c). For the 280-millidarcy case, the $P_{\mathrm{g}}$ gradients are driven by boiling conditions. In the superheated zone straddling the heater horizon, there is virtually no more water to be vaporized and advected away; so there is a minimal $P_{\mathrm{g}}$ gradient in this zone. The boiling zones are evidenced by the relatively steep portions of the $P_{\mathrm{g}}$ profile. The $P_{\mathrm{g}}$ gradients are steepest in the boiling zones, because that is where virtually all of the vaporization and vapor advection take place. Note that vapor diffusion also contributes to vapor transport, but it is not generally significant unless advective dryout is throttled. In the
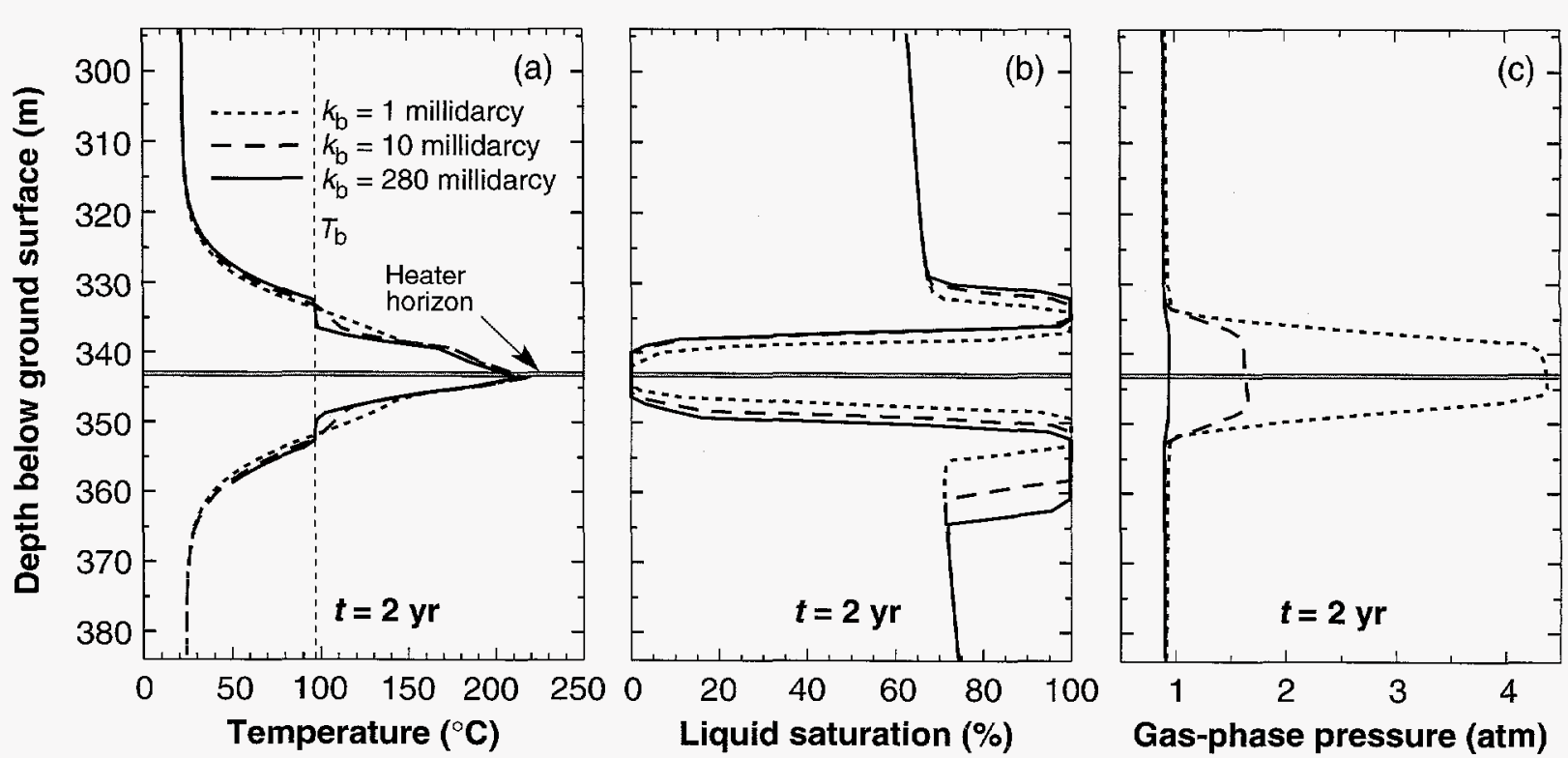

Figure 19. (a) Vertical temperature profile, (b) liquid saturation profile, and (c) gas-phase pressure profile along the centerline of a row of drift-emplaced, large-WP-sized heaters generating a lineal heat load of $0.8 \mathrm{~kW} / \mathrm{m}$ and flanked by two horizontal-borehole-emplaced wing heater arrays. The heater arrays are generating an APD of $105 \mathrm{~W} / \mathrm{m}^{2}$ over the interval $4<|x|<9 \mathrm{~m}$ and $157.5 \mathrm{~W} / \mathrm{m}^{2}$ over the interval $9<|x|<14 \mathrm{~m}$ from the drift centerline at $t=2$ yr. Vapor diffusion tortuosity factor $\tau_{\text {eff }}=0.2$. 
84-darcy case, the $P_{\mathrm{g}}$ gradients are dominated by the gas-phase density distribution and are virtually unaffected by the existence of boiling conditions; consequently, there is no buildup in $P_{\mathrm{g}}$ near the heater horizon (Fig. 20c).

\section{IV.E.1 Evaluating Thermal Test Duration}

The objective of this section is to determine the minimum thermal test duration that facilitates sufficient determination of the dominant $\mathrm{T}-\mathrm{H}$ regime(s) and that does not preclude the occurrence of potentially critical intercoupling between T-H processes and geomechanical and geochemical processes. For the reference singledrift, winged thermal test $\left(\mathrm{APD}=122 \mathrm{~W} / \mathrm{m}^{2}\right)$, full-power heating periods of 1,2 , and 4 yr were considered. The full-power heating period is followed by a 1-yr linear rampdown to zero power. To address all three major T-H regimes, we considered $k_{\mathrm{b}}=1,10$, and 280 millidarcy, and 84 darcy. For most of the cases we assumed that vapor diffusion is not enhanced $\left(\tau_{\text {eff }}=0.2\right)$. For $k_{\mathrm{b}}=280$ millidarcy, we also considered the case of enhanced vapor diffusion $\left(\tau_{\text {eff }}=20\right)$.

Figure 21 shows the temperature on the drift heater and the upper drift wall for all of the cases considered in this section. With exception of the 84-darcy case, the drift heater temperatures are virtually the same for all of these cases. For the 84-darcy case, buoyant gas-phase convection increases the overall heat loss from the test region, which reduces both the peak temperature and the duration of the boiling period. For all but the 84-darcy case, heat flow is dominated by heat conduction. Even when enhanced by two orders of magnitude, the potential effect of vapor diffusion on increasing overall heat loss from the repository is not apparent in any of these tests. Slightly higher peak temperatures occur on the upper drift wall for the 1- and 10-millidarcy cases during the 1- and 2-yr full-power heating periods; however, the duration of the boiling period is virtually

Table 2. Time requirements for diagnosing various T-H-M-C effects.

\begin{tabular}{|c|c|c|c|}
\hline $\begin{array}{l}\text { T-H regimes and processes, } \\
\text { T-H-C processes, and the influence of rock } \\
\text { heterogeneity }\end{array}$ & $\begin{array}{l}\text { Minimum } \\
\text { required } \\
\text { full-power } \\
\text { heating period }\end{array}$ & $\begin{array}{l}\text { Time at which } \\
\text { diagnosis is } \\
\text { possible }\end{array}$ & $\begin{array}{l}\text { Supporting } \\
\text { figure numbers }\end{array}$ \\
\hline 1. Significant heat-pipe zones develop & $1-2 \mathrm{yr}$ & $1-2 \mathrm{yr}$ & $\begin{array}{l}\text { Figs. } 3,4,12, \\
14,17,19,20,27\end{array}$ \\
\hline 2. Throttled advective rock dryout & $1-2 \mathrm{yr}$ & $1-2 \mathrm{yr}$ & Figs. 19, 22 \\
\hline 3. Unthrottled nonbuoyant rock dryout & $1-2 \mathrm{yr}$ & $1-2 \mathrm{yr}$ & $\begin{array}{l}\text { Figs. 3, 4, 12, } \\
19,20,22\end{array}$ \\
\hline $\begin{array}{l}\text { 4. Buoyant gas-phase convection dominates } \\
\text { vapor flow }\end{array}$ & $1-2 \mathrm{yr}$ & $1-2 \mathrm{yr}$ & $\begin{array}{l}\text { Figs. } 3,4,12 \\
20,22\end{array}$ \\
\hline $\begin{array}{l}\text { 5. Buoyant gas-phase convection dominates } \\
\text { heat flow }\end{array}$ & $1-2 \mathrm{yr}$ & $1-2 \mathrm{yr}$ & $\begin{array}{l}\text { Figs. } 3,4,12 \\
20,21\end{array}$ \\
\hline 6. Degree of vapor diffusion enhancement & $2-4 \mathrm{yr}$ & $4-6 \mathrm{yr}$ & Fig. 22 \\
\hline $\begin{array}{l}\text { 7. Reflux-driven geochemical alteration of flow } \\
\text { and transport properties }\end{array}$ & $4 \mathrm{yr}$ & $4 \mathrm{yr}$ & Fig. 25 \\
\hline $\begin{array}{l}\text { 8. Rock heterogeneity dominates vapor and } \\
\text { condensate flow }\end{array}$ & $1-2 \mathrm{yr}$ & $1-2 \mathrm{yr}$ & Fig. 26 \\
\hline $\begin{array}{l}\text { 9. Heat conduction overwhelms effects of } \\
\text { heterogeneity-dominated vapor and } \\
\text { condensate flow* }\end{array}$ & $6+y r$ & $6+\mathrm{yr}$ & Fig. 27 \\
\hline
\end{tabular}

*Is only applicable if item 8 was found to be important. 
the same for all but the 84-darcy case. In general, the temperature history at a particular location is far less diagnostic than the vertical temperature profile in determining the major $\mathrm{T}-\mathrm{H}$ regime(s).

While the temperature history in the heater drift is of marginal use, the gas-phase pressure $P_{\mathrm{g}}$ and relative humidity $R H$ in the drift during heatup and cooldown (Fig. 22) can provide information that is very diagnostic of the dominant $\mathrm{T}-\mathrm{H}$ regime(s). If the heater drift can be adequately isolated from the rest of the ESF tunnel system, a 1-yr full-power heating period is long enough for $P_{\mathrm{g}}$ in the drift to be clearly indicative of whether the throttled nonbuoyant regime dominates $\mathrm{T}-\mathrm{H}$ behavior. The situation improves for the 2- and 4-yr full-power heating periods. For a heterogeneous $k_{\mathrm{b}}$ distribution, a longer test will provide more information about $k_{\mathrm{b}}$ at a larger spatial scale.

If full-power heating lasts for at least $2 \mathrm{yr}, R H$ in the drift (Fig. 22c,e) is extremely diagnostic of the major T-H regimes and is also extremely diagnostic of whether vapor diffusion is substantially enhanced. Although Fig. 22 plots $R H$ on the drift heater, any $R H$ measurement in the drift can serve the same general purpose. Three factors can govern the shape of the $R H$ curves:

1. The spatial extent of rock dryout.

2. Throttled vapor advection causing a substantial increase in $P_{\mathrm{v}}$ that suppresses $R H$ reduction.
3. How fast the rock surrounding the drift is rewetted to ambient $R H$ conditions.

Three processes cause rock dryout: (1) boiling, (2) buoyant gas-phase convection, and (3) vapor diffusion. The second and third processes do not require above-boiling conditions. During heatup it takes about 6 months for the rock to reach boiling conditions, so the 1-yr full-power test spends much of its heatup time below the boiling point. Therefore, dryout processes that do not require boiling conditions will play a larger role in determining the spatial extent of rock dryout during this test than during the 2- and 4-yr full-power tests.

Differences in the $R H$ behavior in the drift for the 1-yr full-power test are more substantially influenced by the spatial extent of dryout than by how fast the rock around the drift rewets to ambient conditions. The 2- and 4-yr full-power tests spend much more of their heatup periods above the boiling point; consequently, boiling conditions dominate the spatial extent of rock dryout. For the 2- and 4-yr full-power tests, differences in $R H$ behavior in the drift reflect differences in how fast the rock rewets to humid conditions (rather than how much rock dryout occurred).

Four major processes govern how fast the dryout zone rewets to ambient (humid) conditions: (1) net infiltration of meteoric water, (2) capillary-imbibitiondriven rewetting of the rock matrix, (3) vapor diffusion
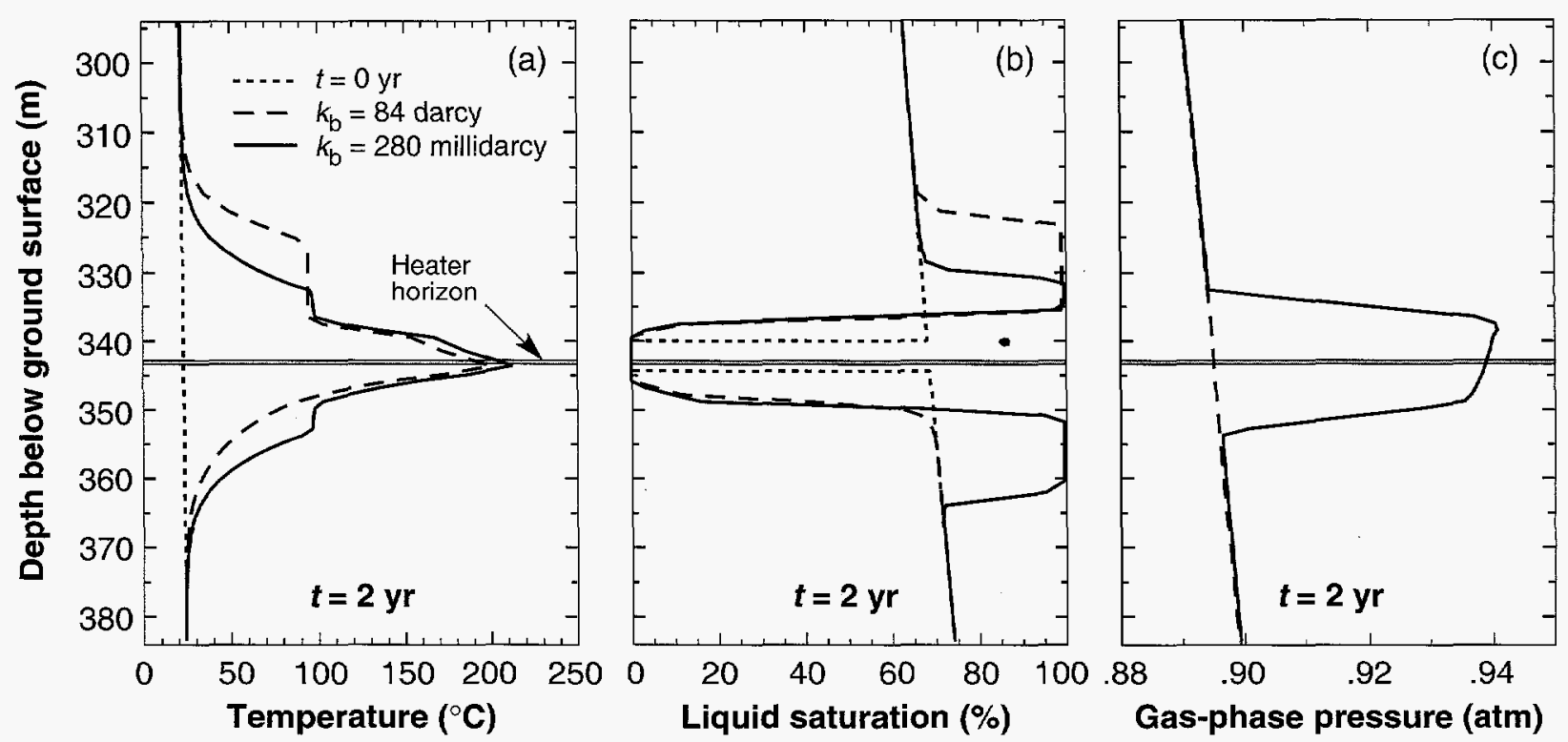

Figure 20. (a) Vertical temperature profile, (b) liquid saturation profile, and (c) gas-phase pressure profile along the centerline of a row of drift-emplaced, large-WP-sized heaters generating a lineal heat load of $0.8 \mathrm{~kW} / \mathrm{m}$ and flanked by two horizontal-borehole-emplaced wing heater arrays. The heater arrays are generating an APD of $105 \mathrm{~W} / \mathrm{m}^{2}$ over the interval $4<|x|<9 \mathrm{~m}$ and $157.5 \mathrm{~W} / \mathrm{m}^{2}$ over the interval $9<|x|<14 \mathrm{~m}$ from the drift centerline at $t=2 \mathrm{yr}$. Vapor diffusion tortuosity factor $\tau_{\text {eff }}=0.2$. 
of humid air into the dryout zone, and (4) buoyant gas-phase convection-driven advection of humid air into the dryout zone. Figure 22b,c clearly shows how the second, third, and fourth rewetting processes influence $R H$ behavior in the drift. For the 1-millidarcy case, the large increase in vapor pressure $P_{\mathrm{y}}$ throttles advective rock dryout and suppresses $R H$ reduction in the drift during heatup, particularly for the 1- and 2-yr full-power tests. Moreover, throttled advective rock dryout results in a smaller dryout volume that takes less time to rewet to ambient (humid) conditions than in the unthrottled nonbuoyant cases with nominal vapor diffusion. Even

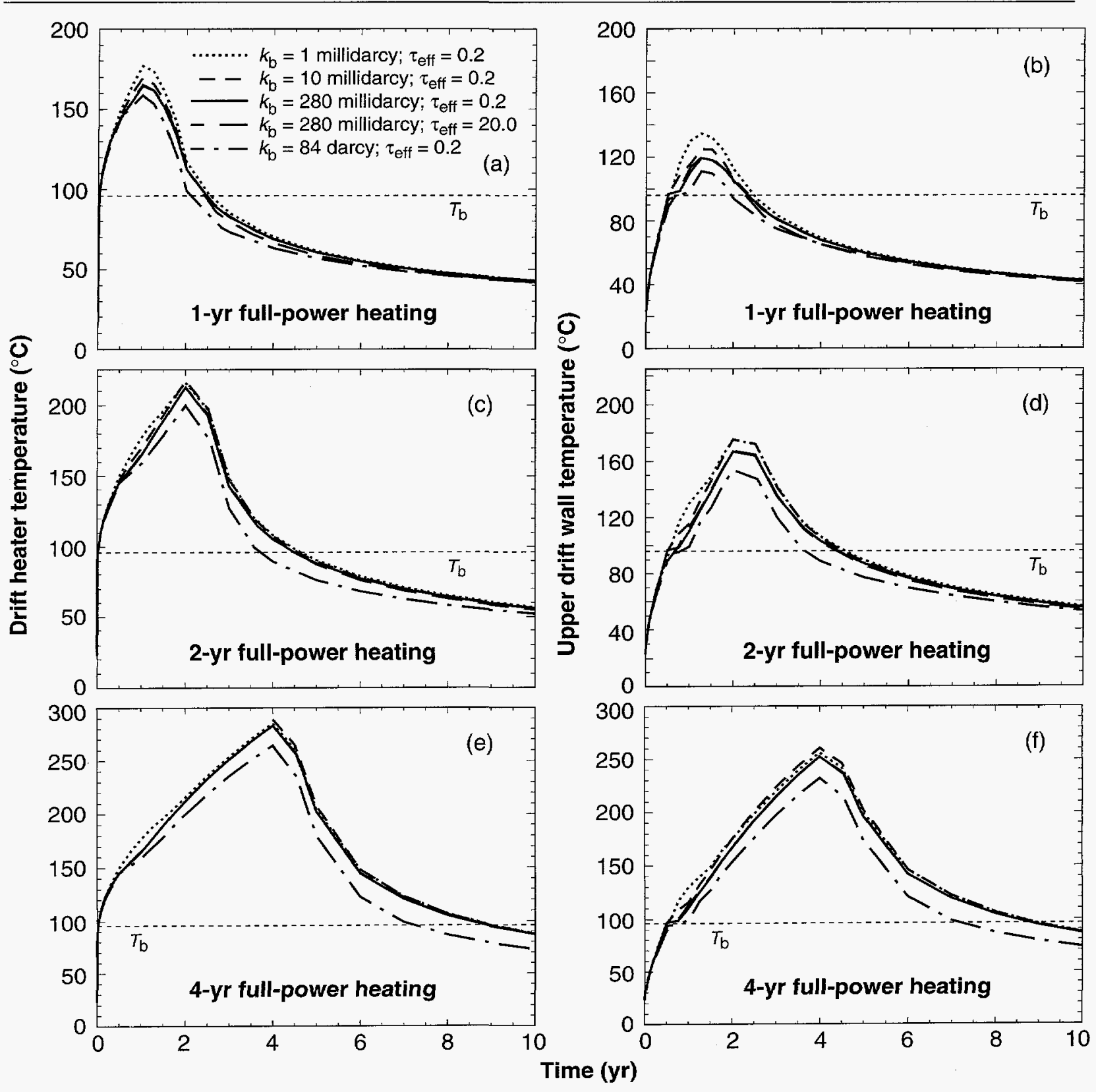

Figure 21. (a, c, e) Temperature history on drift heater and (b, d, f) temperature history on upper drift wall for a row of drift-emplaced, large-WP-sized heaters generating a lineal heat load of $0.8 \mathrm{~kW} / \mathrm{m}$ and flanked by two horizontalborehole-emplaced wing heater arrays. The heater arrays are generating an APD of $105 \mathrm{~W} / \mathrm{m}^{2}$ over the interval $4<|x|<9 \mathrm{~m}$ and $157.5 \mathrm{~W} / \mathrm{m}^{2}$ over the interval $9<|x|<14 \mathrm{~m}$ from the drift centerline. Bulk permeability $k_{\mathrm{b}}=$ 280 millidarcy, and vapor diffusion tortuosity factor $\tau_{\mathrm{eff}}=0.2$. Temperature histories are shown for three different periods of full-power heating. The full-power heating period is followed by a 1-yr linear-rampdown period to zero power. 
though $P_{\mathrm{g}}$ rises noticeably in the 10 -millidarcy case, it is not enough to throttle advective rock dryout and to suppress $R H$ reduction; consequently, the 10 - and 280 millidarcy cases with nominal vapor diffusion have nearly identical $R H$ behavior.
The effect of substantial buoyant gas-phase convection on advecting humid air into the dryout zone becomes evident by $t=6$ yr for the 4 -yr full-power test (Fig. 22e); however, for the 2-yr full-power test, this effect does not become evident until after $10 \mathrm{yr}$

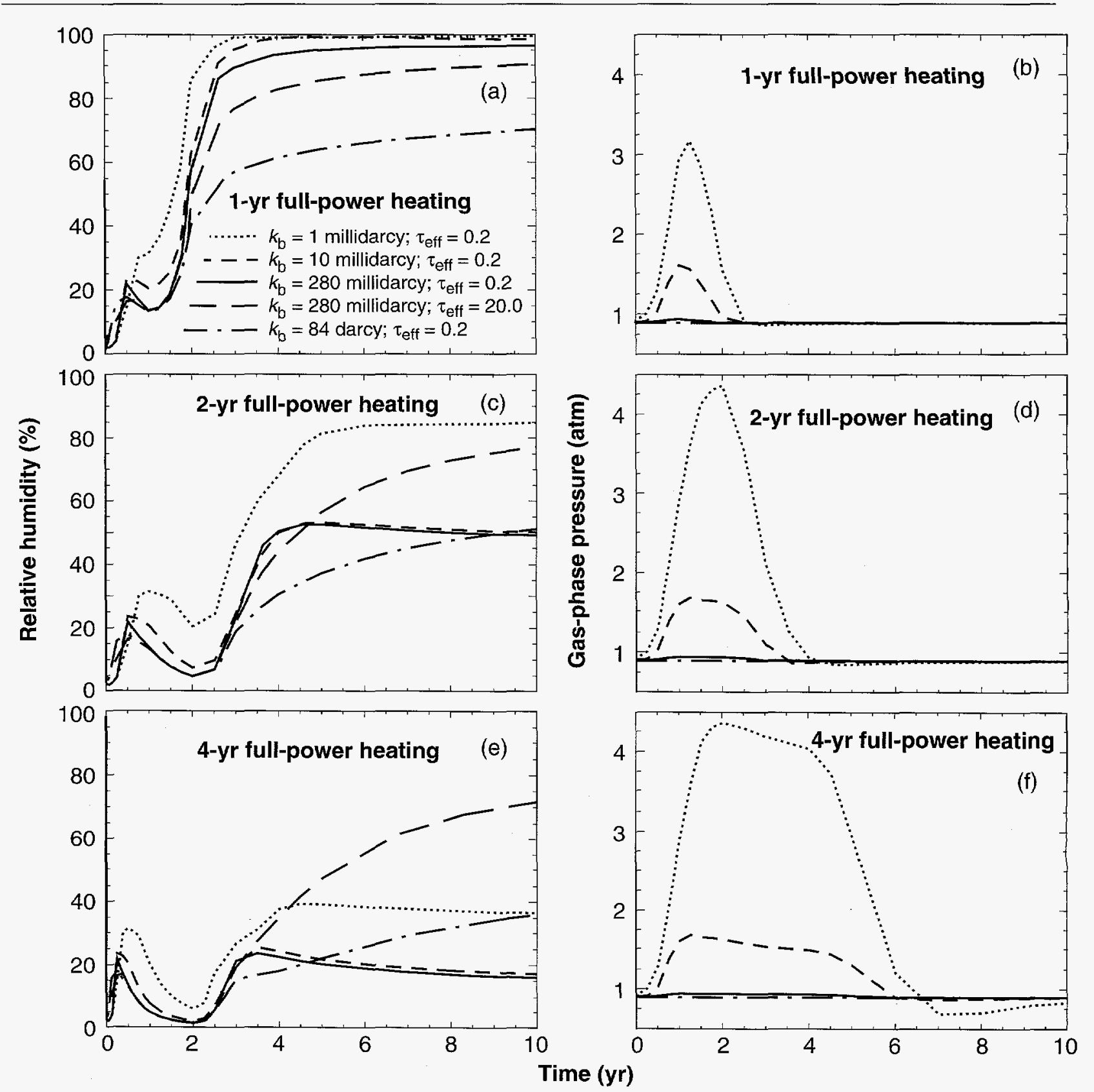

Figure 22. (a, c, e) Relative humidity on surface of drift heater and (b, d, f) gas-phase pressure in heater drift for a row of drift-emplaced, large-WP-sized heaters generating a lineal heat load of $0.8 \mathrm{~kW} / \mathrm{m}$ and flanked by two horizontal-borehole-emplaced wing heater arrays. The heater arrays are generating an APD of $105 \mathrm{~W} / \mathrm{m}^{2} \mathrm{over}$ the interval $4<|x|<9 \mathrm{~m}$ and $157.5 \mathrm{~W} / \mathrm{m}^{2}$ over the interval $9<|x|<14 \mathrm{~m}$ from the drift centerline. Bulk permeability $k_{\mathrm{b}}=280$ millidarcy, and vapor diffusion tortuosity factor $\tau_{\mathrm{eff}}=0.2$. Relative humidity and gas-phase pressure histories are shown for three different periods of full-power heating. The full-power heating period is followed by a $1-y r$ linear-rampdown period to zero power. 
(Fig. 22c). The effect of (enhanced) vapor diffusion of humid air into the dryout zone (for $\tau_{\text {eff }}=20$ ) becomes quite evident at about $t=4 \mathrm{yr}$ for the 4-yr full-power
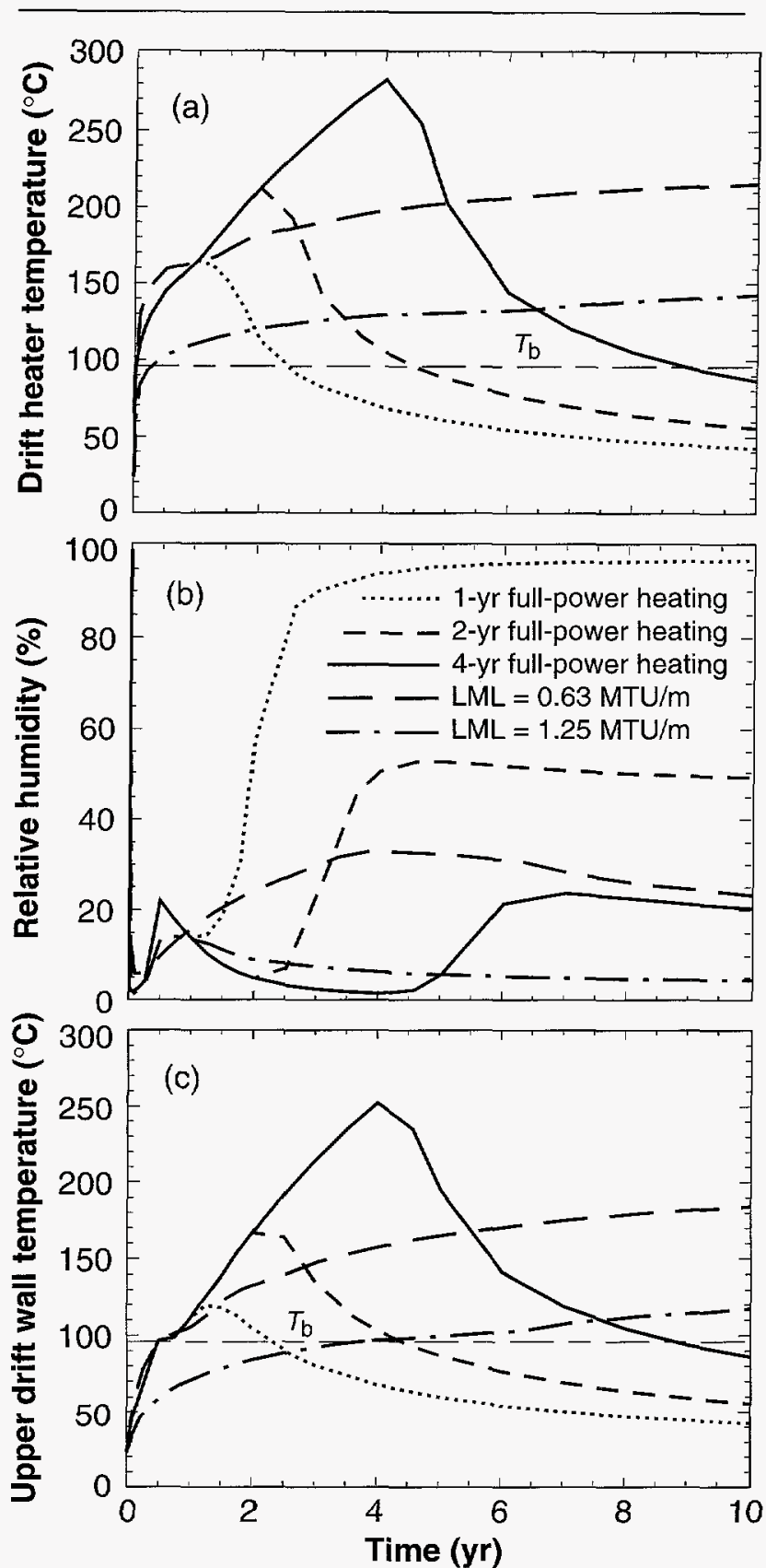

test, whereas it requires $6 \mathrm{yr}$ to become evident in the 2-yr full-power test (item 6 in Table 2).

In the 1-yr full-power test, differences in the $R H$ history in the drift (Fig. 22a) are either too minor or too ambiguous to permit any determination about the major $\mathrm{T}-\mathrm{H}$ regimes or about the degree of vapor diffusion enhancement. Contrary to the relation between rewetting mechanisms and $R H$ behavior seen for the 2 - and 4-yr full-power tests (Fig. 22c,e), the 84-darcy and enhanced-vapor-diffusion cases appear to rewet more slowly than the other cases. This arises because the sub-boiling rock dryout mechanisms create a larger dryout zone than in the cases where boiling is the primary cause of rock dryout.

In general, a 1-yr full-power test provides inconclusive and/or misleading information about the dominant $\mathrm{T}-\mathrm{H}$ regime(s) and the relative contributions of the major rewetting mechanisms addressed in this study. Both the 2-yr and 4-yr full-power tests provide clear and unambiguous information about all three major T-H regimes and all of the rewetting mechanisms addressed in this study; however, the 4-yr full-power test allows for an earlier determination about the degree of vapor diffusion enhancement.

Figures 23 and 24 compare temperature, $R H$, and rock dryout behavior for the 1-, 2-, and 4-yr full-power heating tests with drift-scale behavior calculated for an 80-MTU/acre repository with two combinations of drift and WP spacing. Temperature rises during the first $2 \mathrm{yr}$ of the 2- and 4-yr full-power tests are only slightly more accelerated than repository behavior (Fig. 23a,c). At $t=4 \mathrm{yr}$, the upper drift wall temperature is $252^{\circ} \mathrm{C}$ in the thermal test, while it is $157^{\circ} \mathrm{C}$ in the 80 -MTU/acre repository with a lineal mass loading (LML) of 1.25 $\mathrm{MTU} / \mathrm{m}$. Moreover, $R H$ behavior on the WP in both of the 80-MTU/acre cases is quite similar to that of the 4-yr full-power test. An earlier comparison between thermal test and repository $\mathrm{T}-\mathrm{H}$ behaviors [Buscheck and Nitao, 1993a; Buscheck and Nitao, 1993b] inappropriately used average repository T-H behavior calculated with a mountain-scale model. This comparison should have been done with a drift-scale model of repository T-H behavior. The use of a mountain-scale

Figure 23. (a) Temperature and (b) relative humidity on drift heater and (c) temperature on upper drift wall for a row of drift-emplaced, large-WP-sized heaters generating a lineal heat load of $0.8 \mathrm{~kW} / \mathrm{m}$ and flanked by two horizontal-borehole-emplaced wing heater arrays. The heater arrays are generating an APD of $105 \mathrm{~W} / \mathrm{m}^{2}$ over the interval $4<|x|<9 \mathrm{~m}$ and $157.5 \mathrm{~W} / \mathrm{m}^{2}$ over the interval $9<|x|<14 \mathrm{~m}$ from the drift centerline. Bulk permeability $k_{\mathrm{b}}=280$ millidarcy, and vapor diffusion tortuosity factor $\tau_{\mathrm{eff}}=0.2$. Curves are shown for three different periods of full-power heating. The full-power heating period is followed by a 1-yr linear-rampdown period to zero power. Curves are also shown for two 80-MTU/acre repositories with 26-yr-old (OFF) SNF and the following: (i) LML = $1.25 \mathrm{MTU} / \mathrm{m}$, drift spacing $=60 \mathrm{~m}$, and WP spacing $=6 \mathrm{~m}$; and (ii) $\mathrm{LML}=0.63 \mathrm{MTU} / \mathrm{m}$, drift spacing $=30 \mathrm{~m}$, and WP spacing $=12 \mathrm{~m}$. Repository temperature and relative humidity values pertain to the WP surface. 
model gave rise to the appearance of a larger disparity between the thermal test and repository T-H behaviors than would have been seen had a drift-scale model of the repository been used.

Figure 24 shows that the dryout and boiling zones during the 4-yr full-power test grow about twice as fast as in the $80-\mathrm{MTU} /$ acre case with $\mathrm{LML}=1.25 \mathrm{MTU} / \mathrm{m}$. At $t=4 \mathrm{yr}$, the vertical dryout zone thickness is $21.6 \mathrm{~m}$ in the thermal test (Fig. 24a), whereas it is $12.3 \mathrm{~m}$ in the 80-MTU/acre repository. It takes 14 yr for the 80 -MTU/acre repository to dry out $22 \mathrm{~m}$ vertically. At $t=4 \mathrm{yr}$, the boiling zone has a vertical thickness of $30 \mathrm{~m}$, whereas for the 80 -MTU/acre repository it is $15.7 \mathrm{~m}$. In general, the reference single-drift, winged thermal test does not appear to be overly accelerated relative to repository conditions.

In optimizing a thermal test design, it is important to consider the duration of refluxing conditions (Fig. 25) created by the thermal test. Ideally, refluxing conditions during the test would last long enough for any potentially important intercoupling between T-H behavior and geochemical processes to take place. In Fig. 25, we assume that refluxing occurs if the temperature is between $95^{\circ} \mathrm{C}$ and $97^{\circ} \mathrm{C}$. If vapor pressure lowering is particularly pronounced, refluxing may occur over a wider temperature range than that. Nonetheless, Fig. 25 provides a useful means of comparing the ability of the $1-, 2-$, and 4-yr full-power tests to provide T-H conditions that may lead to significant coupled T-H-C effects. The 1-yr full-power test (Fig. 25a) provides a rather limited opportunity (at best) to observe the potential for reflux-driven coupled T-H-C effects. The 2-yr fullpower test appears to be a significant improvement over the 1-yr full-power test in this regard, while the 4-yr test provides a fairly extensive zone over which coupled T-H-C effects may develop. The 4-yr full-power test appears to allow determination of the relative importance of reflux-driven geochemical alteration of flow and transport properties within the first $4 \mathrm{yr}$ of the test (item 7 in Table 2). Note that a heterogeneous $k_{\mathrm{b}}$ distribution may focus these effects into certain regions of the test, so that finding (and sampling) such locations may pose a significant challenge. Increasing the volume of rock within which coupled T-H-C effects may develop should certainly increase the chances of encountering such areas.

\section{IV.E.2 Evaluating the Effects of Heterogeneity}

So far we have analyzed thermal test cases in which the hydrological and thermal property distributions were assumed to be homogeneous and isotropic. We now consider two cases in which the $k_{\mathrm{b}}$ distribution is highly heterogeneous (Fig. 26). In both cases, the high $-k_{\mathrm{b}}$ zones are assumed to have $k_{\mathrm{b}}=84$ darcy. Adjacent to the high $-k_{\mathrm{b}}$ zones are "nominal"- $k_{\mathrm{b}}$ zones in which $k_{\mathrm{b}}=1$ millidarcy. Both cases result in similar
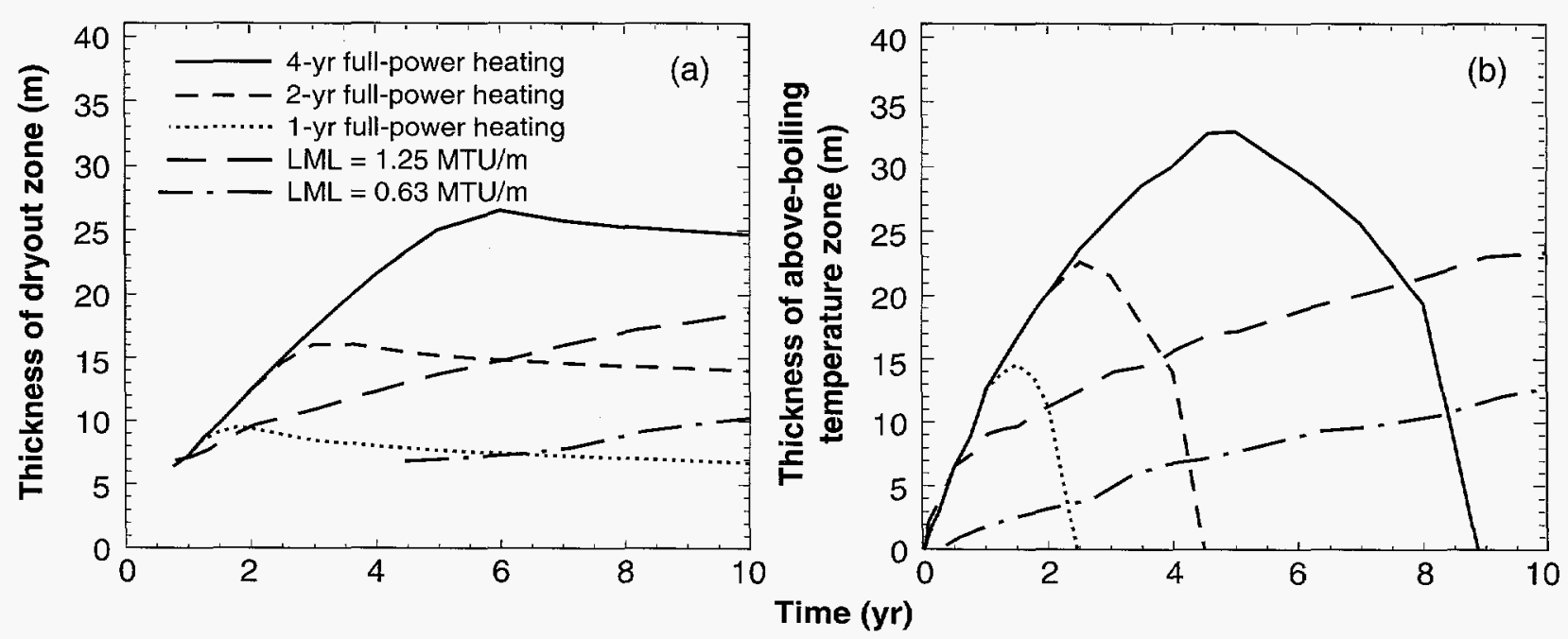

Figure 24. Vertical thickness of (a) dryout zone and (b) above-boiling temperature zone along the centerline of a row of drift-emplaced, large-WP-sized heaters generating a lineal heat load of $0.8 \mathrm{~kW} / \mathrm{m}$ and flanked by two horizontalborehole-emplaced wing heater arrays. The heater arrays are generating an APD of $105 \mathrm{~W} / \mathrm{m}^{2}$ over the interval $4<$ $|x|<9 \mathrm{~m}$ and $157.5 \mathrm{~W} / \mathrm{m}^{2}$ over the interval $9<|x|<14 \mathrm{~m}$ from the drift centerline. Bulk permeability $k_{\mathrm{b}}=280 \mathrm{milli}-$ darcy, and vapor diffusion tortuosity factor $\tau_{\mathrm{eff}}=0.2$. Curves are shown for three different periods of full-power heating. The full-power heating period is followed by a 1-yr linear-rampdown period to zero power. Curves are also shown for two 80-MTU/acre repositories with 26-yr-old (OFF) SNF and the following: (i) LML = 1.25 MTU/m, drift spacing $=60 \mathrm{~m}$, and WP spacing $=6 \mathrm{~m}$; and (ii) $\mathrm{LML}=0.63 \mathrm{MTU} / \mathrm{m}$, drift spacing $=30 \mathrm{~m}$, and WP spacing $=12 \mathrm{~m}$. 
behavior in the heater drift. Zones of sharply contrasting $k_{\mathrm{b}}$ can dominate condensate drainage during a thermal test (or in the repository). Because the $k_{\mathrm{b}}$ contrast between neighboring zones is large, the $P_{\mathrm{g}}$ differential drives water vapor into the high $-k_{\mathrm{b}}$ zone, where it condenses and drains, causing persistent refluxing and condensate drainage into heater drift at $t=2 \mathrm{yr}$ (Fig. 26a,b). The resulting heat-pipe effect enables the temperature at the top of the drift to remain at the boiling point (Fig. 26c,d), causing a depression in the dryout zone (Fig. 26a,b), Whether rock heterogeneity will dominate vapor and condensate flow will be very evident within the first 1 to $2 \mathrm{yr}$ of the single-drift, winged thermal test (item 8 in Table 2).

The amount of vapor flow focusing into the high- $k_{\mathrm{b}}$ zone and the resulting duration of refluxing at the heater test horizon depend on three factors. First, $k_{\mathrm{b}}$ in the nominal- $k_{\mathrm{b}}$ zone must be high enough not to significantly throttle the rate of vapor generation due to boiling (or due to evaporation, under sub-boiling conditions). Second, a large contrast in $k_{\mathrm{b}}$ between the high- and nominal- $k_{\mathrm{b}}$ zones results in a difference in gas-phase pressure $P_{\mathrm{g}}$ between these zones that drives vapor flow into the high- $k_{\mathrm{b}}$ zone (Fig. 26a,b). If enough vapor enters and condenses in the high- $k_{\mathrm{b}}$ zone, the return condensate flux will be large enough to maintain refluxing at the heater test horizon, possibly resulting in water draining into the heater drift. Third, there must be sufficient spacing between the high- $k_{\mathrm{b}}$ zones to drive enough water vapor into these zones to result in the local condensate drainage flux being substantially greater than the mean condensate flux.

The heat-pipe zone "attracts" heat (mainly by conduction) from the neighboring, nominal- $k_{\mathrm{b}}$ rock. In effect, the heat-pipe zone functions as a "cooling fin" that is manifested by an elongated region of liquid saturation buildup (Fig. 26a,b). The process of gas-phase focusing into the heat-pipe zone develops more quickly than the process of attracting heat (by heat conduction) from the neighboring rock. Focused condensate drainage causes a sharp depression in the temperature field (Fig. 26c,d) at $t=2 \mathrm{yr}$. In the case with multiple high- $k_{\mathrm{b}}$ zones (Fig. 27a), this sharp depression results in near-boiling temperatures $\left(96^{\circ} \mathrm{C}\right)$ at the elevation of the upper drift wall at $t=2 \mathrm{yr}$, while just a few meters away at this horizon, temperatures are well above boiling. Within $4 \mathrm{yr}$ (Fig. 27b), enough heat is being conducted into the central high $-k_{\mathrm{b}}$ zone to overwhelm its heat pipe, causing the top of the heater drift to begin to dry out and drift temperatures to climb well above $96^{\circ} \mathrm{C}$. The heat pipe in the high- $k_{\mathrm{b}}$ zone located roughly midspan along the wing heater array has also been overwhelmed by heat conduction, causing the

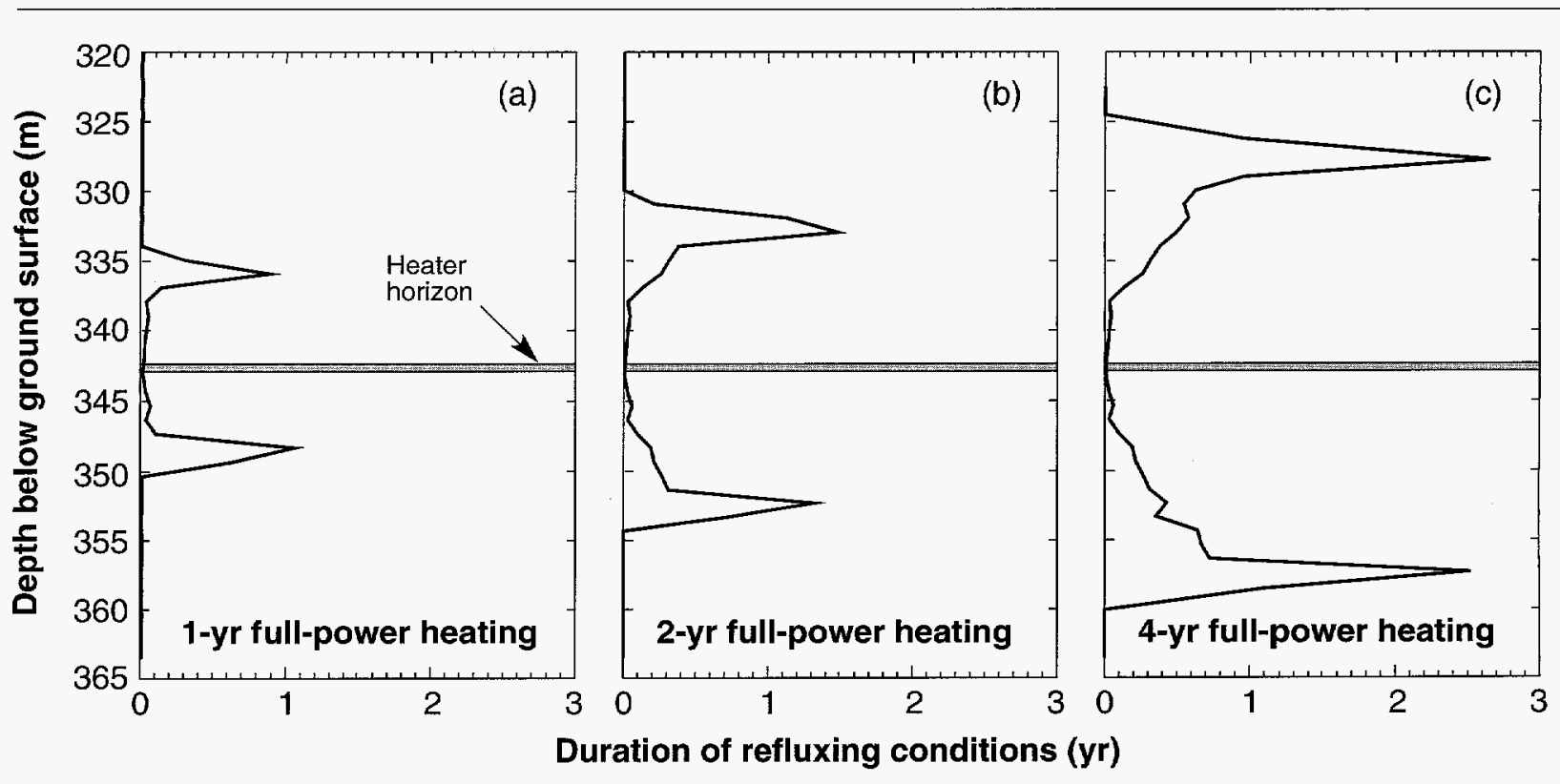

Figure 25. Duration of refluxing conditions (as given by the time between 95 and $97^{\circ} \mathrm{C}$ ) vs depth along the centerline of a row of drift-emplaced, large-WP-sized heaters generating a lineal heat load of $0.8 \mathrm{~kW} / \mathrm{m}$ and flanked by two horizontal-borehole-emplaced wing heater arrays. The heater arrays are generating an APD of $105 \mathrm{~W} / \mathrm{m}^{2}$ over the interval $4<|x|<9 \mathrm{~m}$ and $157.5 \mathrm{~W} / \mathrm{m}^{2}$ over the interval $9<|x|<14 \mathrm{~m}$ from the drift centerline. Bulk permeability $k_{\mathrm{b}}=280$ millidarcy, and vapor diffusion tortuosity factor $\tau_{\mathrm{eff}}=0.2$. Curves are shown for three different periods of full-power heating. The full-power heating period is followed by a 1-yr linear-rampdown period to zero power. 
temperature to exceed $150^{\circ} \mathrm{C}$. Because of the edge-cooling effect, there is not enough heat conducted into the high- $k_{\mathrm{b}}$ zone at the edge of the heated area to overwhelm its heat pipe; consequently, the temperature continues to be $96^{\circ} \mathrm{C}$ at the outer edge of the wing heater array (Fig. 27b).

At $t=6 \mathrm{yr}$, focused vapor and condensate flow continues to cause refluxing in the high- $k_{\mathrm{b}}$ zones at

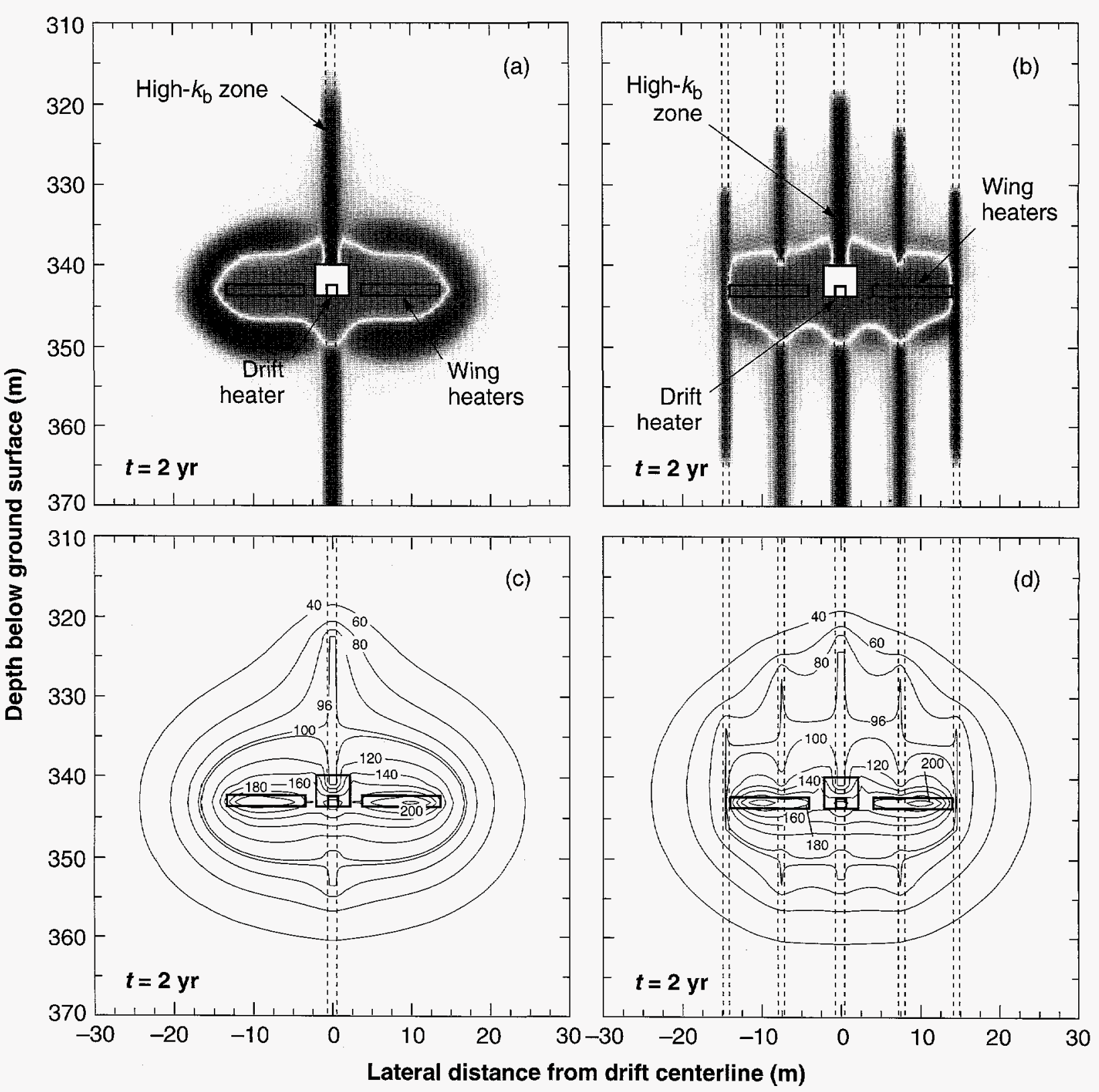

Figure 26. ( $a, b)$ Dimensionless liquid saturation distribution and (c, d) temperature distribution orthogonal to a row of drift-emplaced, large-WP-sized heaters generating a lineal heat load of $0.8 \mathrm{~kW} / \mathrm{m}$ and flanked by two horizontalborehole-emplaced wing heater arrays. The heater arrays are generating an APD of $105 \mathrm{~W} / \mathrm{m}^{2}$ over the interval $4<|x|<$ $9 \mathrm{~m}$ and $157.5 \mathrm{~W} / \mathrm{m}^{2}$ over the interval $9<|x|<14 \mathrm{~m}$ from the drift centerline. The heterogeneous bulk permeability $k_{\mathrm{b}}$ distribution consists of 84 -darcy high- $k_{\mathrm{b}}$ zones separated by 1-millidarcy nominal- $k_{\mathrm{b}}$ zones. Vapor diffusion tortuosity factor $\tau_{\text {eff }}=0.2$. The medium-shaded area surrounding the heater array corresponds to regions that are drier than ambient liquid saturation (dryout zone). The dark-shaded areas correspond to regions that are wetter than ambient liquid saturation (condensation zone). The light shading surrounding the dark-shaded area corresponds to a small rise in liquid saturation (outer edges of the condensation zone). No shading indicates no change in liquid saturation. 


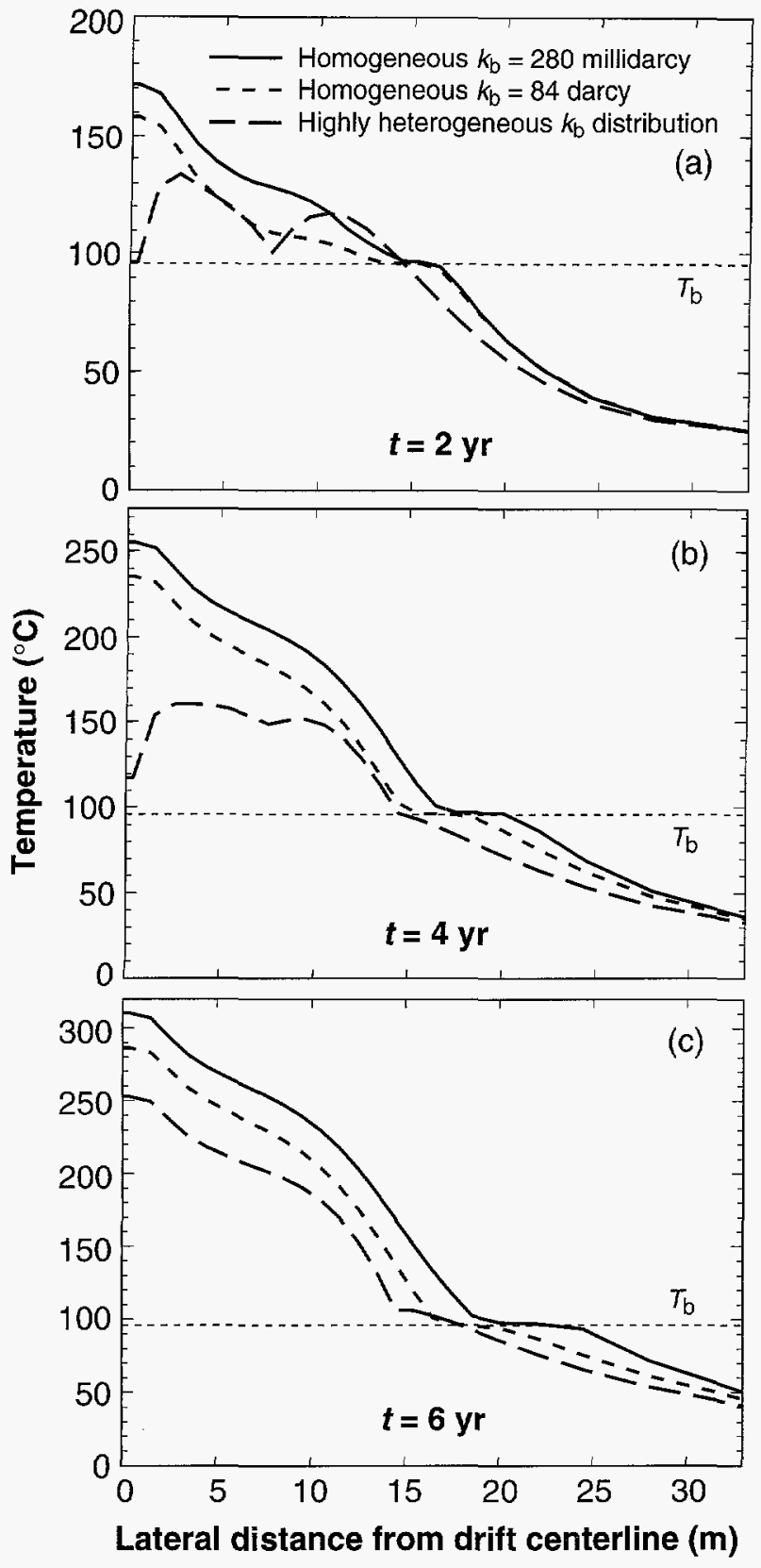

Figure 27. Horizontal temperature profile at the elevation of the upper drift wall ( $2.9 \mathrm{~m}$ above the top of the drift heaters) for a row of drift-emplaced, large-WP-sized heaters generating a lineal heat load of $0.8 \mathrm{~kW} / \mathrm{m}$ and flanked by two horizontal-borehole-emplaced wing heater arrays. The heater arrays are generating an APD of $105 \mathrm{~W} / \mathrm{m}^{2}$ over the interval $4<|x|<9 \mathrm{~m}$ and $157.5 \mathrm{~W} / \mathrm{m}^{2}$ over the interval $9<$ $|x|<14 \mathrm{~m}$ from the drift centerline. Bulk permeability $k_{\mathrm{b}}=$ 280 millidarcy, and vapor diffusion tortuosity factor $\tau_{\text {eff }}=$ 0.2 . Temperature profiles are shown for three bulk permeability $k_{\mathrm{b}}$ distributions, including two homogeneous cases with $k_{\mathrm{b}}=280$ millidarcy and 84 darcy, and a highly heterogeneous case that consists of vertically oriented, narrow 84-darcy zones separated by 1-millidarcy zones (see Fig. 10). elevations above the heater horizon. Preferential heat conduction into the high- $k_{\mathrm{b}}$ zone continues to dry it out, and the influence of focused vapor and condensate flow on temperatures (Fig. 27c) at (or above) the heater horizon is no longer evident, except that the heat-pipe zones at the outer edge of the wing heater array continue to result in near-boiling temperatures at the margins of the heated area. At late time, the primary effect of the heat pipes above the main heater area is to increase the overall heat loss from the thermal test region, which results in lower temperatures than in the homogeneous- $k_{\mathrm{b}}$ cases above the dryout zone; however, the temperature distribution in the vicinity of the heater drift (and for most of the heater horizon) is as it would be if heat conduction dominated heat flow. It is interesting to note that although the $k_{\mathrm{b}}$ (averaged over the heater array) for the highly heterogeneous- $k_{\mathrm{b}}$ case is only 17 darcy, the convective cooling effect is greater than it is for the 84-darcy case (Fig. 27c).

The effect of heat being conducted toward the high $-k_{\mathrm{b}}$ zone (from neighboring regions of the superheated rock) and thereby overwhelming the heat pipe in the high- $k_{\mathrm{b}}$ zone was seen in drift-scale and mountain-scale T-H calculations [Buscheck and Nitao, 1993a; Buscheck and Nitao, 1994a]. In a similar calculation for a 155-MTU/acre repository, heat conducted from neighboring regions overwhelmed the heat pipe in the high $-k_{\mathrm{b}}$ zone and began drying out the top of the emplacement drift $8 \mathrm{yr}$ after emplacement of the WPs. In that calculation, the high- $k_{\mathrm{b}}$ zones were spaced every $38.4 \mathrm{~m}$, which is comparable to the scale of the reference single-drift, winged thermal test. The analysis in this section indicates that confirmation of major hypothesis MH-3 (Sec. II.D) and whether heat conduction will eventually overwhelm the effects of heterogeneity-dominated vapor and condensate flow (item 9 in Table 2) may require a thermal test with a full-power period of $6 \mathrm{yr}$ or more. Short-duration tests may leave the misleading impression that focused liquid flow could persistently overwhelm the heat conduction flow field and thereby result in liquid water persistently draining into emplacement drifts.

\section{IV.E.3 Evaluating Accelerated Heating Rates}

To evaluate the feasibility of accelerating the heating schedule of the single-drift, winged thermal test, we considered tests in which the overall APDs (177 and $236 \mathrm{~W} / \mathrm{m}^{2}$ ) were roughly 50 and $100 \%$ greater than in the reference case $\left(\mathrm{APD}=122 \mathrm{~W} / \mathrm{m}^{2}\right)$. We assumed $k_{\mathrm{b}}=280$ millidarcy and $\tau_{\text {eff }}=0.2$ (nominal vapor diffusion) for these three APDs and 1- and 2-yr full-power heating periods (Figs. 28 and 29). The full-power period is followed by a 1-yr linear-rampdown to zero power. 
Figure 28 shows that the temperature increase in the drift is proportional to APD. The $177-\mathrm{W} / \mathrm{m}^{2}$ case with a 2-yr full-power heating period causes $R H$ behavior in the drift (Fig. 28d) to be very similar to that of the reference case $\left(A P D=122 \mathrm{~W} / \mathrm{m}^{2}\right)$ with a 4-yr full-power heating period (Fig. 22e). Temperature behaviors for the reference case (Fig. 21e,f) and the $177-\mathrm{W} / \mathrm{m}^{2}$ case

(Fig. 28f) are also quite similar. Moreover, the
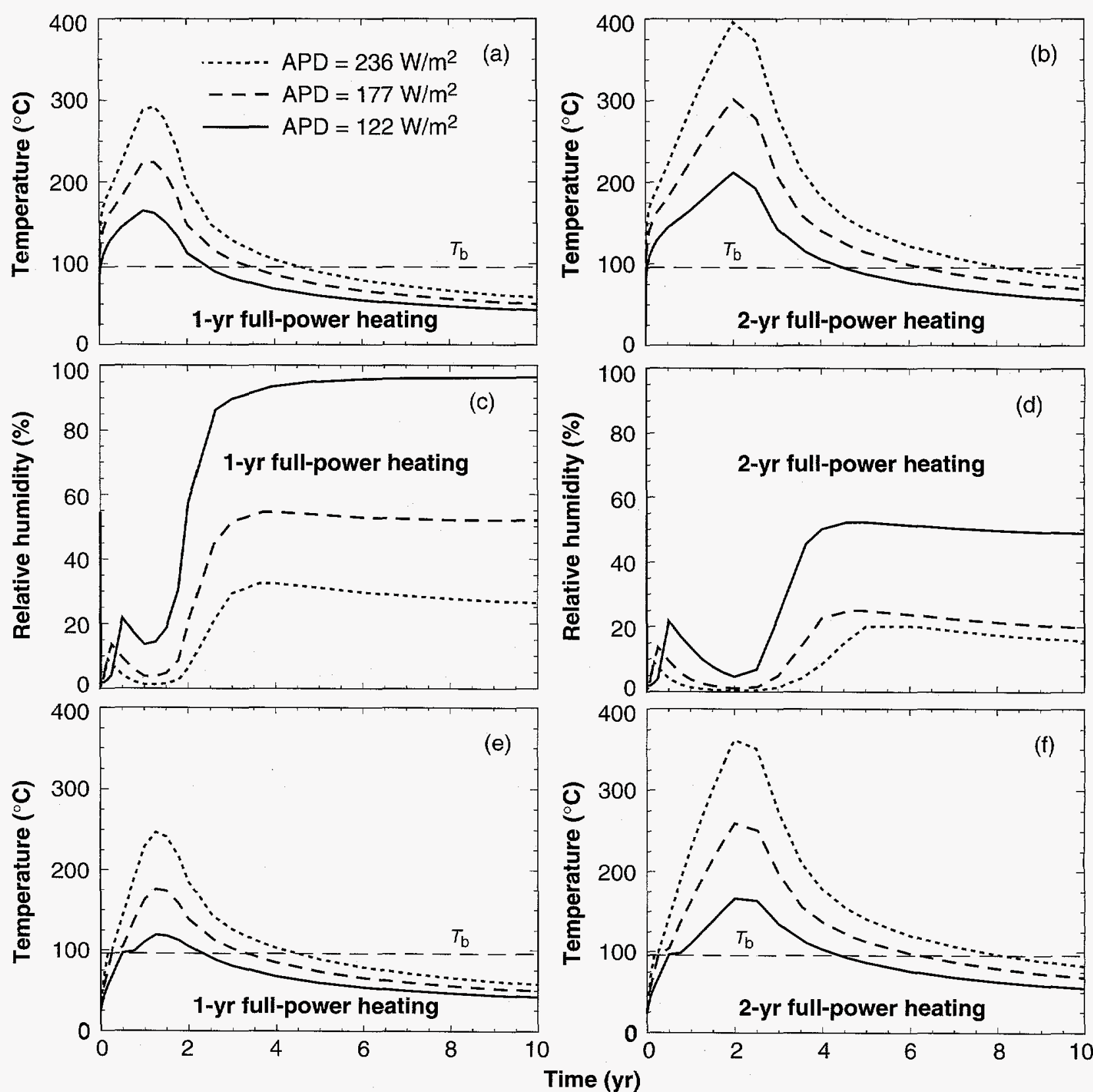

Figure 28. (a, b) Temperature and (c, d) relative humidity on drift heater and (e, f) temperature on upper drift wall for a row of drift-emplaced, large-WP-sized heaters generating, for the reference heating-rate case $\left(A P D=122 \mathrm{~W} / \mathrm{m}^{2}\right)$, a lineal heat load of $0.8 \mathrm{~kW} / \mathrm{m}$ and flanked by two horizontal-borehole-emplaced wing heater arrays. The heater arrays are generating an APD of $105 \mathrm{~W} / \mathrm{m}^{2}$ over the interval $4<|x|<9 \mathrm{~m}$ and $157.5 \mathrm{~W} / \mathrm{m}^{2}$ over the interval $9<|x|<14 \mathrm{~m}$ from the drift centerline. Bulk permeability $k_{\mathrm{b}}=280$ millidarcy, and vapor diffusion tortuosity factor $\tau_{\text {eff }}=0.2$. Curves are shown (a, c, e) for a 1-yr full-power heating period and (b, d, f) for a 2-yr full-power heating period. The full-power heating period is followed by a 1-yr linear-rampdown period to zero power. Curves are shown for three different heating rates, including the reference case $\left(\mathrm{APD}=122 \mathrm{~W} / \mathrm{m}^{2}\right)$ and two accelerated-heating-rate cases $\left(\mathrm{APD}=177\right.$ and $\left.236 \mathrm{~W} / \mathrm{m}^{2}\right)$. 
$177-\mathrm{W} / \mathrm{m}^{2}$ case dries out nearly as much rock (Fig. 29c) as the reference case (Fig. 24a); in both cases, the vertical thickness of the dryout zone exceeds $20 \mathrm{~m}$. In general, the $177-\mathrm{W} / \mathrm{m}^{2}$ case with a 2 -yr full-power heating period appears to have all of the advantageous characteristics of the reference case with a 4-yr full- power heating period, while not requiring greater peak temperatures. The rate of temperature rise will, of course, be greater for the accelerated test. Additional calculations are under way to extend the analysis of the $177-\mathrm{W} / \mathrm{m}^{2}$ case to include evaluation of enhanced vapor diffusion and rock heterogeneity.
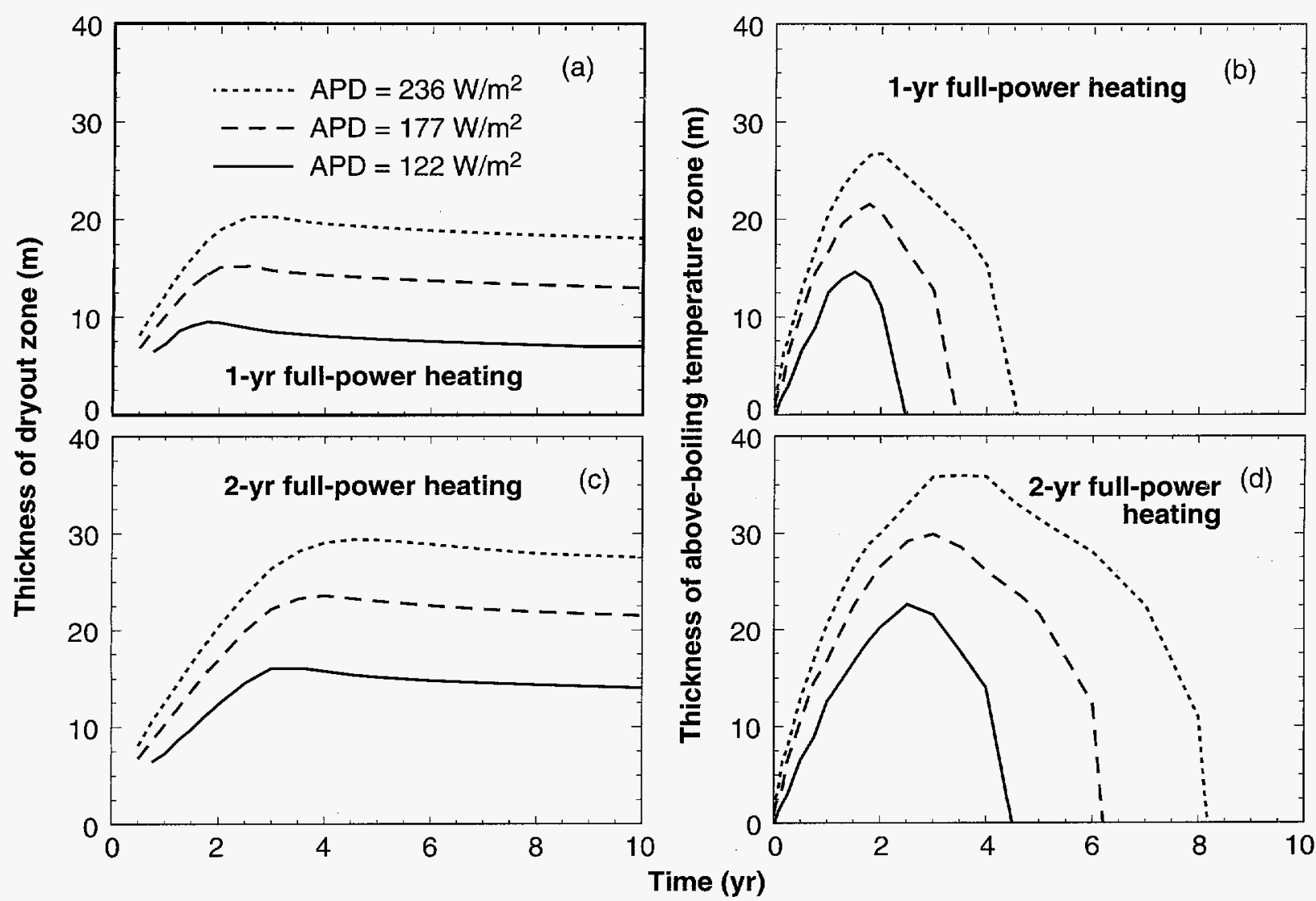

Figure 29. (a, c) Vertical thickness of dryout zone and (b, d) above-boiling temperature zone for a row of driftemplaced, large-WP-sized heaters generating, for the reference heating-rate case (APD $=122 \mathrm{~W} / \mathrm{m}^{2}$ ), a lineal of heat load of $0.8 \mathrm{~kW} / \mathrm{m}$ and flanked by two horizontal-borehole-emplaced wing heater arrays. The heater arrays are generating an APD $105 \mathrm{~W} / \mathrm{m}^{2}$ over the interval $4<|x|<9 \mathrm{~m}$ and $157.5 \mathrm{~W} / \mathrm{m}^{2}$ over the interval $9<|x|<14 \mathrm{~m}$ from the drift centerline. Bulk permeability $k_{\mathrm{b}}=280$ millidarcy, and vapor diffusion tortuosity factor $\tau_{\mathrm{eff}}=0.2$. Curves are shown $(\mathrm{a}, \mathrm{b})$ for a 1-yr full-power heating period and $(\mathrm{c}, \mathrm{d})$ for a 2-yr full-power heating period. The full-power heating period is followed by a 1-yr linear-rampdown period to zero power. Curves are shown for three different heating rates, including the reference case $\left(\mathrm{APD}=122 \mathrm{~W} / \mathrm{m}^{2}\right)$ and two accelerated-heating-rate cases (APD $=177$ and $236 \mathrm{~W} / \mathrm{m}^{2}$ ). 


\section{Conclusions}

In situ thermal tests, which are to be conducted in the Exploratory Studies Facility (ESF) at Yucca Mountain, will provide a major portion of the experimental basis supporting the testing of coupled T-H-M-C process models required to assess the total system performance. The ESF thermal tests must provide an understanding of coupled T-H-M-C processes that are relevant to expected repository conditions. Current ESF thermal test planning has identified two tests: (1) the first ESF (drift-scale) thermal test, which will be conducted under an accelerated heatup and cooldown schedule, and (2) a second ESF (multi-drift) thermal test, which will be a larger-scale, longer-duration test, conducted under a less accelerated heatup and cooldown schedule.

With the V-TOUGH code, we modeled and evaluated a range of heater test sizes, heating rates, and heating durations under a range of plausible hydrological conditions to help optimize an in situ thermal test design that provides sufficient (and timely) information to determine the following:

1. The dominant mode(s) of heat flow.

2. The major T-H regime(s) and the T-H-M-C processes that determine the magnitude and direction of vapor and condensate flow.

3. The influence of heterogeneous properties and conditions on the flow of heat, vapor, and condensate.

Perhaps the single most important purpose of the ESF thermal tests is to determine which major decay-heat-driven $\mathrm{T}-\mathrm{H}$ flow regime(s) will govern the magnitude and direction of vapor flow (and the resulting condensate flow) in the unsaturated zone (UZ) at Yucca Mountain. With respect to advective rock dryout, the three major T-H flow regimes are as follows:

Throttled, nonbuoyant advective rock dryout: the regime in which $k_{\mathrm{b}}$ is low enough $\left(k_{\mathrm{b}}<1\right.$ millidarcy) to significantly throttle the rate of boiling-driven rock dryout. The threshold $k_{\mathrm{b}}$ at which rock dryout is throttled decreases with increasing areal mass loading (AML).

Unthrottled, nonbuoyant advective rock dryout: the regime in which $k_{\mathrm{b}}$ is high enough $\left(k_{\mathrm{b}}>1\right.$ millidarcy) not to significantly throttle the rate of boiling-driven rock dryout, but not large enough ( $k_{\mathrm{b}}<5$ darcy) to allow buoyant gas-phase convection to dominate the direction of vapor flow.

Unthrottled, buoyant advective rock dryout: the regime in which $k_{\mathrm{b}}$ is high enough not to throttle the rate of boiling-driven rock dryout and is also large enough $\left(k_{\mathrm{b}}>5\right.$ darcy) to allow buoyant gas-phase convection to dominate the direction of vapor flow.

How these major $\mathrm{T}-\mathrm{H}$ regimes influence the flow of heat, vapor, and condensate depends in part on whether vapor diffusion is substantially enhanced. Therefore, another major purpose of the thermal tests is to determine the degree of vapor diffusion enhancement.

We evaluated (1) thermal test sizes of 50,270, 490, 1475 , and $5077 \mathrm{~m}^{2}$; (2) three heating schedules, including 1-, 2-, and 4-yr full-power heating periods; and (3) three heating rates $\left(122,177\right.$, and $\left.236 \mathrm{~W} / \mathrm{m}^{2}\right)$. We then determined a minimum thermal test size, minimum heating duration, and a preferred heating rate based the following criteria: (1) ability of the test to discriminate between the major T-H regimes, (2) rock dryout volume, (3) peak rock temperatures, (4) duration of refluxing conditions, (5) ability to observe the influence of heterogeneity, and (6) ability to observe whether heat conduction is able to overwhelm the effects of heterogeneity.

We started with an evaluation of the plate thermal test, which was the basis for recommending a minimum heated area of 1000 to $1500 \mathrm{~m}^{2}$. This heated area is needed to diagnose whether buoyant or nonbuoyant behavior predominates and to minimize the peak temperatures associated with a given dryout zone thickness.

We then evaluated the single-drift thermal test (without wing heaters) and found that the substantial lateral heat flow from this test necessitated very high peak temperatures in order to create a thick enough dryout zone; moreover, we found that this test does not promote enough condensate perching to generate significant refluxing conditions. We then evaluated a number of single-drift, winged thermal tests and determined that an optimal configuration consists of the following: a row of drift heaters that generates $0.8 \mathrm{~W} / \mathrm{m}$ along the drift access, flanked by wing heater arrays generating an APD of $105 \mathrm{~W} / \mathrm{m}^{2}$ averaged over the interval $4<|x|<9 \mathrm{~m}$ and $157.5 \mathrm{~W} / \mathrm{m}^{2}$ over the interval $9<|x|<14 \mathrm{~m}$. This configuration (called the reference case) generates an APD of $122 \mathrm{~W} / \mathrm{m}^{2}$ averaged over the heated area.

We then evaluated the reference single-drift, winged thermal test and found that a 2-yr full-power heating period is required to provide clear and unambiguous information about all three major T-H regimes and about whether vapor diffusion is substantially enhanced. We also found that a 4-yr full-power test provides an earlier determination than the 2-yr full-power test of the 
degree of vapor diffusion enhancement and of whether buoyant gas-phase convection of humid air significantly increases the rate at which the dryout zone rewets to humid conditions.

For determining the dominant $\mathrm{T}-\mathrm{H}$ regime(s) and dominant heat flow mode(s), we found that the most diagnostic measurements are the following:

1. Vertical temperature distributions.

2. Vertical gas-phase pressure distributions.

3. Gas-phase pressure history in the drift during heatup.

4. $R H$ history in the drift during heatup.

For determining the degree of vapor diffusion enhancement, we found that the most diagnostic measurement is

1. $R H$ history in the drift during cooldown.

We then evaluated the ability of the tests to allow observations about the influence of heterogeneity on the flow of heat, vapor, and condensate. We found that the influence of heterogeneity will be observable within the first 1 to 2 yr of the test (after a sufficiently large boiling zone has developed). The effects of heterogeneity are quite apparent in the temperature distribution. We found that a full-power heating period of at least $6 \mathrm{yr}$ might be required to determine whether heat conduction is able to overwhelm the effects of heterogeneity on the temperature and liquid saturation distributions near the heater horizon.

For determining the influence of heterogeneity on the flow of heat, vapor, and condensate, we found the most diagnostic measurements are the following:

1. Horizontal temperature distributions.

2. Horizontal liquid saturation (or $R H$ ) distributions.

3. $R H$ history in the drift during heatup.

We also evaluated whether the tests provide for refluxing conditions of sufficient duration and over a large enough volume to allow for observations of potentially important coupled T-H-C processes. We found that the 4-yr full-power test was far more likely to promote conditions necessary to make these observations than the 1- or 2-yr full-power tests.

We then evaluated heating rate and made a preliminary determination that the $177-\mathrm{m}^{2} 2-\mathrm{yr}$ full-power test has virtually all of the advantages of the $122-\mathrm{m}^{2} 4$-yr full-power test. We plan to conduct additional analyses of the $177-\mathrm{m}^{2} 2$-yr full-power test to determine whether we can recommend it for the first ESF thermal test. 


\section{Acknowledgments}

We acknowledge the timely review of Jim Blink, the highly valuable editorial assistance of Peter Murphy, and the mountain of graphical support of Rick Wooten. Work performed under the auspices of the U.S. Department of Energy by Lawrence Livermore National Laboratory under Contract W-7405-Eng-48.

\section{References}

Buscheck, T.A., J.J. Nitao, and D.A. Chesnut, "The Impact of Episodic Nonequilibrium FractureMatrix Flow on Geological Repository Performance," Proceedings American Nuclear Society Topical Meeting on Nuclear Waste Packaging (Focus 91), Las Vegas, NV, Sept. 30-Oct. 2, 1991. Also, UCRL-JC-106759, Lawrence Livermore National Laboratory, Livermore, CA (1991).

Buscheck, T.A., and J.J. Nitao, "The Impact of Thermal Loading on Repository Performance at Yucca Mountain," American Nuclear Society, Proceedings Third International High-Level Radioactive Waste Management Conference, Las Vegas, NV, April 12-16, 1992. Also, UCRL-JC-109232, Lawrence Livermore National Laboratory, Livermore, CA (1992).

Buscheck, T.A., and J.J. Nitao, "The Impact of Repository Heat on Thermo-Hydrological Performance at Yucca Mountain," Proceedings American Nuclear Society Topical Meeting on Site Characterization and Model Validation (Focus 93), Las Vegas, NV, Sept. 26-30 (1993a).

Buscheck, T.A., and J.J. Nitao, "Repository-HeatDriven Hydrothermal Flow at Yucca Mountain, Part I: Modeling and Analysis," Nuclear Technology, Vol. 104, No. 3, pp. 418-448 (1993b).

Buscheck, T.A., D.G. Wilder, and J.J. Nitao, "Large-Scale In Situ Heater Tests for the Characterization of Hydrothermal Flow at Yucca Mountain," American Nuclear Society, Proceedings Fourth International High-Level Radioactive Waste Management Conference, Las Vegas, NV, April 1993. Also, UCRL-JC-112445, Lawrence Livermore National Laboratory, Livermore, CA (1993a).

Buscheck, T.A., D.G. Wilder, and J.J. Nitao, "Repository-Heat-Driven Hydrothermal Flow at Yucca Mountain, Part II: Large-Scale In Situ Heater
Tests," Nuclear Technology, Vol. 104, No. 3, pp. 449-471 (1993b).

Buscheck, T.A., and J.J. Nitao, "The Impact of Buoyant Gas-Phase Flow and Heterogeneity on ThermoHydrological Behavior at Yucca Mountain," American Nuclear Society, La Grange Park, IL, Proceedings Fifth International High-Level Radioactive Waste Management Conference, Las Vegas, NV, May 1994a. Also UCRL-JC-115351, Lawrence Livermore National Laboratory, Livermore, CA (1994a).

Buscheck, T.A. and J.J. Nitao, "The Importance of Thermal Loading Conditions to Waste Package Performance at Yucca Mountain," Materials Research Society, Pittsburgh, PA, Proceedings Materials Research Society XVIII International Symposium on the Scientific Basis for Nuclear Waste Management, Oct. 23-27, 1994. Also UCRL-JC-116429, Lawrence Livermore National Laboratory, Livermore, CA (1994b).

Buscheck, T.A., J.J. Nitao, and L.D. Ramspott, "Localized Dry-Out: An Approach for Managing the Thermal-Hydrological Effects of Decay Heat at Yucca Mountain," Materials Research Society, Pittsburgh, PA, Proceedings Materials Research Society XIX International Symposium on the Scientific Basis for Nuclear Waste Management, Nov. 27-Dec. 1 (1995).

Buscheck, T.A., J.J. Nitao, and S.F. Saterlie, "Evaluation of Thermo-Hydrological Performance in Support of the Thermal Loading Systems Study," American Nuclear Society, Proceedings Fifth International High-Level Radioactive Waste Management Conference, Las Vegas, NV, May (1994).

DOE (U.S. Dept. of Energy), "Site Characterization Plan: Yucca Mountain Site, Nevada Research and Development Area," DOE/RW-0199 (1988).

DOE (U.S. Dept. of Energy), "Yucca Mountain Project Reference Information Base," YMP/CC-0002 (Version 04.002), Nevada Operations Office, Las Vegas, NV (1990).

Jones, D.A., Principles and Prevention of Corrosion, Macmillan Publishing Company, New York (1992).

Klavetter, E.A., and R.R. Peters, "Estimation of Hydrologic Properties of an Unsaturated Fractured Rock Mass," SAND84-2642, Sandia National Laboratories, Albuquerque, NM (1986).

Konikow, L.F., and J.D. Bredehoeft, "Ground-Water Models Cannot Be Validated," Advances in Water Resources, Vol. 15, pp. 75-83 (1992). 
Lin, W., D.G. Wilder, J.A. Blink, S.C. Blair, T.A. Buscheck, R.S. Glass, W.E. Glassley, K. Lee, R.D. McCright, M.W. Owen, and J.J. Roberts, "A Large Block Heater Test for High Level Nuclear Waste Management," Materials Research Society, Pittsburgh, PA, Proceedings Materials Research Society XVIII International Symposium on the Scientific Basis for Nuclear Waste Management, Oct. 23-27, 1994. Also UCRL-JC-116431, Lawrence Livermore National Laboratory, Livermore, CA (1994).

Montazer, P., and W.E. Wilson, "Conceptual Hydrologic Model of Flow in the Unsaturated Zone, Yucca Mountain, Nevada," Water Resources Investigation Report 84-4345, U.S. Geological Survey (1984).

Nitao, J.J., "Numerical Modeling of the Thermal and Hydrological Environment Around a Nuclear Waste Package Using the Equivalent Continuum Approximation: Horizontal Emplacement," UCID-21444, Lawrence Livermore National Laboratory, Livermore, CA (1988).

Nitao, J.J., "V-TOUGH - An Enhanced Version of the TOUGH Code for the Thermal and Hydrologic Simulation of Large-Scale Problems in Nuclear Waste Isolation," UCID-21954, Lawrence Livermore National Laboratory, Livermore, CA (1989).

Nitao, J.J., T.A. Buscheck, and D.A. Chesnut, "Implications of Episodic Nonequilibrium Fracture-Matrix Flow on Repository Performance," Nuclear Technology, Vol. 104, No. 3, pp. 385-402 (1993).

Nitao, J.J., and T.A. Buscheck, "Discrete-Fracture Modeling of Thermal-Hydrological Processes at Yucca Mountain and the LLNL G-Tunnel Field Test," Materials Research Society, Pittsburgh, PA, Proceedings Materials Research Society XIX International Symposium on the Scientific Basis for Nuclear Waste Management, Nov. 27-Dec. 1 (1995).

Nuclear Regulatory Commission, "Generic Technical Position on In Situ Testing During Site Characterization for High-Level Nuclear Waste Repositories," Engineering Branch, Division of Waste Management, December (1985).

Peters, R.R., E.A. Klavetter, I.J. Hall, S.C. Blair, P.R. Hellers, and G.W. Gee, "Fracture and Matrix Hydrologic Characteristics of Tuffaceous Materials from Yucca Mountain, Nye County, Nevada," SAND84-1471, Sandia National Laboratories, Albuquerque, NM (1984).

Popper, K., The Logic of Scientific Discovery, Harper and Row, New York (1959).

Pruess, K., "TOUGH User's Guide," NUREG/CR-4645, Nuclear Regulatory Commission (1987).

Pruess, K., J.S.Y. Wang, and Y.W. Tsang,"Numerical Modeling Studies of Fluid and Heat Flow near High-Level Nuclear Waste Packages in Partially Saturated Fractured Tuff," LBL-18522, Lawrence Berkeley Laboratory, Berkeley, CA (1984).

Ramirez, A.L., T.A. Buscheck, R. Carlson, W. Daily, K. Lee, W. Lin, N. Mao, T.S. Ueng, H. Wang, and D. Watwood, "Prototype Engineered Barrier System Field Test (PEBSFT) Final Report," UCRL-ID-106159, Lawrence Livermore National Laboratory, Livermore, CA (1991).

Stahl, D., J.K. McCoy, and R.D. McCright, "Impact of Thermal Loading on Waste Package Material Performance," Material Research Society, Pittsburgh, PA, Proceedings Material Research Society XVIII Symposium on the Scientific Basis for Nuclear Waste Management, Oct. 23-27 (1994).

U.S. Code of Federal Regulations Part 60, "Disposal of High-Level Radioactive Waste in a Geologic Repository," March (1990). 


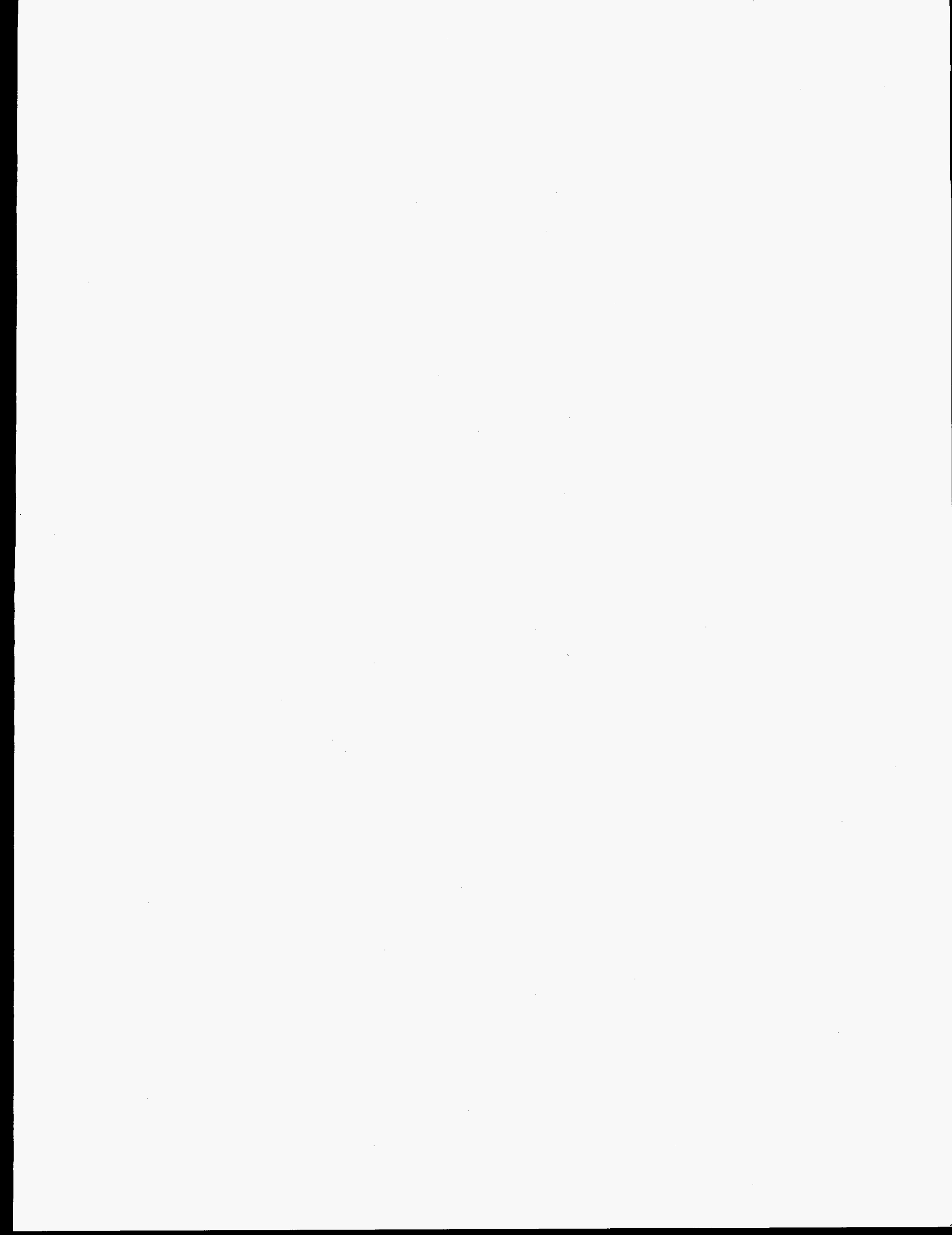




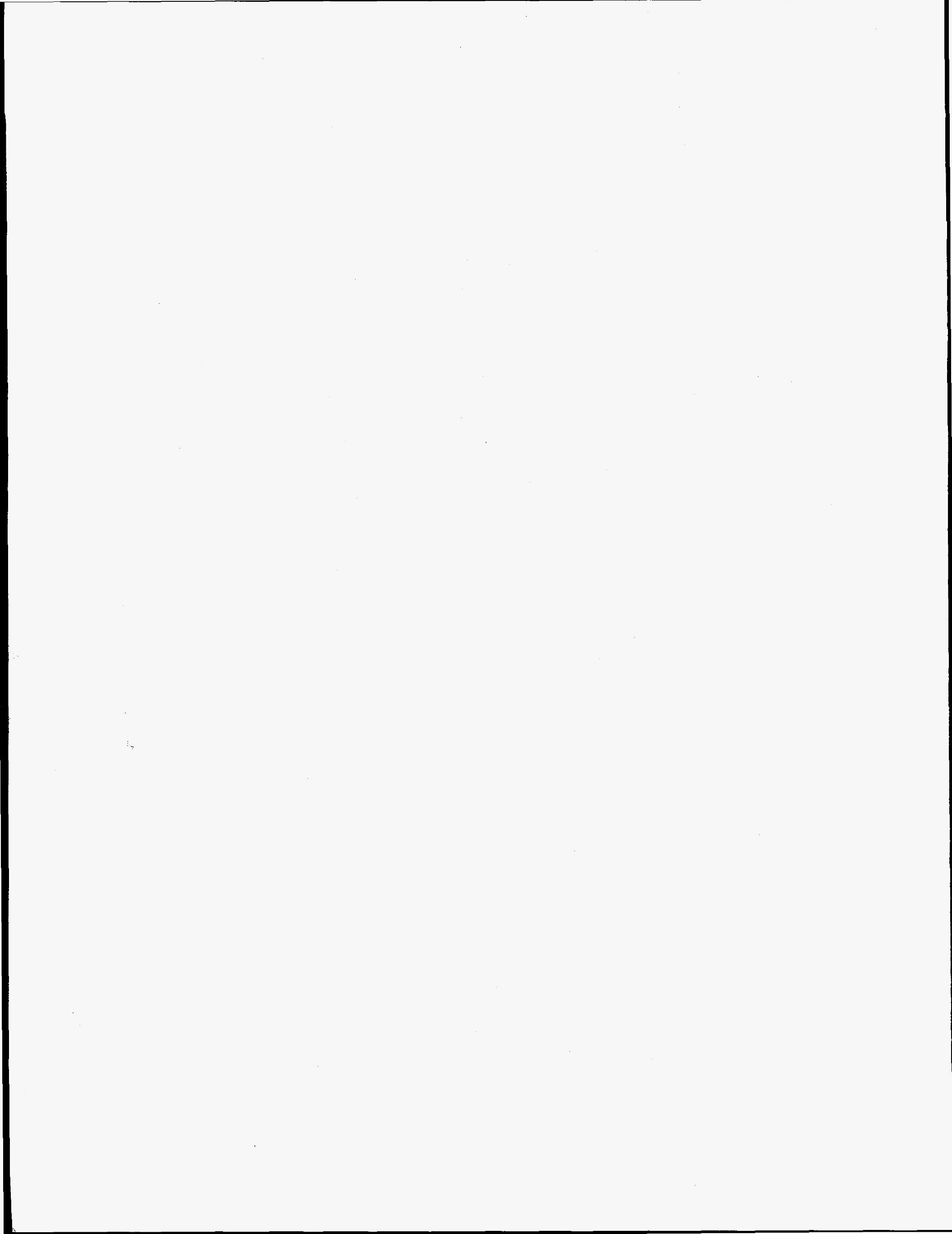

